\title{
The introduction of the nurse practitioner in general practice
}

Citation for published version (APA):

Dierick-Van Daele, ATM. (2010). The introduction of the nurse practitioner in general practice. [Doctoral Thesis, Maastricht University]. Maastricht University. https://doi.org/10.26481/dis.20100408ad

Document status and date:

Published: 01/01/2010

DOI:

10.26481/dis.20100408ad

Document Version:

Publisher's PDF, also known as Version of record

\section{Please check the document version of this publication:}

- A submitted manuscript is the version of the article upon submission and before peer-review. There can be important differences between the submitted version and the official published version of record.

People interested in the research are advised to contact the author for the final version of the publication, or visit the DOI to the publisher's website.

- The final author version and the galley proof are versions of the publication after peer review.

- The final published version features the final layout of the paper including the volume, issue and page numbers.

Link to publication

\footnotetext{
General rights rights.

- You may freely distribute the URL identifying the publication in the public portal. please follow below link for the End User Agreement:

www.umlib.nl/taverne-license

Take down policy

If you believe that this document breaches copyright please contact us at:

repository@maastrichtuniversity.nl

providing details and we will investigate your claim.
}

Copyright and moral rights for the publications made accessible in the public portal are retained by the authors and/or other copyright owners and it is a condition of accessing publications that users recognise and abide by the legal requirements associated with these

- Users may download and print one copy of any publication from the public portal for the purpose of private study or research.

- You may not further distribute the material or use it for any profit-making activity or commercial gain

If the publication is distributed under the terms of Article $25 \mathrm{fa}$ of the Dutch Copyright Act, indicated by the "Taverne" license above, 


\section{The Introduction of the \\ Nurse Practitioner in General Practice}


ISBN 978-90-79488-87-2

(C) Copyright Angelique Dierick-van Daele, Maastricht 2010

Cover image: Mike Roelofs

Printed by Drukkerij Duplica

Lay-out by Inge Duimel

Financial support by MUMC+ Maastricht, Catharina-ziekenhuis Eindhoven, Brabant Medical School, Covidien, Boehringer Ingelheim, Zorgverzekeraar Univé-VGZ-IZA-Trias, Schering-Plough for the publication of this thesis is gratefully acknowledged. 


\section{THE INTRODUCTION OF THE NURSE PRACTITIONER IN GENERAL PRACTICE}

PROEFSCHRIFT

Ter verkrijging van de graad van doctor

aan de Universiteit Maastricht,

op gezag van de Rector Magnificus,

Prof. mr. G.P.M.F. Mols

volgens het besluit van het College van Decanen,

in het openbaar te verdedigen op donderdag

8 april 2010 om 16h

door

ANGELIQUE THEO MARIA DIERICK-VAN DAELE 


\section{PROMOTORES}

Prof. dr. C. Spreeuwenberg

Prof. dr. J.F.M. Metsemakers

Prof. dr. H.J.M. Vrijhoef (Universiteit van Tilburg)

\section{BEOORDELINGSCOMMISSIE}

Prof. dr. L.P. de Witte (voorzitter)

Prof. dr. B. Meyboom (Universitair Medisch Centrum Groningen)

Prof. dr. H. Philipsen

dr. P. Ram

dr. M.P.M.H. Rutten - van Mölken (Erasmus Medisch Centrum Groningen) 


\section{Contents}

$\begin{array}{lll}\text { Chapter } 1 & \text { General Introduction } & 7\end{array}$

Chapter $2 \quad$ Critical appraisal of the literature on economic 21 evaluations of substitution of skills between professionals: a systematic literature review

Chapter 3 The value of nurse practitioners in Dutch general practices

Chapter $4 \quad$ Nurse practitioners substituting for general practitioners in the care for patients with common complaints; a randomised controlled trial

Chapter 5 Economic evaluation of substituting nurse practitioners 81 for general practitioners in the care for patients with common complaints

Chapter 6 Is it economically viable to employ the nurse practitioner in general practice?

Chapter $7 \quad$ General Discussion

Summary

Samenvatting

Dankwoord 



\section{Chapter}

General Introduction

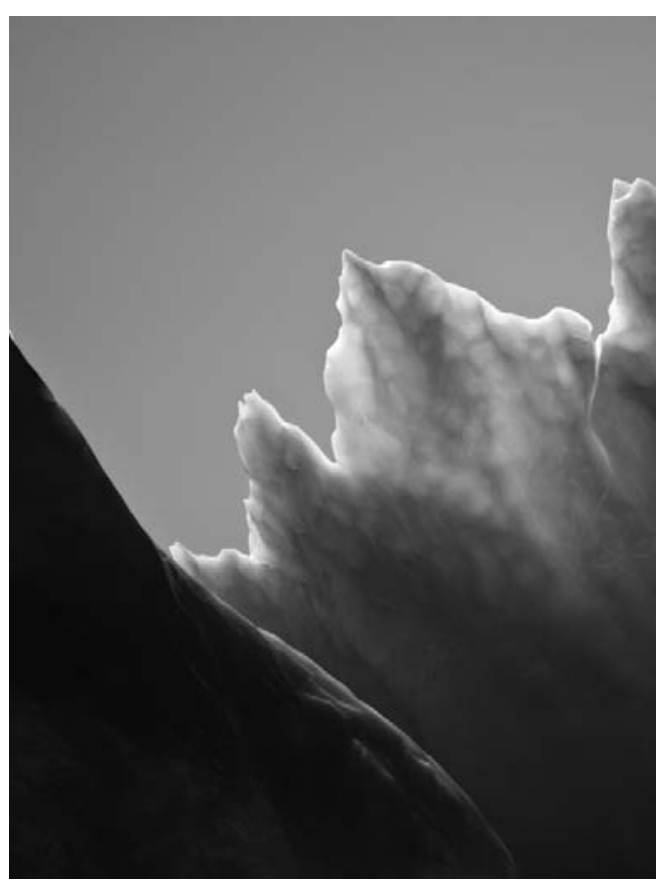


8 Chapter 1 


\section{APPROPRIATE SKILLS IN GENERAL PRACTICE}

Determining and achieving an adequate mix of health personnel are major challenges for most health care organizations and health systems (WHO 2000). Considerations like skill shortages, cost containment, quality improvement, new medical interventions, new health sector programs, health sector reform and changes in the legislative environment explain why new combinations of skills in health care are assessed and adjusted (Vrijhoef et al., 2001; Buchan and Dal Poz, 2002).

Since decades the roles of professionals working in general practice have changed. In the ' 50 s practice assistants have been introduced in general practice. Initially they functioned predominantly as receptionists and administrative assistants (Ten Cate, 1956). The role of the practice assistant developed and general practitioners (GP) were likely to delegate simple executive tasks. Since the eighties various medical-technical skills, patient information and organizational tasks were conducted by practice assistants (Engels et al., 2004). In the early nineties, following the example in the United Kingdom, practice nurses and nurse specialists in the '90s have been introduced in the Netherlands. New nursing roles were seen to be a potential solution to diverse problems and needs in different fields of the tasks of GPs. In some countries with a scarceness of family doctors in rural areas, nurses were introduced to assure or improve the access to health (Hooker, 2006). Nurses took on certain roles that had traditionally been the domain of the GP (Romanow, 2002; Tyrell and Dauphinee, 1999). Currently, nurses perform many tasks ranging from health assessment to education and prescribing. Traditionally GPs focus on curative care but the introduction of nurses facilitated the shift of primary care to prevention and chronic care management (Atkin et al., 1994; Mc. Kenna, 1995; Brown, 1995). In general, tasks or functions performed by nurses on the boundaries with physicians can assume different forms (Starfield, 1992):

- supplementary: tasks or functions that could be done, although inefficiently, by physicians;

- complementary: tasks or functions for which physicians often have neither the skills nor the time to do well;

- substitute: tasks or functions that are traditionally performed by physicians. It has been demonstrated that nurses can undertake much of the health promotion work of general practice and can have a leading role in the routine management of chronic diseases such as asthma, diabetes, and coronary heart disease (Vrijhoef et al., 2000; Laurant et al., 2004). A review of available research has shown that nurses can achieve health outcomes that are as good as those of general practitioners and that they may have superior interpersonal skills (Laurant et al., 2004).

Depending on the complexity of tasks, degree of autonomy, and level of training, traditional forms of curative care may be provided by nurse practitioners, nurse specialists, specialized nurses, practice nurses and practice 
assistants (Kernick and Scott, 2002). Regardless the large quantity of different nursing functions, there is also considerable variety in nursing education. Regular nursing education programs can be divided in the level of vocational education and the university level. One of the major career opportunities for registered nurses, is a specialization in a specific area. Worldwide, there are many specialized courses with different levels of education (i.e. vocational education and university level). The conditions for access to a training program are in certain cases questionable. In some countries, practice assistants, can join a nursing specialization course without being trained as a nurse. As a result, the variety in functions and education causes confusion about the skills and competencies of "nursing" professionals.

In the Netherlands, GPs reflect on their current activities and the ways to anticipate on developments in the health care system taking into consideration their role and desired contribution to the health of people in the future (Projectgroep Toekomstvisie Huisartsenzorg, 2003; Werkgroep functietaakomschrijving Huisartsenzorg, 2003; RVZ, 2002; Commissie Modernisering Eerste lijn, 2002; Meyboom-de Jong et al., 2002). The scope of practice is changing, including the scope of general practice, disease prevention, and health promotion and, increasingly, chronic care management is shifting from the hospital into the community (Woodroffe, 2006). Health care will be more rationalized to increase the levels of effectiveness and efficiency of care. The future needs of the population, the changes to support people by technology and the changing available workforce in health care make it necessary to look at new, more comprehensive models of professional practice. To ensure optimal use of available expertise, professional roles must adapt. In this area, the different nursing roles will further develop.

\section{The nurse practitioner: what's in a name?}

One of the relative youngest branch within the wide scope of nursing functions is the nurse practitioner (NP). The first nurse practitioners were educated in 1965 in the USA. In 2007, there were about 120,000 practicing NPs in the US. Also in countries as Canada, United Kingdom, Australia, and Scandinavian countries, the NP is well known.

Generally, the term NP is used to identify registered nurses with additional education and training, who work within an expanded scope of practice that includes diagnosing, prescribing, and treating medical conditions within specific settings (Reay et al., 2003). Besides clinical care, NPs focus on health promotion, disease prevention, health education and counseling. NPs have graduate, advanced education and clinical training, i.e. Master in Advanced Nursing Practice, beyond their registered nurse preparation. Most NPs are certified in their specialty area and are recognized as expert healthcare providers. NPs practice in rural, urban, and suburban communities and in many types of settings (www.AANP.org). 
Notwithstanding, there is also confusion about the NP roles, inconsistent titling and educational preparation. Varied interpretations about the purpose of the different roles exist (Dunn and Nicklin, 1995; Woods, 1997; Brown, 1998; Styles and Lewis, 2000; Chang and Wong, 2001).

\section{The project "Nurse Practitioner in general practice"}

Against the background of the need to increase service capacity, to meet a rising demand of care, and to improve access, the project Nurse Practitioner in General Practice (NPGP-project) was initiated in 2003 by two Local Associations of General Practitioners (DHV Zuidoost Brabant and DHV Midden-Brabant) and the Foundation for Development of Quality Care in General Practice in Eindhoven (Vening et al., 2003, Derckx et al., 2005). The project has been financially supported by the Dutch Ministry of Health, Welfare, and Sport and the Health Insurance Companies CZ and VGZ (UVIT), Province North Brabant and the Foundation ROS Robuust. The evaluation of this project focuses on the impact of the implementation of the NP in general practices in terms of processes and effects of care delivery. In this project two prior conditions were defined to support the implementation of the NP in general practice: the development of a new care model for general practice, and the development of a training program for NPs on vocational level.

Fifteen general practices in the Southern region of the Netherlands were recruited to educate and employ a total number of 12 NPs. After their recruitment, senior nurses started the practice-oriented training program.

\section{The new care model for general practice}

To determine how well a model of care is meeting patient health needs, an analysis has to be made of the availability, accessibility and acceptability of health services (Spitzer, 1978; Mitchell-DiCenso et al., 1996). The new care model, which is developed in the NPGP-project, was based on the assumption that the availability and accessibility of primary care could be increased when common complaints are not treated by GPs but by NPs. If this is the case, GPs can spend more time to patients with more complex diagnoses or diseases and/or other patient related activities.

In this project, a specified set of common complaints is compiled for which patients seek medical attention. Common complaints included in this set are simple or non complex and will often lead to minor health problems. The NP sees patients with respiratory and throat complaints, ear and nose complaints, musculoskeletal complaints and injuries, skin injuries, urological complaints, gynaecological complaints, sexual transmitted diseases and geriatric problems. The role of the NP involves assessing symptoms, including physical examinations where appropriate, diagnosing and making decisions for further treatment, including prescriptions, referrals to primary or secondary services and 
clinical investigations. The NP has no full authority to prescribe medications, the GP is always available for consultation and to assign prescriptions and referrals. NPs have also a role in the improvement of quality of care delivery in general practice. All NPs are appointed part-time (0.6 full time equivalent).

To refer patients to the right provider, a triage system is needed. The triage is accomplished by the practice assistants at first point of contact with patients.

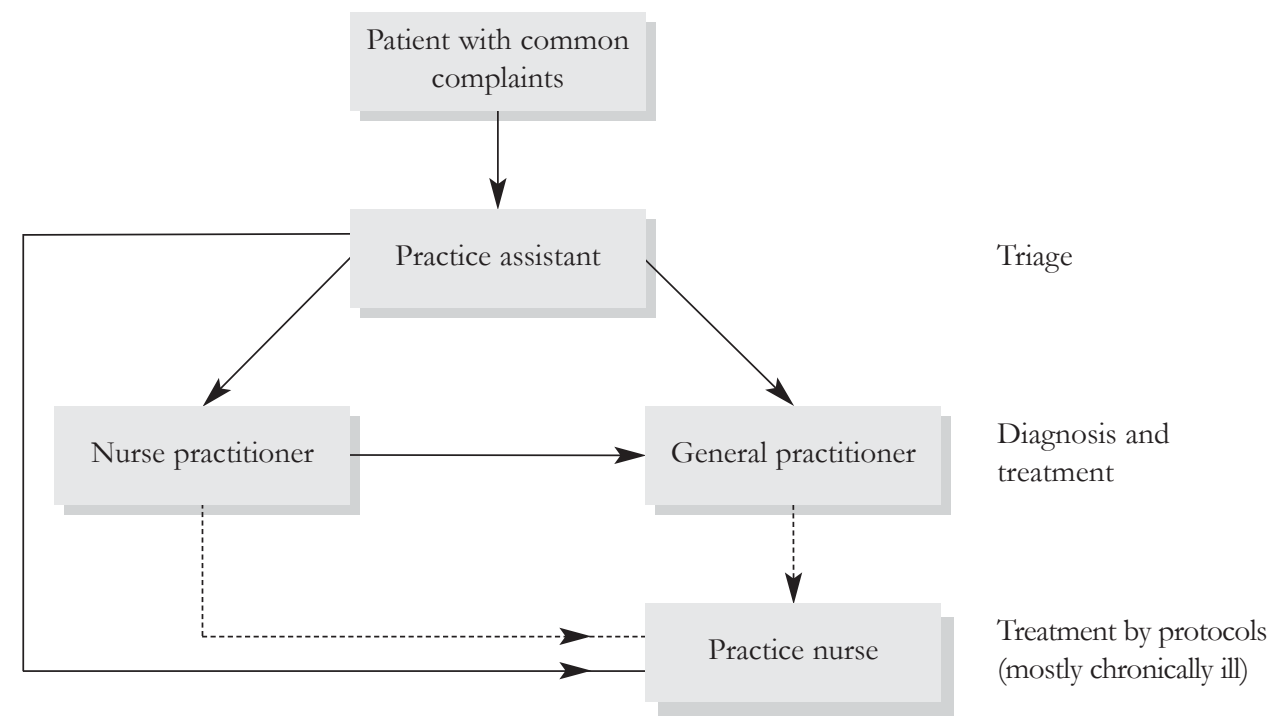

Figure 1 The NPGP Model (Derckx, Toemen, 2005)

The relations and collaboration between professionals in general practice in the new care model are described in Figure 1. During the first stage of triage the practice assistants explore the complaints expressed by the patients. By means of triage, the practice assistants first of all assess if they can provide patients an advice or instruction by themselves. If necessary, they refer patients with common complaints for a consultation by the NP. Patients with other complaints or diseases are referred for a consultation by the GP. Patients participating in a disease management program (i.e. patients with COPD, diabetes, hypertension) were usually seen by a practice nurse. When the NP assesses or presumes that the patient's complaints are misdiagnosed as common complaints, the NP consults the GP how to proceed or directly asks the GP to take over the patient. In case the NP concludes that the patient has a chronic disease and needs educational instructions or advice, the NP refers the patient to the practice nurse. In all other cases, the NP is the first responsible caregiver for the patient. 


\section{Training program for NPs}

At the start of this project in 2004, the NPs start a specific two year practiceoriented training program on vocational level: the Master in Advanced Nursing Practice (MANP). This program is adapted with a differentiation in primary care and the inclusion of a course on managing common complaints (Toemen, 2006). Other courses of the program are the training of basic medical skills, role development, collaboration, context of care, and research. The areas and competencies of the training program are described in Box 1. The modules are finished with a theoretical exam or an aptitude test.

Box 1 Areas and competencies formulated in the training program

Patient care:

- Analyzes and interprets patients'(and relatives') history, including presenting symptoms, physical findings, and diagnostic information to develop appropriate diagnoses (in a multidisciplinary way);

- Diagnoses and manages conditions, prioritizes health problems and intervenes appropriately including initiation of effective emergency;

- Formulates an action plan based on scientific rationale, evidence-based standards of care, and practice guidelines, provides guidance and counseling regarding management of the health/illness condition.

Collaboration:

- Coordinates the patients' treatment, if necessary, initiates appropriate and timely consultation and/or referral when the problem exceeds the NP's scope of practice and/or expertise;

- Initiates a professional collaboration with patients and other health care professionals.

Quality Improvement:

- Improves the quality of care by means of research and implementing evidence based practice;

- Educates and coaches other professionals to improve their skills

All NPs are employed and facilitated by GPs, and trained in general practices. During the training program, NPs attend one day in two weeks their courses. The other days they train in general practice and are supervised by a GP. During the first two months, NPs join the GPs during consultations. After this period, consultations conducted by NPs are recorded by camera. Afterwards, NPs evaluate the consultations with the supervising GP. As soon as NPs finish a specific medical module successfully, they treat those patients with the corresponding complaint independently. To develop new skills, NPs describe learning goals, conduct and evaluate them with the supervising GP. Furthermore, they collect their aptitude tests, reflection papers and feedback of the supervising GP and the lecturer of the training program in a portfolio. In the final part of the training program the NP conducts a research study or a project with the main goal to further improve the quality of patient care. As the NPs are new professionals, the supervising GPs participate in the teach-theteacher-program, wherein they get instructions to educate the NPs and they reflect on their own experiences (Toemen and Ram, 2006). 


\section{THE EVALUATION OF THE NPGP-PROJECT}

In this paragraph the evidence and the research questions are described in brief, followed by the methods we apply in this study. The details of the study methods are described in the chapters 2-7.

\section{Study background and aims}

Several studies show that quality of care remains at least equal or gets improved, when skills related to specific patient groups are more concentrated by substitution (Vrijhoef et al., 2001; Buchan and Dal Poz, 2002; AANP, 2000; Laurant et al., 2004). Questions surrounding efficiency however, are often left untouched (McGrath, 1990; Richardson, 1999; Horrocks et al., 2002; Buchan and Dal Poz, 2002; Laurant et al., 2004).

To evaluate APN roles, several structure-process-outcome frameworks have been developed (Grimes and Garcia, 1997; Byers and Brunell, 1998; Irvine et al., 1998). One conceptual framework (Sidani and Irvine, 1999) represents the complex system of interrelated factors that represent in the NP practice situation and which effect the role effectiveness. The model is originally developed for evaluating roles of NPs in acute care settings. This model is described in general terms. However, it is assumed that the model can be used for evaluating the NP roles in general practice.

\section{Structure}

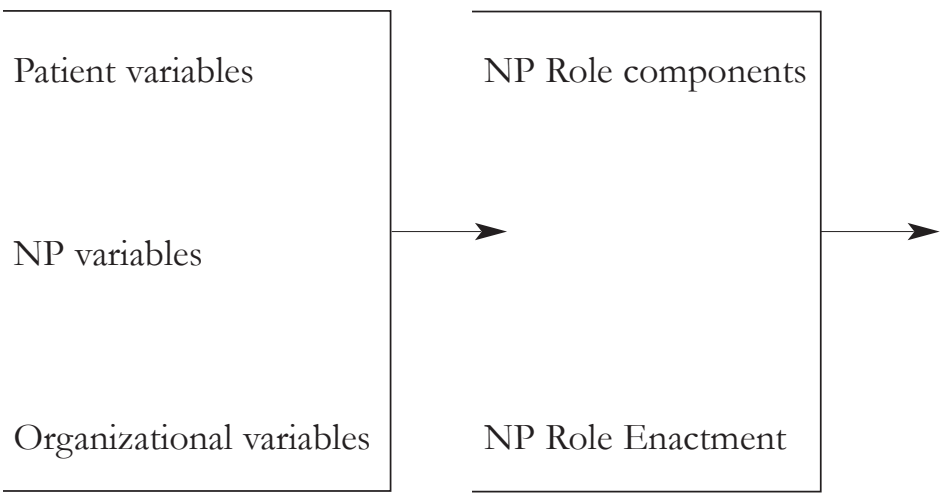

\section{Outcome}

Quality

Costs

Figure 2 Model for evaluating the nurse practitioner role (Sidani and Irvine, 1999)

The major propositions of this model are:

- the effects of structures on process represent the influence of patients variables, NP characteristics and organizational variables on the different roles of NPs;

- the effects of structure on outcomes are mainly limited by patient characteristics, as for example the severity of illness;

- the NP roles effect the outcomes in terms of quality of care and costs. 
The implementation of the NP in general practice is evaluated focusing on characteristics of professionals and organizations and prior conditions (structure), NP roles (process) and impact on quality of the care and costs (outcome). This study focuses on the relations as described in Figure 2.

To introduce these themes, first we have identified economic evaluations of substitution between professionals. This evaluation study is divided in a process evaluation and a cost-effectiveness evaluation. The aim of the process evaluation is to explore the feasibility of the implementation of the NP in the care for patients with common complaints and the conditions needed (structure and process). The objective of the effectiveness evaluation is to investigate, the impact on quality of the care and the level of (cost-)effectiveness of care provided by the NP in general practice.

In detail the study has the following aims:

- to identify economic evaluations of substitution between professionals, to assess the quality of the study methods applied and to value the evaluation results for decision making;

- to explore the concordance of the NP roles with the initial concepts of the NP training program;

- to evaluate the impact on process and outcomes of care provided by GPs and specially trained NPs for patients at first point of contact;

- to estimate the costs of consultations by GP or NP from a practice perspective and a societal perspective;

- to describe and explore the economic viability of NPs employed in general practices.

The hypothesis regarding the level of (cost-)effectiveness of care provided to patients with common complaints by NPs as first point of contact is that this level is indifferent to the situation wherein care gets delivered by GPs.

\section{RESEARCH METHODS AND DESIGN}

Several research methods were used in this study.

\section{Literature review}

A systematic review has been performed to summarize what is known about the (cost-)effectiveness of substitution and the methodology of identified studies. These results give us input to conduct the study related to quality of the care and (cost-)effectiveness of the care provided by NPs and GPs.

\section{Evaluation of processes}

An observational longitudinal design has been conducted to explore the concordance of the NP roles with the initial training program. Use is made of mixed methods (qualitative and quantitative) to maximize case completeness and validity. A convenience sample of NPs and teaching GPs working in NPGPpractices is used. Data have been collected of prior conditions, NPs competencies, objective and subjective workload. 
The economic viability of NPs' employment has been investigated on national level. The conditions under which NPs are able to earn back their costs of employment, in terms of an increase in productivity or capacity, and the economic viability are identified.

\section{Evaluation of cost-effectiveness}

To evaluate the quality of the care provided by NPs and GPs and the costs of consultations a randomised controlled trial (RCT) has been conducted in the NPGP-practices. Patients were randomly allocated to either the intervention group (NP-led care) or the reference group (GP-led care). Data have been collected of the quality of care from a patient perspective, resource use and length of consultations.

Furthermore, an economic evaluation has been conducted alongside this RCT. Consultations of patients visiting NPGP-practices are also compared with those in a second, external reference group, who receive treatment of GPs without the involvement of NPs. Direct costs within the health care sector and costs outside the health care sector are calculated.

\section{OUTLINE OF THE THESIS}

The outline of the thesis is structured as follows. In Chapter 2 the results of the systematic review are described: economic evaluations of substitution between professionals are identified and assessed with the aim to value these results for decision making.

In Chapter 3 the concordance of the NP roles with the initial concepts of the NP training program are explored.

Impact on outcomes, as defined by parameters of quality of care and costs, are described in Chapter 4 and Chapter 5. Chapter 4 describes the evaluation of process and outcomes of care as provided by GPs or NPs for patients with common complaints at first point of contact. In Chapter 5 an estimation of the costs of consultations by GP or NP dealing with patients with common complaints is given from two perspectives: general practice and society. Chapter 6 describes the results of a descriptive and explorative design investigating the economic viability of NPs employed in general practices on a national level and its implications for policy making.

A summary and discussion of the main findings are presented in Chapter 7. In this chapter also recommendations for an effective and efficient organisation are presented as well as recommendations for further research. 


\section{REFERENCES}

1. American Academy of Nurse Practitioners. Nurse Practitioners - providers of quality primary care. Documentation of cost effectiveness. Washington DC: AANP revised, 2000.

2. Atkin K, Hirst M, Lunt N, Parker G. The role and self perceived training needs of nurses employed in general practice: observations from a national census of practice nurses in England and Wales. Journal of Advanced Nursing 1994; 20: 46-52.

3. Brown S. A framework for advanced practice nursing. Journal of Professional Nursing 1998; 14: 157-64.

4. Brown SA, Grimes DE. A meta-analysis of nurse practitioners and nurse midwives in primary care. Nursing Research 1995; 44: 332-9.

5. Bryant-Lukosius D, Dicenso A, Browne G, Pinelli J. Advanced practice nursing roles: development, implementation and evaluation. Journal of Advanced Nursing 2004; 48(5): 519-29.

6. Buchan J, Dal Poz MR. Skill mix in the health care workforce: reviewing the evidence. Bulletin of World Health Organisation 2002; 80(7): 575-80.

7. Byers J, Brunell M. Demonstrating the value of the advanced practice nurse: an evaluation model. AACN Clinical Issues 1998; 9: 296-305.

8. Chang KPK, Wong KST. The nurse specialist role in Hong Kong: perceptions of nurse specialists, doctors, and staff nurses. Journal of Advanced Nursing 2001; 36: 36-40.

9. Commissie Modernisering Eerste lijn. Een perspectief voor de eerstelijnszorg. Utrecht 2002. (In Dutch)

10. Derckx EWCC, Leeuwen van YD, Toemen T, Legius MJM. Tussen cure en care. De nurse practitioner verdient zichzelf terug. Medisch Contact 2005; 60(49): 1992-5. (In Dutch)

11. Dunn K, Nicklin W. The status of advanced nursing roles in Canadian teaching hospitals. Canadian Journal of Nursing Administration 1995; 111-35.

12. Engels Y, Mokkink H,van den Hombergh P, van den Bosch W, van den Hoogen H, Grol R. Het aantal taken van de praktijkassistente in de huisartsenpraktijk is toegenomen. Huisarts en Wetenschap 2004; 47: 325-30. (In Dutch)

13. Grimes DE, Garcia MK. Advanced practice nursing and work site primary care: challenges for outcomes evaluation. Advanced Practice Nurse Quarterly 1997; 3: 19-28.

14. Hollinghurst $S$, Horrocks $S$, et al. Comparing the cost of nurse practitioners and GPs in primary care; modelling economic data from randomised trials. British Journal of General Practice 2006; 56: 530-35.

15. Hooker RS. Physician assistants and nurse practitioners: the United States experience. Medical Journal of Australia 2006; 185 (1): 4-7.

16. Horrocks S, Anderson E, Salisbury C. Systematic review of whether nurse practitioners working in primary care can provide equivalent care to doctors. British Medical Journal 2002; 324: 819-23.

17. Irvine D, Sidani S, McGillis, Hall L. Finding value in nursing care: a framework for quality improvement and clinical evaluation. Nursing Economics 1998; 16: 110-6.

18. Kernick D, Scott A. Economic approaches to doctor/nurse skill mix: problems, pitfalls, and partial solutions. British Journal of General Practice 2002; 52: 42-6.

19. Kinnersley P, Anderson E, Parry K, Clement J, Archard L, Turton P, Stainthorpe A, Fraser A., Butler, C, Rogers C. Randomised controlled trial of nurse practitioner 
versus general practitioner care for patients requesting "same day" consultations in primary care. British Medical Journal 2000; 320: 1043-8.

20. Laurant M, Reeves D, et al. Substitution of doctors by nurses in primary care. The Cochrane Database of Systematic Reviews Collaboration, 2004: (4).

21. Lenz ER, Mundinger MO, Kane RL, Hopkins SC, Lin, S. X. Primary care outcomes in patients treated by nurse practitioners or physicians: two-year follow-up. Medical Care Research and Review 2004; 61: 332-51.

22. McGrath S. The cost-effectiveness of nurse practitioners. Nurse Practitioner 1990; 15: 40-2.

23. Mc Kenna HP. Nursing skill mix substitutions and quality of care: an exploration of assumptions from the research literature. Journal of Advanced Nursing 1995; 21: 425-59.

24. Meyboom- de Jong B, Schmit Jongbloed LJ, Willemsen MC De arts van straks. Projectgroep nieum medisch opleidingscontinuïm. Wijk bij Duurstede. Hentenaar 2002. (In Dutch)

25. Mitchell-DiCenso A, Pinelli J. Southwell D. Introduction and evaluation of an advanced nursing practice role in neonatal intensive care. In Outcomes of Effective Management Practice Thousand Oaks, CA 1996.

26. Mundinger MO, Kane RL, Lenz ER, Totten AM, Tsai WY, Cleary PD, Friedewald W'T, Siu AL, Shelanski ML Primary care outcomes in patients treated by nurse practitioners or physicians: a randomized trial. Journal of the American Medical Association 2000; 283: 59-68.

27. Projectgroep Toekomstvisie huisartsenzorg. Huisartsenzorg in 2012: medische zorg in de buurt. LHV/NHG 2003. (In Dutch)

28. Reay T, Golden-Biddle K, Germann K. Challenges and leadership strategies for managers of nurse practitioners. Journal of Nursing Management 2003; 11(6): 396-403.

29. Richardson G. Identifying, evaluating and implementing cost-effective skill mix. Journal of Nursing Management 1999; 7(5): 265-270.

30. Romanow RJ. Building on values: The future of health care in Canada. Commission on the Future of Health Care in Canada. Ottawa 2002: first edition.

31. Raad van de Volksgezondheid en Zorg (RVZ). Taakherschikeing in de gezondheidszorg. Zoetermeer 2002. (In Dutch)

32. Shum C, Humphreys A, Wheeler D, Cochrane MA, Skoda S, Clement, S. (2000) Nurse management of patients with minor illnesses in general practice: multicentre, randomised controlled trial. British Medical Journal 2000; 320: 1038-43.

33. Sidani S, Irvine D. A conceptual framework for evaluate the nurse practitioner role in acute care settings. Journal of Advanced Nursing 1999; 30(1): 58-66.

34. Spitzer WO. Evidence that justifies the introduction of new health professionals. The Professions and Public Policy (Slayton P. and Trebilcock M.J., eds), University of Toronto Press, Toronto 1978; 211-36.

35. Starfield B. Primary care: concept, evaluation and policy. New York: Oxford University Press, 1992.

36. Styles M, Lewis C. Conceptualizations of advanced nursing practice. Advanced Nursing Practice: An Integrative Approach (Hamric AB, Spross JA, Hanson CM, eds), W.B. Saunders, Philadelphia, 2000; 33-51.

37. Ten Cate RS. De praktijkhulp van de huisarts (Proefschrift). Leiden: Stenfert Kroese, 1956. (In Dutch) 
38. The World Health Report, 2000 - Health systems: improving performance. Geneva: World Health Organization, 2000.

39. Toemen T. Master of ANP-Huisartsenzorg 2004-2006: overzicht inhoud en ICPCcodes modules patiëntenzorg huisarts-geneeskunde. Stichting $\mathrm{KOH}$, Fontys Hogescholen Eindhoven 2006. (In Dutch)

40. Toemen T, Ram P. De NPH-opleiders begeleid -begeleiding van opleiders van nurse practitioners werkzaam in de huisarstenpraktijk. Stichting $\mathrm{KOH} /$ Huisartsopleiding Maastricht, Eindhoven 2006. (In Dutch)

41. Tyrell L, Dauphinee WD. Task force on physician supply in Canada. Ottawa: Canadian Medical Forum 1999.

42. Vening RA, Banken MMM, van Schaijk ME, Derckx EWCC. Nurse practitioner in de huisartsenpraktijk; projectplan NPH. Stichting KOH, Eindhoven 2003. (In Dutch)

43. Venning P, Durie A, Roland M, Roberts C, Leese B. Randomised controlled trial comparing cost effectiveness of general practitioners and nurse practitioners in primary care. British Medical Journal 2000; 320: 1048-53.

44. Vrijhoef HJM, Diederiks JPM, Spreeuwenberg C. Effects on quality of care for patients with NIDDM or COPD when the specialised nurse has a central role: a literature review. Patient Education and Counseling 2000; 41: 243-50.

45. Vrijhoef HJM, Spreeuwenberg C, Eijkelberg IMJG, Wolffenbuttel BHR, Merode GG, van. Adoption of disease management model for diabetes in region of Maastricht. British Medical Journal 2001; 323: 983-5.

46. Werkgroep Functie-taakomschrijving Huisartsenzorg. Huisartsenzorg en buisartsenvoorziening. Concretisering Toekomstvisie 2012. Utrecht 2003. (In Dutch)

47. Woodroffe E. Nurse-led general practice: the changing face of general practice British Journal of General Practice 2006; 632-3.

48. Woods L. Conceptualizing advanced nursing practice: curriculum issues to consider in the educational preparation of advanced practice nurses in the UK. Journal of Advanced Nursing 1997; 25: 820-8. 


\section{Chapter}

Critical appraisal of the literature on economic evaluations of substitution of skills between professionals: a systematic literature review

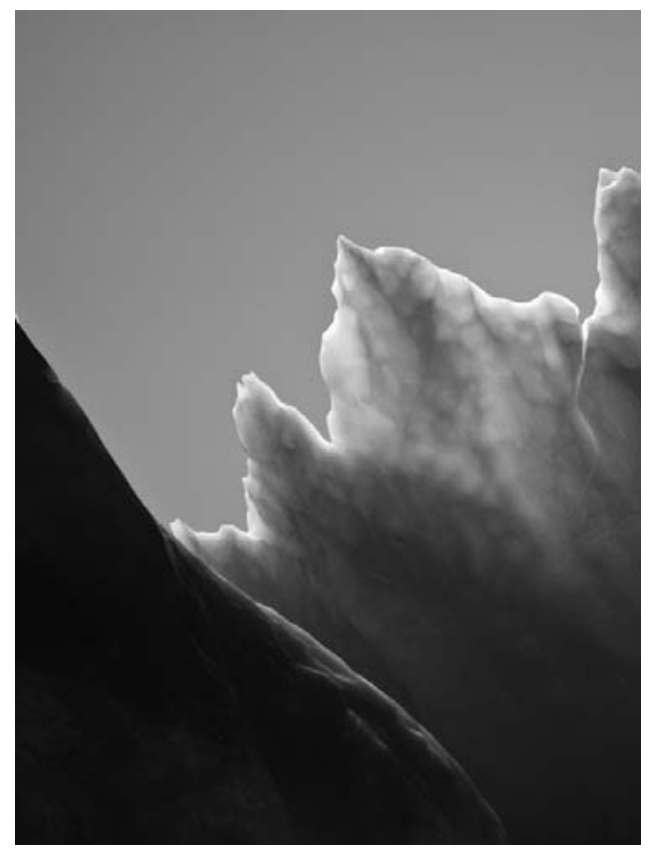

A.T.M. Dierick-van Daele, C. Spreeuwenberg, E.W.C.C. Derckx, J.F.M. Metsemakers, H.J.M. Vrijhoef

Published in: Journal of Evaluation in Clinical Practice 2008; 14: 481-92 


\section{Abstract}

Objective. Substitution of skills has been introduced to increase health service efficiency, but little evidence is available about its cost-effectiveness. This systematic review aims to identify economic evaluations of substitution between professionals, to assess the quality of the study methods applied and to value the results for decision making.

Methods. Publications between January 1996 and November 2006 were searched in Medline, Cochrane, Cinahl, database of Health Technology Assessments, EPOC and Embase. Randomized controlled trials (RCTs), cost-benefit analysis, interrupted time series design and systematic reviews were selected. The methodological quality of the papers was reviewed, using the critical appraisal of Drummond and the EPOC list.

Results. Eleven studies were finally included of 7,605 studies: three costeffectiveness studies, three cost-minimization studies and five studies related to partial economic evaluations. Small numbers of participating professionals and several limitations in the cost valuation and the measurement of costs were identified.

Conclusions. Several potential limitations influence the validity and generalizability. Full economic evaluations per se are of limited value for making decisions about substitution of skills. The tenuous relationship between structural, process and outcome variables is not sufficient investigated. For meaningfully placing the costs and consequences of substitution of skills in the context of health care and generating relevant data for decision making, it is strongly recommended to combine an economic evaluation (RCT) with an observational longitudinal study.

Keywords. cost-effectiveness, economic evaluation, skills, substitution, systematic review 


\section{INTRODUCTION}

Determining and achieving an adequate mix of health personnel are major challenges for most health care organizations and health systems [1]. Considerations like skill shortages, cost containment, quality improvement, new medical interventions, new health sector programmes, health sector reform and changes in the legislative environment explain why new combinations of skills in health care are assessed and adjusted [2]. An increasing interest in hiring nurse practitioners (NPs) is seen from health care executives in several countries [3]. The term NP is used to identify registered nurses with additional education and training (Master in Advanced Nursing Practice), who work within an expanded scope of practice that includes diagnosing, prescribing and treating medical conditions within specific settings [3].

The need for NPs, as being noticed in the USA, Europe, Canada, Australia and the Far East, is fourfold: (1) to overcome a shortage of doctors in particular settings; (2) to improve the quality of care; (3) to advance the career of nurses; and (4) to lower health care costs by employing the 'lowest cost provider' [3,4]. At a time when skill mix changes are being introduced in an effort to increase health service efficiency, there is little evidence with regard to the costeffectiveness of innovative nursing roles like the clinical nurse specialist or the NP $[2,4-6]$. There is evidence that quality of care will be equal or improved when skills are substituted [2,7,8]. Moreover, the current evidence on skill mix in the health workforce has significant limitations. If studies move beyond the status of descriptive accounts, their usefulness is often constrained by methodological weaknesses, lack of appropriate evaluations of quality/outcome and costs, and/or use of small sample sizes [2].

Despite evidence suggesting that decision makers appreciate the potential value of cost-effectiveness information to the process of making choices between competing alternatives, use of economic evaluation information is moderate to low $[9,10]$. Moreover, the relevance of cost-effectiveness data of a mix of health personnel including the NP in, for example, the USA [7] or Canada [11] cannot necessarily be applied in other countries. Skill mix is both a determinant and determined by organizational and system context, because the basis on which skill mix is examined is the need to identify care needs of a specific population and match these to the skills of staff available [2].

However, this does not imply that economic evaluation in studies of substitution of skills should not be applied. The reverse is true; considering the little evidence there is, more economic evaluations of substitution of skills are required $[2,5,6]$. By reviewing recent literature on economic evaluation of substitution of skills from one professional to another, this paper aims to: (1) identify studies wherein the role of the 'new type' of health care worker is evaluated in terms of the costs and the consequences it has generated; (2) assess the quality of the methods applied in the identified studies; and (3) question the results of these studies for informed decision making. Ultimately, this paper presents recommendations to 
improve the accessibility and the acceptability of economic evaluation related to the introduction of new professionals, or new substituted skills of health care workers.

\section{Methods}

To identify to which extent basic forms of economic evaluations applied to skill mix substitution, the following databases were searched: Medline, Cochrane, Cinahl, the database of Health Technology Assessments, EPOC, Embase. In doing so, different keywords related to skill mix substitution and economic evaluations were used (Table 1).

Table 1 Medical Subject Headings and key words used to identify economic evaluations

Medical Subject Headings
Economic evaluation
Cost effectiveness
Cost minimisation
Nurse AND economic evaluation OR cost effectiveness OR cost minimisation
Substitution AND economic evaluation OR cost effectiveness OR cost minimisation
Equivalent care AND economic evaluation OR cost effectiveness OR cost minimisation
Skill mix AND economic evaluation OR cost effectiveness OR cost minimisation
Delegation AND economic evaluation OR cost effectiveness OR cost minimisation
Referral of tasks AND economic evaluation OR cost effectiveness OR cost minimisation
Professional AND economic evaluation OR cost effectiveness OR cost minimisation
Coordination AND economic evaluation OR cost effectiveness OR cost minimisation
Dentist AND economic evaluation OR cost effectiveness OR cost minimisation
Eyedoctor AND economic evaluation OR cost effectiveness OR cost minimisation
Ophtalmologist AND economic evaluation OR cost effectiveness OR cost minimization
Keywords
Patientsatisfaction, Quality of Life, health status, process of care, satisfaction of professionals, resource
utilisation, prescriptions, examinations, referrals, direct cost, indirect costs inside healthcare, indirect cost
outside health care, training, consultation, return consultation

To be included, papers had to be written in English, or Dutch and be published between January 1996 and November 2006. First, titles and abstracts were reviewed, followed by handsearching of papers being part of the reference lists of initially selected papers. If considered relevant, the full text was reviewed. To be included for this review, a description of indicators related to substitution of skills between doctors and other professionals (i.e. nurses and paramedics) in various settings (i.e. general practice, hospital- or community-based settings) had to be presented and the study design had to be a randomized controlled trial (RCT), cost-benefit analysis (CBA), interrupted time series design, systematic review or meta-analysis (see Appendix 1). Two reviewers (ATMD, HJMV) independently reviewed the papers and assessed independently the methodological quality. 


\section{Assessment of economic evaluations}

The critical appraisal developed by Drummond [12] was used to assess the full economic evaluations. With this appraisal method the appropriateness of the methodology, employed in the study and the validity of the results, was determined. The critical appraisal identifies 10 key elements of any economic evaluation and discuss the methodological characteristics which users may expect to find in well-executed studies. The items were scored as 'yes', 'no' or 'can't tell'.

We used the EPOC list, developed by the Cochrane Effective Practice and Organisation of Care group, to assess the methodological quality of systematic reviews towards interventions, designed to improve professional practice and the delivery of effective health services [13]. Each criterion in the list is scored as 'done', 'not clear' or 'not done' and the list is divided in two parts, scored by 'major limitations', 'moderate limitations' or 'minor limitations'.

\section{RESUlts}

\section{Description of studies}

The search identified 7,605 studies between January 1996 and November 2006. We accepted 7,512 papers for further screening. After reading titles and abstracts, we excluded 6,412 papers, because they did not meet the inclusion criteria. As a result, 93 full-text papers were retrieved for more detailed information, and screening the references resulted in another 20 papers. Papers were excluded when not dealing with substitution of skills (e.g. nurse supplements or additional care), when costs were not investigated, when outcomes were not related to costs, or when the study had severe methodological weaknesses. Another exclusion criterion was substitution of skills on the level of the unit or organization and not on the level of professionals. In those studies, many external factors can influence the outcomes and/or might increase the heterogeneity in measurements. One review [14] was excluded, because its results were being published in another paper [15]. One review [16] was excluded, because its results do not contain economic data. Finally, after screening the full-text papers we included 11 studies for this review (Table 2). 
26| Chapter 2

Table 2 Included publications

\begin{tabular}{|llllll|}
\hline \multicolumn{2}{l}{ Cost effectiveness } & \multicolumn{2}{c}{ Cost minimisation } & \multicolumn{2}{c|}{ Partial economic evaluation } \\
\hline Venning '00 & RCT & Caine '02 & RCT (same as Sharples) & Richardson '05 & RCT \\
\hline Den Hout '03 & RCT & Sharples '02 & RCT (same as Caine) & Pioro '01 & RCT \\
\hline Richardson '98 & SR & Kinley '01 & RCT & Kamps "04 & RCT \\
\hline & & & & Laurant '05 & SR \\
\hline
\end{tabular}

RCT: randomized controlled trial; SR: systematic review

One of the included studies [17] refers to another paper [18], wherein the effects of the same RCT were described. Of the included studies, three were labelled as a cost effectiveness study [17,19,20], three as a cost-minimization study analysis $[15,21,22]$, of which two papers referred to the same study [15,21]. Five studies were labelled as a partial economic evaluation [8,23-26]. Eight articles were related to RCTs $[15,17,19,21-25]$ and three studies were systematic reviews $[8,20,26]$.

\section{Reasons for conducting studies}

In the objective section, the comparison between two or more alternatives was formulated, related to cost-effectiveness or costminimization (Tables 3-5) $[15,17,19,21]$. This was described as: 'to estimate the equivalence in quality and costs [22], "what is known about the cost-effectiveness in the substitution field" [20], or "what the impact of nurses working is as substitutes for primary care doctors" ' [8]. All but one paper [20] mention the effectiveness of the service established, whereby cost-effectiveness or cost-minimization is related to activities of the doctor being substituted to another professional. Others hypothesized that the quality of care provided by the substituting professional is equivalent to doctors or usual care $[8,15,17,24-26]$, that equivalent care is delivered against lower costs [8], or with the aim to reduce the workload of the doctors [22,26]. One paper [20] did not describe the results of studies estimating the evidence, but formulated some developments in policy making.

The need for substitution is related to the decrease in the number of doctors $[8,19,22-24,26]$, to skill mix $[17,23,25,26]$ and to increasing the training of nondoctors [24]. Alternative motives to initiate this research are the lack of or weaknesses of previous studies $[8,15,17,19,21,24]$ and an increasing pressure to contain costs [26]. 
Critical appraisal of economic evaluations of substitution of skills?

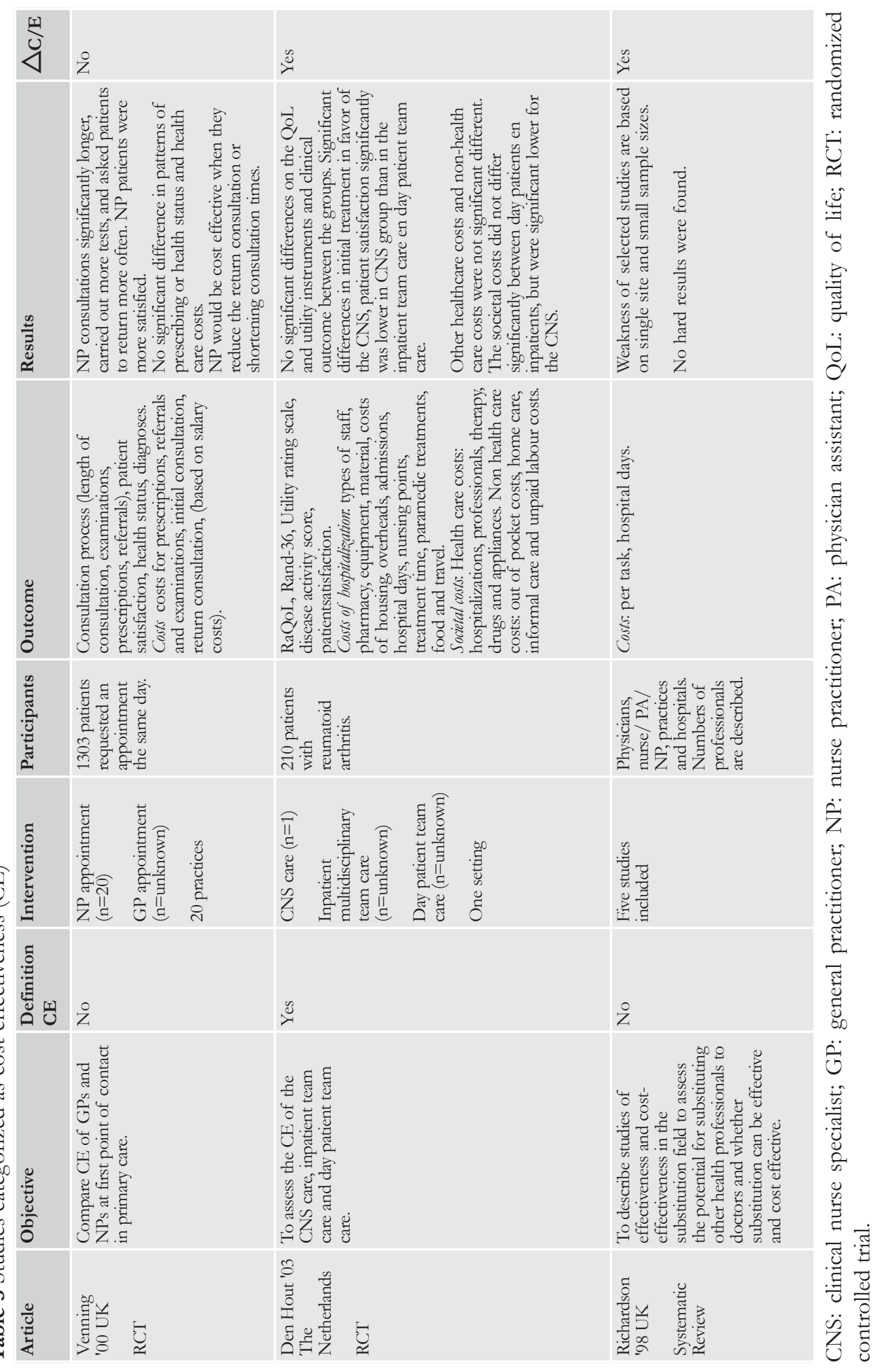




\begin{tabular}{|c|c|c|}
\hline 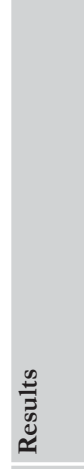 & 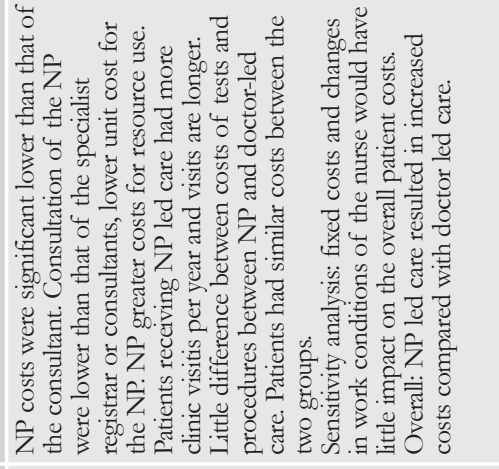 & 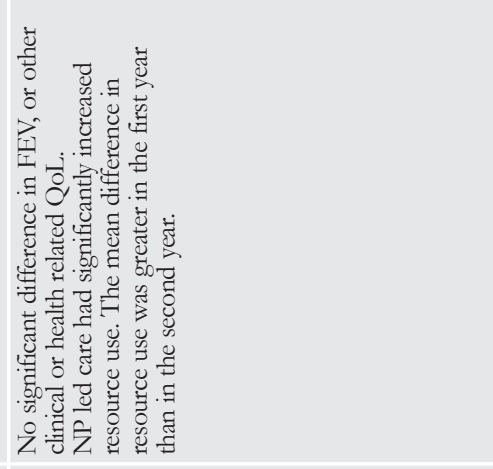 \\
\hline 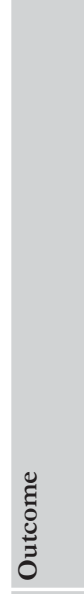 & 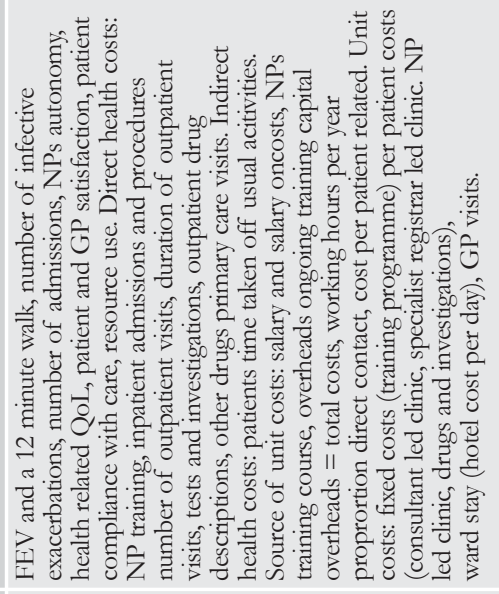 & 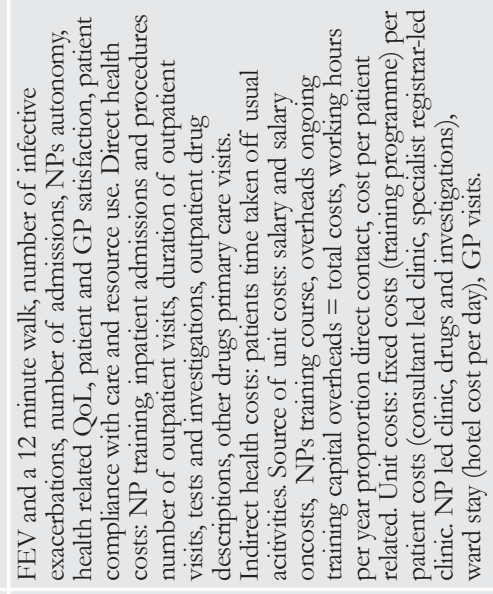 \\
\hline 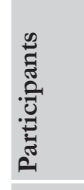 & 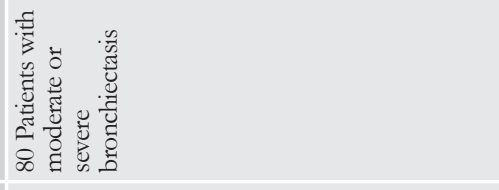 & 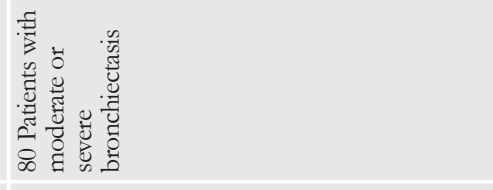 \\
\hline 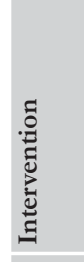 & 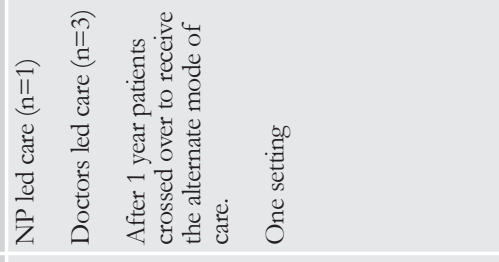 & 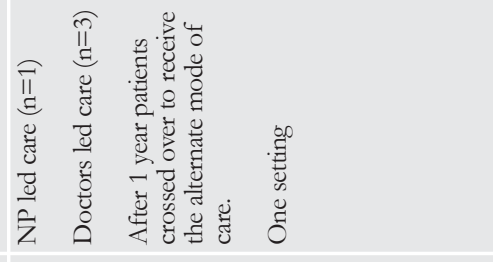 \\
\hline : & $\stackrel{\circlearrowright}{\check{c}}$ & $\stackrel{\circ}{Z}$ \\
\hline 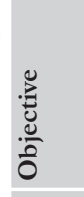 & 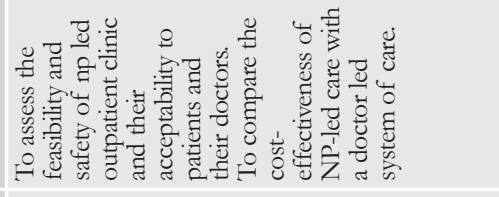 & 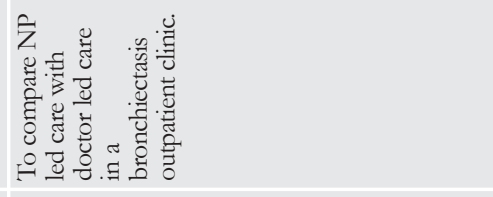 \\
\hline 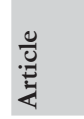 & 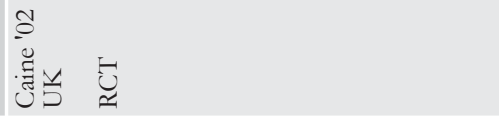 & 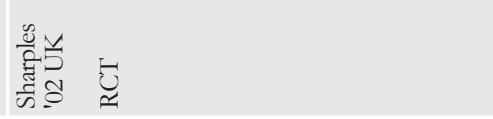 \\
\hline
\end{tabular}


Critical appraisal of economic evaluations of substitution of skills? $\mid 29$

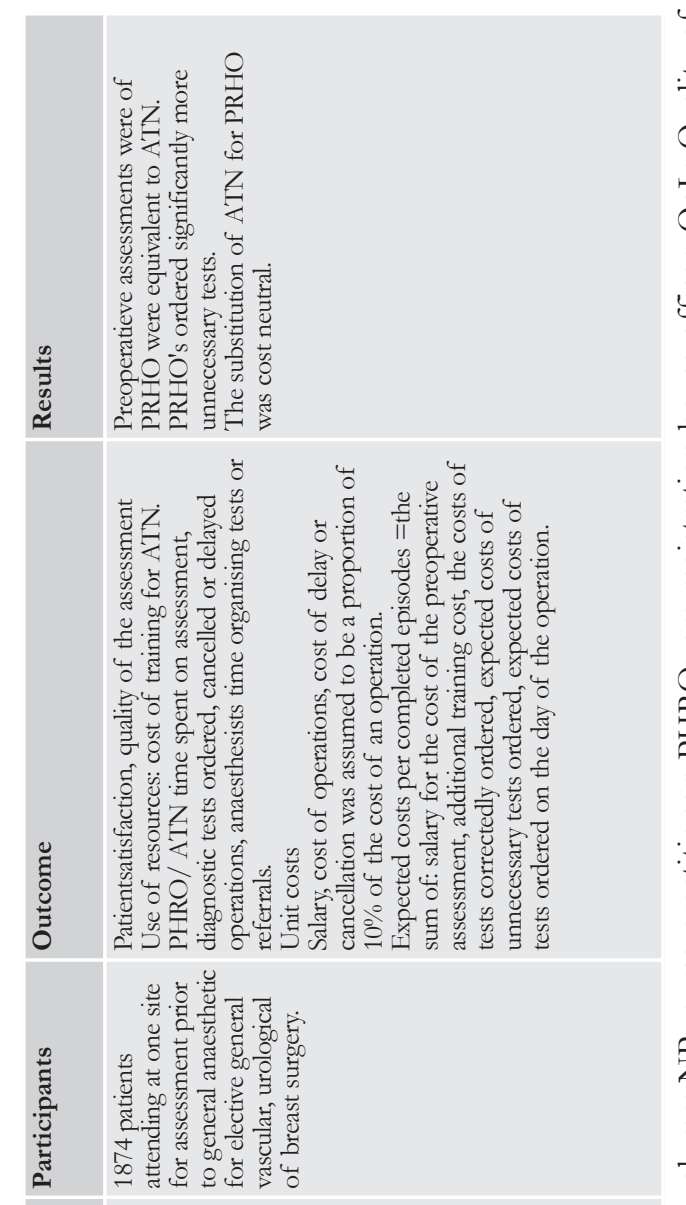

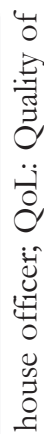

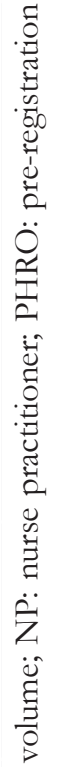

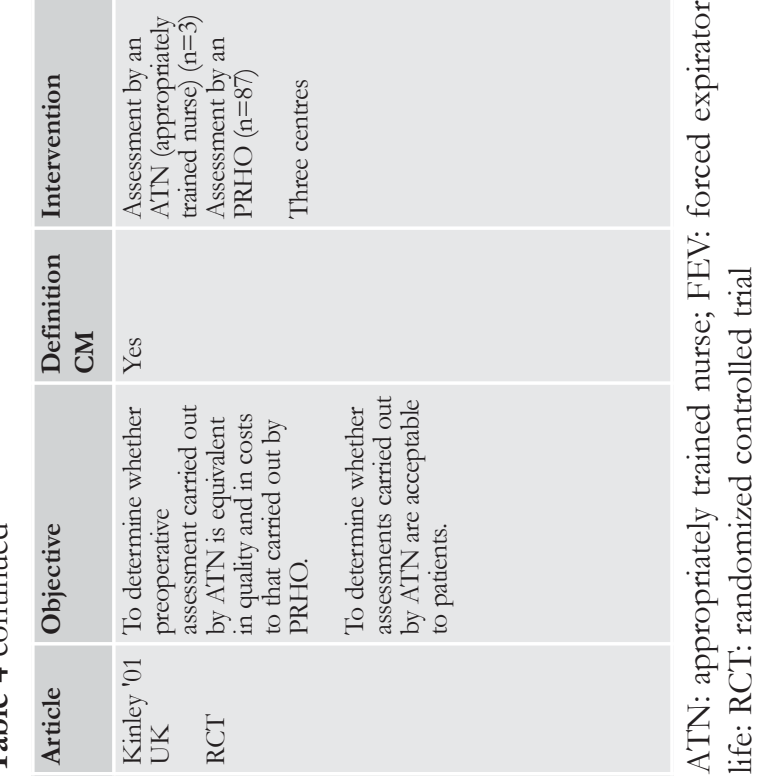



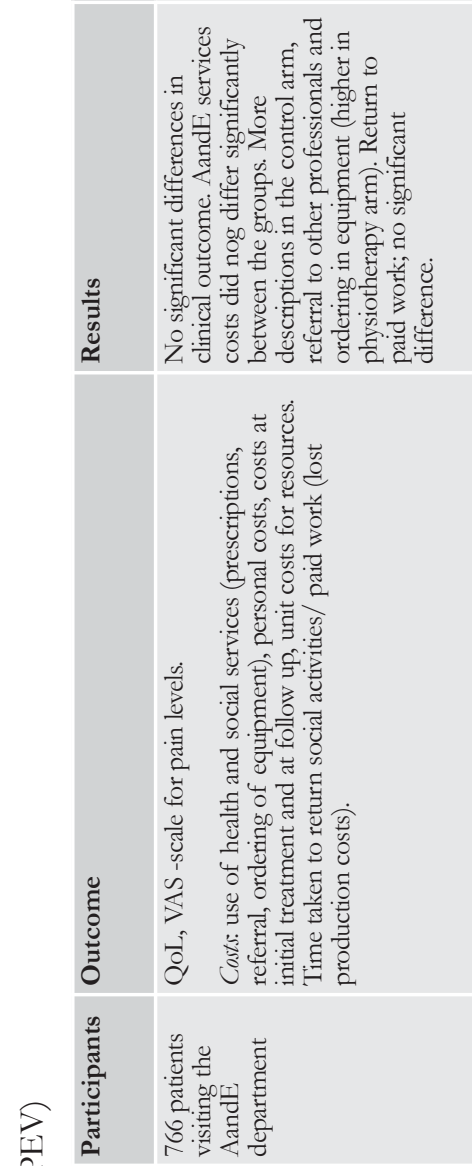

ह

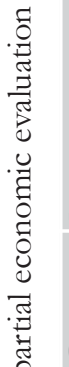

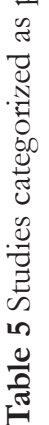
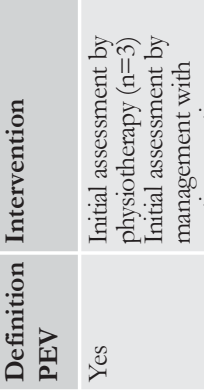

ลำ
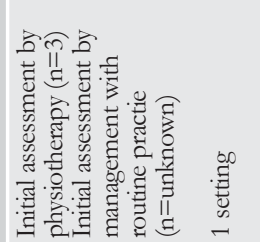

.

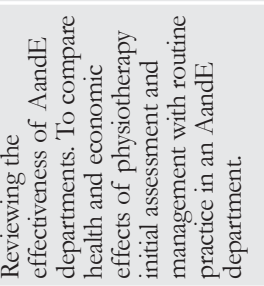

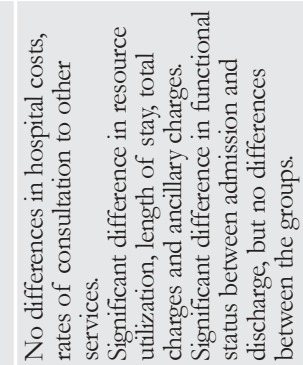
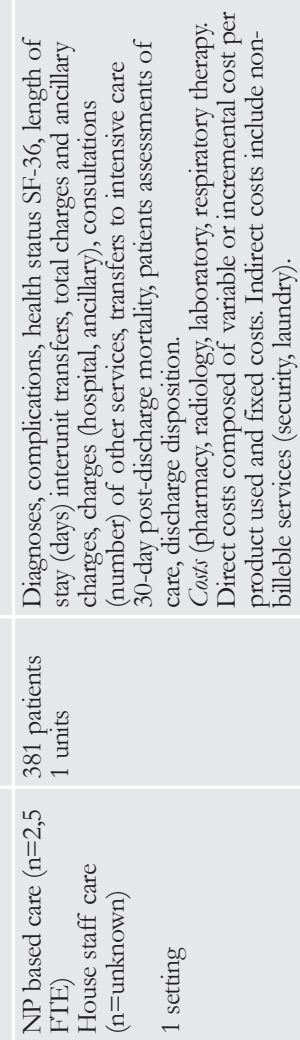

Z
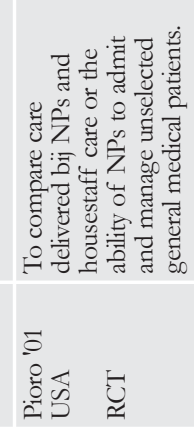

$z$

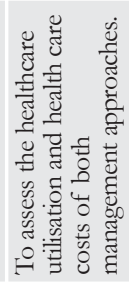

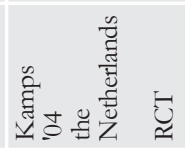


Critical appraisal of economic evaluations of substitution of skills?

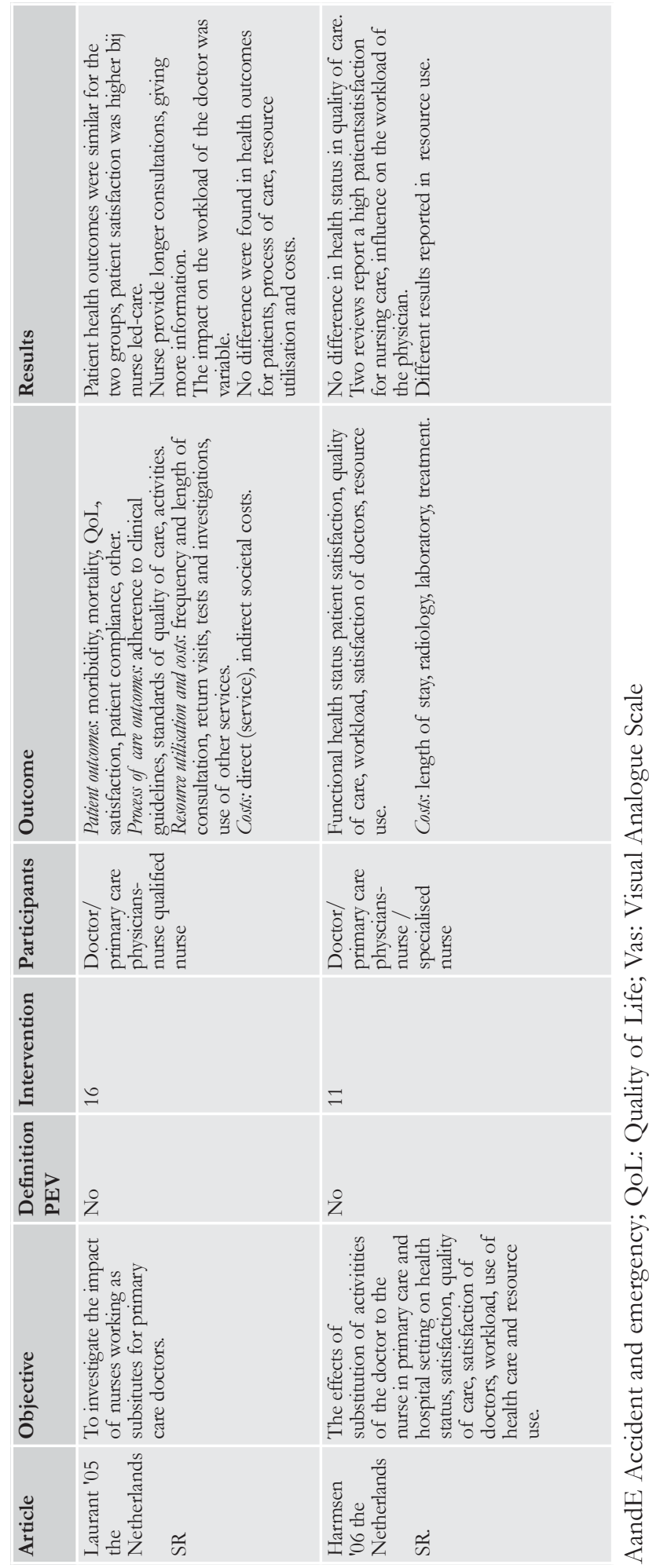




\section{Interventions studied}

In three studies, the consults for patients in general practices [19], an acute care and emergency department [23], and a general medical ward in a hospital [24] were part of the intervention, while other studies focused on the treatment of patients with chronic diseases $[15,17,21,25]$ or surgery patients having an preoperative assessment (Tables 3-5) [22]. Except the training of nurses [15,21,22], the educational level of the professional [19] or management protocol [17], no other prior conditions were described to make skill mix substitution possible. In four papers the intervention group received care by a NP [15,19,21,24], a doctor assistant [20], nurse or clinical nurse specialist [8,17,20,22,25], or physiotherapist [23]. In the control group care was delivered by doctors [8,15,19-22,24], or by a combination of doctor and NP [23]. One paper formulated three alternatives: the clinical nurse specialist, inpatient multidisciplinary team care and day patient team care [17].

Two studies were multicentred, that is, 20 general practices [19] and three centres [22]. All other studies were related to a single setting. An extensive description of the care delivered in the intervention and control group was described in only five studies [17,21,22,24,25]. Only in those studies a comparison between the intervention and control group was transparent.

\section{Quality assessment of methods}

The included publications were assessed by the critical appraisal for full economic evaluations [12] and the EPOC checklist [13] (Tables 6 and 7). In six publications of RCTs allocation concealment was written $[15,17,19,21,22,25]$. In all these studies the professionals were not blinded for the patients and vice versa. Two RCTs [15,21] used a crossover trial, whereby both types of professionals were recognized by the patients. Three papers presented a power calculation for assessing the sample size [15,21,22]. One study did not [19], because 'there were no British studies which investigated the comparison between nurse practitioners and general practitioners'. Depending on the intervention, the population and the measured outcomes, the follow-up varied between 2 years [15,17,21], 1 year [22,25] and 6 weeks [19,23]. 
Table 6 Assessment of the economic evaluations

\begin{tabular}{|c|c|c|c|c|c|c|c|c|c|c|}
\hline \multicolumn{11}{|c|}{ Full economic evaluation } \\
\hline Author & A & B & C & D & $\mathbf{E}$ & F & G & $\mathbf{H}$ & I & $\mathbf{J}$ \\
\hline \multicolumn{11}{|c|}{ Cost effectiveness analysis } \\
\hline Venning '00 & 0 & 0 & 1 & 0 & $*$ & 0 & 0 & 0 & 0 & 0 \\
\hline Den Hout '03 & 0 & 1 & 1 & 1 & 0 & 1 & 1 & 1 & 1 & 1 \\
\hline \multicolumn{11}{|c|}{ Cost minimisation analysis } \\
\hline Caine '02 & 1 & 1 & 1 & 1 & 1 & 1 & 1 & 1 & 1 & 1 \\
\hline Sharples '02 & 0 & 1 & 1 & 1 & 1 & 1 & 1 & 1 & 1 & 0 \\
\hline Kinly '01 & 1 & 1 & 1 & 1 & 1 & 1 & 1 & 1 & 1 & 1 \\
\hline \multicolumn{11}{|c|}{ Partial economic evaluation } \\
\hline Author & A & B & C & D & $\mathbf{E}$ & $\mathbf{F}$ & G & $\mathbf{H}$ & I & $\mathbf{J}$ \\
\hline Richardson '05 & 0 & 0 & 0 & $*$ & $*$ & $*$ & 0 & 1 & 1 & 0 \\
\hline Pioro '01 & 0 & 1 & 1 & 0 & $*$ & $*$ & 0 & 0 & 0 & 0 \\
\hline Kamps '04 & 0 & 1 & 1 & 1 & $*$ & $*$ & 0 & 0 & 0 & 0 \\
\hline
\end{tabular}

A. Was a well defined question posed in answerable form?

B. Was a comprehensive description of the competing alternatives given?

C. Was the effectiveness of the programmas or services established?

D. Were all the important relevant costs and consequences for each alternative identified?

E. Were costs and consequences measured accurately in appropriately physical units?

F. Were costs and consequences valued credibly?

G. Were costs and consequences adjusted for differential timing?

H. Was an incremental analysis of costs and consequences of alternatives performed?

I. Was allowance made for uncertainty in the estimates of costs and consequences?

J. Did the presentation and discussion of study results include all issues of concern to users?

Answer categories: "Yes"=1, "No"=0, "Can't tell"=* 
34 Chapter 2

Table 7 Systematic reviews analysed by the EPOC checklist

\begin{tabular}{|l|l|l|}
\hline Related to full economic evaluations & A & B \\
\hline Author & & 0 \\
\hline Richardson '98 & 0 & 0 \\
\hline Related to partial economic evaluations & & \\
\hline Author & 2 \\
\hline Laurant '05 & 2 & 2 \\
\hline Harmsen '06 & 1 & 1 \\
\hline
\end{tabular}

A. How would you rate the methods used to identify, include and critically appraise of the studies in the review?

B. How would you rate the methods used to analyse the findings of the relevant studies, relative to the primary question, adressed in the review?

Answer categories: Minor limitations = "2" , moderate limitations = "1", major limitations $=" 0 "$

All but one review [20] valued patient outcomes and effects (Tables 8 and 9). Effects were operationalized as patient satisfaction and health status [8,17,19,2426], and quality of life [8,17,24-26]. Patient outcomes encompassed health status, quality of life, patient satisfaction and compliance $[8,15,21,22]$. Other outcomes were work satisfaction of general practitioners [15,21], the quality of the assessment of surgical patients [22] adherence to clinical guidelines [8]. In eight papers outcomes are related to the process of care $[8,15,19-22,24,26]$. Resource use and its costs were measured in terms of prescriptions, referrals, examinations (return) visits, length of consults, salary [8,17,19,23-26] and hospital stay $[8,17,19,20,24-26]$. Direct health care costs contained training, admissions, procedures, visits, tests, investigations and drugs. Indirect health care costs were defined as time taken off from work, usual activities and overhead costs $[8,15,21-23,25,26]$. Indirect costs both inside and outside health care were studied in two papers [17,23].

Quality of life was measured by disease-specific instruments [15,19,21,23-25]. For measuring patient satisfaction, written questionnaires [15,19,21,23,25] or interviews [22,24] were applied. In all RCTs generic instruments were applied for measuring health-related quality of life. Only one study [17] combined a generic instrument with a disease-specific quality-of-life measurement.

For measuring resource use, medical records $[15,19,21,22,24]$ and questionnaires $[15,17,21,23,25]$ were used. In three papers the cost calculation was described $[15,17,21]$. In another three papers $[19,22,23]$ making use of a RCT as a study design, the cost calculation was not described extensively. Furthermore, different cost calculations were performed, that is, cost per patient $[15,17,21-23,25]$ or cost per consultation (Table 10) [19]. 
Critical appraisal of economic evaluations of substitution of skills?

Table 8 Effects and costs in full economic evaluations

\begin{tabular}{|c|c|c|c|c|c|c|}
\hline & \multicolumn{3}{|c|}{ Cost effectiveness } & \multicolumn{3}{|c|}{ Cost minimisation } \\
\hline & Venning & Den Hout & Richardson* & Caine & Sharples & Kinley \\
\hline \multicolumn{7}{|l|}{ Patientoutcome } \\
\hline Health status & 0 & 0 & -- & 0 & 0 & -- \\
\hline Satisfaction & + & -- & -- & 0 & 0 & 0 \\
\hline QoL & 0 & 0 & -- & 0 & 0 & -- \\
\hline Compliance & 0 & -- & -- & 0 & 0 & -- \\
\hline \multicolumn{7}{|l|}{ Process of care } \\
\hline Physical examinations & 0 & -- & -- & -- & -- & -- \\
\hline Professionals'satisfaction & -- & -- & -- & 0 & 0 & -- \\
\hline Medical treatment/assessment & -- & -- & -- & -- & -- & 0 \\
\hline Activities & -- & -- & $1 \mathrm{x}+$ & -- & -- & -- \\
\hline \multicolumn{7}{|l|}{ Resource use and costs } \\
\hline Direct costs within health care: & 0 & 0 & $1 \mathrm{x}+1 \mathrm{x} 0$ & -- & -- & -- \\
\hline Number of visits & 0 & 0 & -- & -- & -- & -- \\
\hline Length of consultation & -- & -- & -- & -- & -- & $\mathrm{X}$ \\
\hline Number of return consultations & -- & 0 & -- & -- & -- & -- \\
\hline Prescriptions & 0 & 0 & -- & 0 & 0 & -- \\
\hline Examination & -- & 0 & -- & 0 & 0 & + \\
\hline Referrals & 0 & 0 & -- & -- & -- & 0 \\
\hline Staff and salary & -- & 0 & $1 \mathrm{x}+$ & + & + & $\mathrm{X}$ \\
\hline Training & -- & -- & -- & -- & -- & $\mathrm{X}$ \\
\hline Equipment and material & -- & 0 & -- & -- & -- & -- \\
\hline GP visit & -- & -- & -- & -- & -- & -- \\
\hline Hospital stay & -- & -- & -- & -- & -- & -- \\
\hline Length of hospital stay & -- & 0 & $1 \mathrm{x}+$ & -- & -- & -- \\
\hline Paramedic treatment & -- & 0 & -- & -- & -- & -- \\
\hline Food and travel & -- & 0 & -- & -- & -- & -- \\
\hline Overheads & -- & 0 & -- & 0 & 0 & -- \\
\hline Admissions & -- & 0 & -- & -- & -- & -- \\
\hline Working hours per year & -- & & -- & -- & -- & -- \\
\hline $\begin{array}{l}\text { Direct costs outside health cares } \\
\text { (time and travel) }\end{array}$ & -- & 0 & -- & -- & -- & -- \\
\hline $\begin{array}{l}\text { Indirect health care costs } \\
\text { (productivity lossess) }\end{array}$ & -- & 0 & -- & 0 & 0 & -- \\
\hline Overall societal costs & -- & + & -- & -- & -- & -- \\
\hline
\end{tabular}

+ positive result for the nurse/ np/ paramedics/CNS (intervention Group)

- positive result for the doctor (control; usual care)

0 no difference between the groups

-- not investigated

* Richardson included five studies 
36 Chapter 2

Table 9 Effects and costs in partial economic evaluations

\begin{tabular}{|c|c|c|c|c|c|}
\hline & \multicolumn{5}{|c|}{ Partial economic evaluation } \\
\hline & Richardson & Pioro & Kamps & Laurant & Hamsen \\
\hline \multicolumn{6}{|l|}{ Patientoutcome } \\
\hline Health status & + & 0 & 0 & 0 & 0 \\
\hline Satisfaction & + & -- & -- & + & + \\
\hline QoL & 0 & 0 & 0 & 0 & 0 \\
\hline Compliance & -- & -- & -- & 0 & -- \\
\hline \multicolumn{6}{|l|}{ Process of care } \\
\hline Physical examinations & -- & -- & -- & 0 & -- \\
\hline Professionals'satisfaction & -- & -- & -- & -- & -- \\
\hline Medical treatment/assessment/guidelines & -- & 0 & -- & 0 & -- \\
\hline Activities & -- & 0 & -- & 0 & -- \\
\hline Workload & -- & - & -- & -- & 0 \\
\hline \multicolumn{6}{|l|}{ Resource use and costs } \\
\hline Direct costs within bealth care: & -- & -- & -- & 0 & 0 \\
\hline Number of visits & 0 & - & 0 & 0 & 0 \\
\hline Length of consultation & -- & 0 & -- & -- & -- \\
\hline Number of return consultations & 0 & -- & -- & -- & -- \\
\hline Prescriptions & -- & & 0 & 0 & 0 \\
\hline Examination & 0 & 0 & 0 & 0 & 0 \\
\hline Referrals & 0 & 0 & -- & 0 & 0 \\
\hline Staff and salary & -- & -- & 0 & -- & -- \\
\hline Training & -- & -- & -- & -- & -- \\
\hline Equipment and material & 0 & -- & -- & -- & -- \\
\hline GP visit & 0 & - & 0 & -- & -- \\
\hline Hospital stay & -- & 0 & 0 & -- & 0 \\
\hline Length of hospital stay & & 0 & 0 & -- & -- \\
\hline Paramedic treatment & 0 & 0 & 0 & -- & -- \\
\hline Food and travel & -- & 0 & -- & -- & -- \\
\hline Overheads & 0 & -- & 0 & -- & -- \\
\hline Admissions & 0 & 0 & -- & -- & -- \\
\hline Working hours per year & -- & -- & -- & -- & -- \\
\hline $\begin{array}{l}\text { Direct costs outside bealth cares } \\
\text { (time and travel) }\end{array}$ & 0 & -- & + & 0 & -- \\
\hline $\begin{array}{l}\text { Indirect health care costs } \\
\text { (productivity lossess) }\end{array}$ & 0 & -- & 0 & 0 & -- \\
\hline Overall societal costs & -- & -- & -- & 0 & -- \\
\hline
\end{tabular}

+ positive result for the nurse/ np/ paramedics/CNS (intervention Group)

- positive result for the doctor (control; usual care)

0 no difference between the groups

-- not investigated 
这

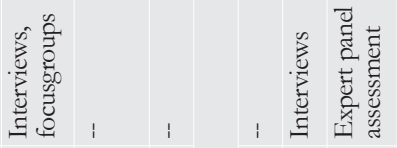

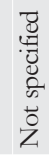

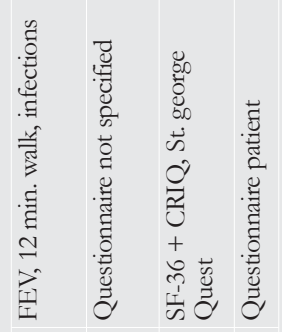

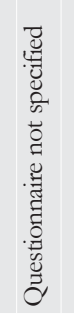

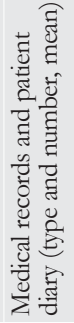

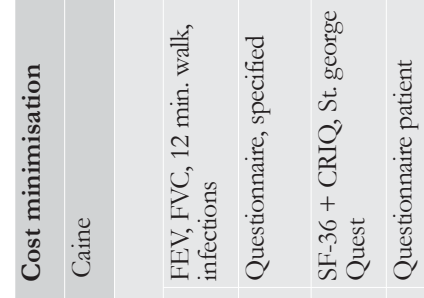

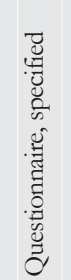

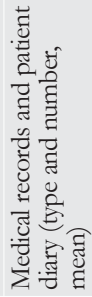

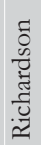

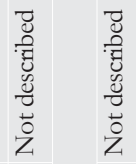

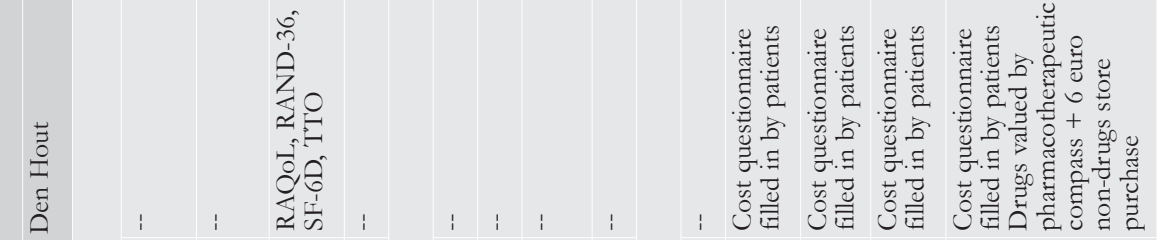

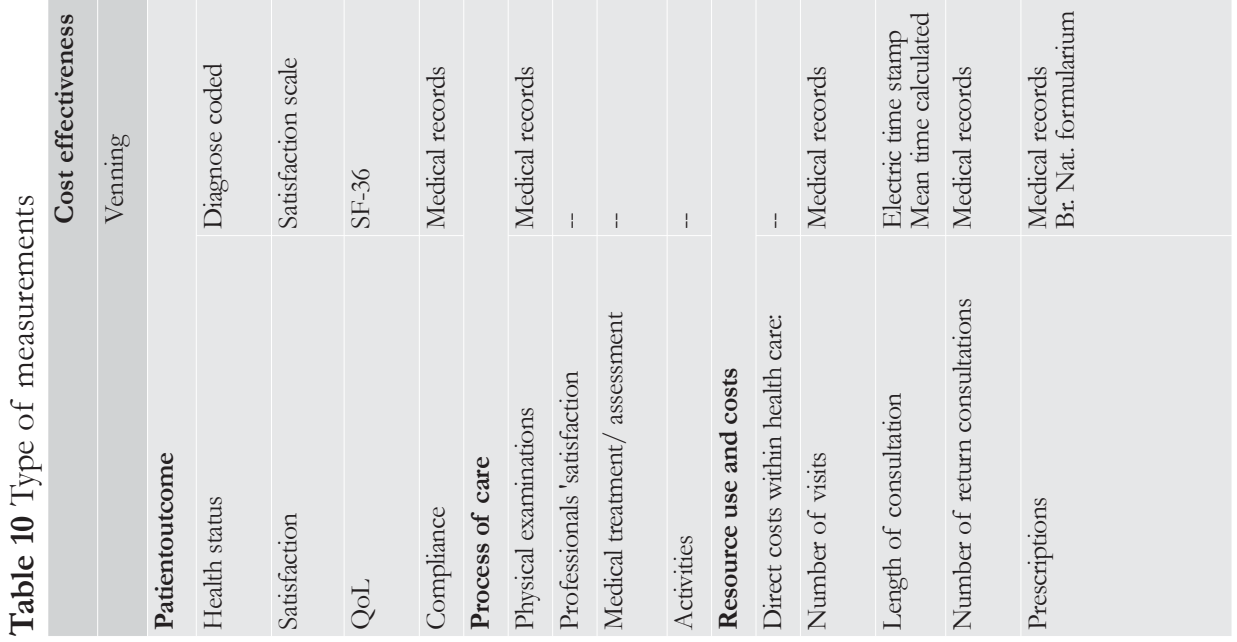


38 Chapter 2

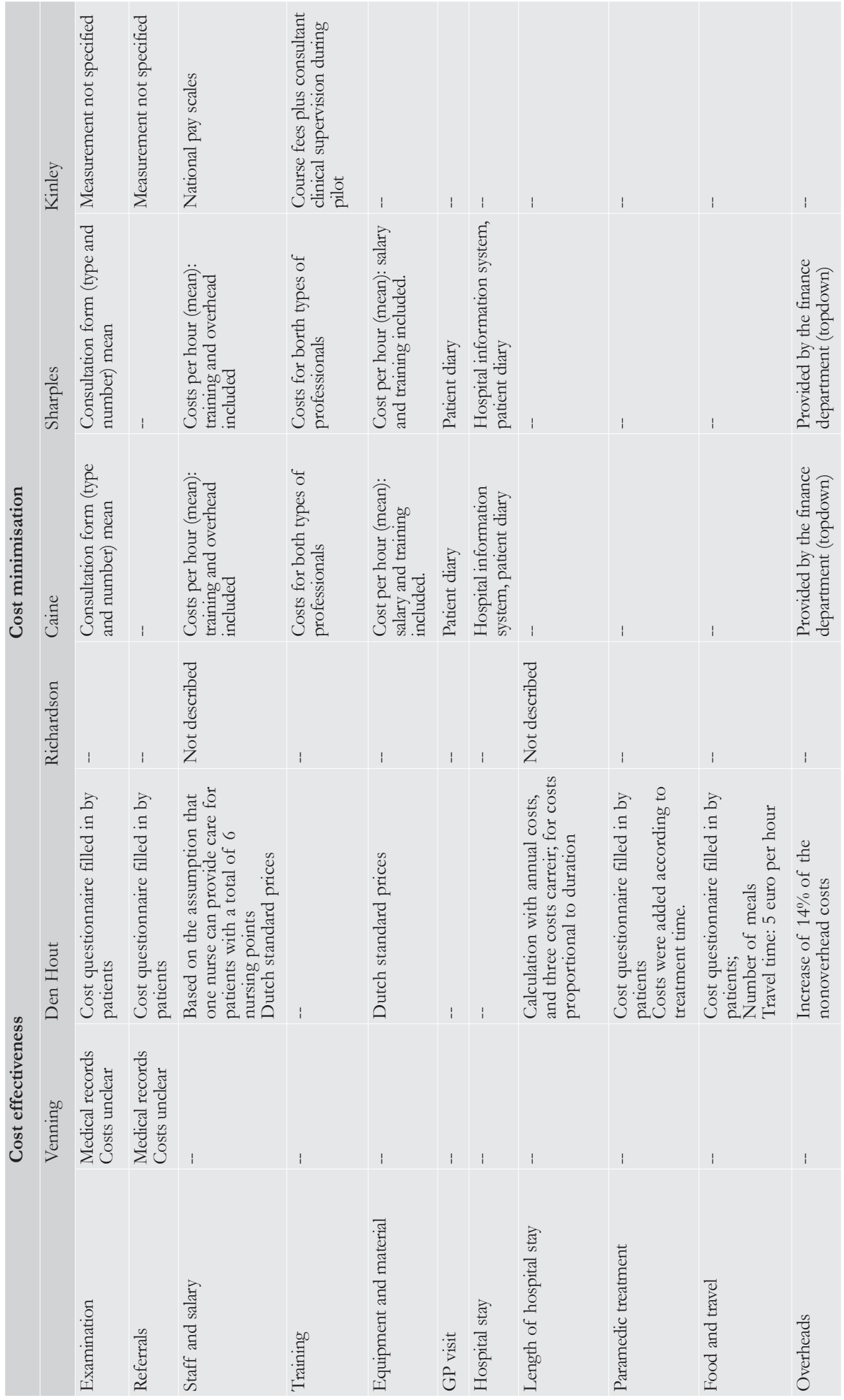


Critical appraisal of economic evaluations of substitution of skills? |39

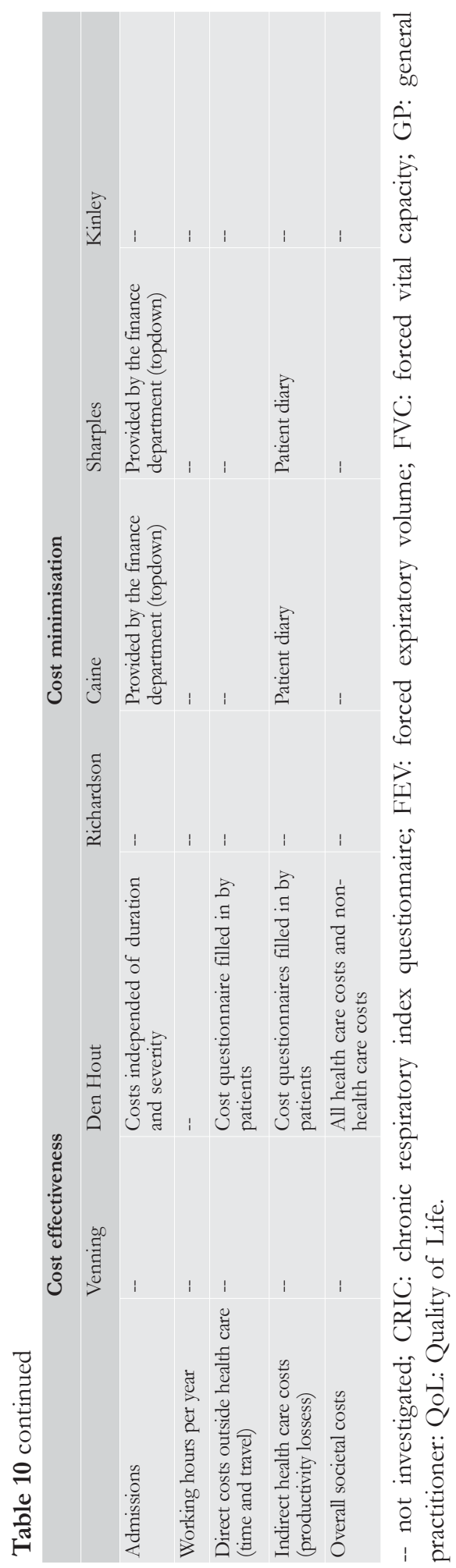




\section{Informed decision making}

In almost all studies an analysis for uncertainty was made in terms of a sensitivity analysis [17,22,23,25] or bootstrapping [15,19,21,23]. Only one paper described a cost-effectiveness ratio [17]. Studies report the absence of a significant difference in effects like quality of life or utilities, health status, prescriptions $[17,19,24]$, health care costs $[17,19,20,23,24]$ or societal costs $[17,23]$.

One paper presented that patients were more satisfied with a consultation by the nurse (practitioner) [8,19,23,26] or physiotherapist [23]. Consultations in the intervention group lasted significantly longer $[8,19,25,26]$, and the patients in the intervention group had more return visits [8,19,25,26]. Two studies [15,21] reported NP-led care resulting in a significantly increased resource use [15], and the overall costs of NP-led care were significantly higher than those in the group receiving doctor-led care [21]. The preoperative assessment carried out by an appropriately trained nurse or by the pre-registration house officer was reported to be cost-neutral. The mean number of days off from work - productivity loss was not found to be significant different between the two groups. Out-of-pocket expenses, like travel costs, are reported to be higher when a patient has more visits by the NP [22].

Two reviews $[8,26]$ report that no evidence was found for the cost-effectiveness when activities are substituted from one professional to another. Both reviews mention that included studies have some methodological weaknesses. Another review [20] described results per study and report that in all studies the results are equal or positive for the 'physician extender'. Again, it was stated that the included studies had weaknesses in terms of small sample sizes and poor design.

\section{Discussion}

Introduction of new roles has an impact on the interface in health care systems and between professionals. There is evidence that substitution of skills is justifiable, because quality of care will be equal or improved $[2,7,8]$. This review aims to identify studies wherein the role of the 'new type' of health care worker is evaluated in terms of costs and consequences, and to assess the quality of the methods applied in the identified studies. Our search for published studies revealed little evidence to answer these questions; only 11 publications met our criteria. Several potential limitations have to be considered, which influence the validity and generalizability of the publications. First of all, the small number of publications related to economic evaluations and substitution of activities and a limited number of professionals participating in the trials. Secondly, the populations were homogenic, while it is recommendable having diverse samples of both patient groups and clinical settings [27]. Third, only prior conditions as training, education level and management were mentioned, but there will be other prior conditions which have to be arranged, to make substitution of activities successful. Fourth, only in five studies an extensive description was 
given of care delivered in the intervention and control group, which makes the comparison between the intervention and control group transparent. Also the various types of health care systems in different countries will influence the generalizability of the research findings.

More systematic collection of economic measures is needed to evaluate new interventions accurately. Until more is known about costs and cost-effectiveness of new interventions, it is unreasonable to expect that decision- or policy-makers are willing to adopt or reimburse such programmes [27]. How costs are derived and combined will depend on the assumptions that have been made in their derivation and there are a number of rules that must be used when estimating cost data [6]. In the selected publications, there were also some limitations in the cost valuation. Problems in measuring indirect costs outside health care like informal care or productivity costs were described. The great awareness of doctors to costs and budgets can influence the results related to costs [17]. Some studies do not describe the type of measurement [22] or use medical records as a resource $[15,17,19,21]$, but the quality of registration was not described.

Furthermore, it should be noted that two publications describe a costeffectiveness analysis, without describing a cost-effectiveness ratio [17,19,20]. One study [17] was a cost-effectiveness study, but the effects were equal, so the study can be considered as a cost minimization study.

How useful are economic evaluations for this kind of intervention? The difficulty of establishing the cost-effectiveness of complex interventions is an explanation for the modest number of publications found. An RCT has an artificial surrounding and is useful in measuring costs and effects, directly related to the intervention. But regarding the analysis of this intervention, this phenomenon is complex by three factors. One factor is the limited evidence and another factor is the lack of clarity about strategic objectives. Strategic options and their resource implications are complex and include combinations of health care workers, investment/disinvestment and substitution/complementation. And the last factor is the difference in skills between professionals. Effective teamwork is driven by the difference between the members [6]. These kind of research is related to many variables, structure and process, which influence the results. The outcomes are related not only to clinical health status, process of care and costs, but also to non-health care outcome, like accessibility or continuation of care.

Full economic evaluations are widespread, but there are some generic limitations in relation to studies investigating substitution of skills, the introduction of 'new' health care workers or professionals with new roles. Regarding the costeffectiveness analysis, cost-minimization analysis or cost-utility analysis, it is very difficult to choose one common effect of interest. For example, can quality of life or patient preferences be considered as the primary outcome in this type of research? A CBA values the outcomes in monetary terms, but not every outcome can be valued in monetary terms. 
The relationship between structural and process variables to final health outcomes may also be tenuous in this area. Outcomes are often multidimensional and assessment may be affected by timing and characteristics by difficulties in attribution [6]. Using only full economic evaluations by this complex interventions give some results about efficacy, not about effectiveness.

\section{Implications for further research in relation to decision-makers}

We have described some issues in undertaking an economic evaluation in the area of the introduction of new professionals, or new substituted skills of health care workers. This phenomenon has to deal with different forces: health policies have the issue how to meet increased needs and expectations within a limited budget, the resource problem in health care (scarcity or overflow) and the (financial) interests of the professional. Here we offer some recommendations to improve the accessibility and the acceptability of economic evaluation research for informed decision making.

Not only do the facts have to be investigated, but also variables related to structure and process. Exploring relationships among structural and process variables, and patient and cost outcome can contribute to the development of a solid knowledge base which forms the basis for building theory or developing a conceptual framework [28,29]. An RCT combined with an observational longitudinal study can be helpful to put the effects in the context of health care. Adaptation of these kind of innovation will be influenced by time dimensions, such as a shortage of doctors in specific settings. Observational longitudinal studies should include the following research questions: (1) What incentives facilitate skill mix or substitution? (2) What are the prior conditions? (3) What is the productivity in terms of consultations or contacts and what are the professionals currently doing? (4) What are the side effects of substitution, uncertainty of the role, competition, domain discussion, acceptance of other professionals? (5) What are the motives and perspectives for implementing the innovation? These are all components to explore how we can reach the optimal skill mix to improve the effects against the same costs or to obtain same effects and reduce the costs. Prior conditions are the constant dialogue between policymakers, professionals and researchers and accessible publications, which also describes implications for clinical practice.

\section{ConClusion}

In spite of the limitations, our findings contribute new information about the quality of economic evaluations related to the substitution of skills. We conclude that a small number of papers are related to a full economic evaluation and that there are difficulties in the generalizability and validity of the results. Finally, we discuss that full economic evaluations have some limitations for investigating substitutions of tasks or the introduction of new roles of health care workers. 


\section{An economic evaluation (RCT) combined with an observational longitudinal study is strongly recommended.}

\section{Appendix 1}

Two features characterize an economic evaluation. It deals with costs and consequences and secondly an economic evaluation concerns itself with choices. An economic analysis seeks to identify and to make explit sets of criteria which may be useful in deciding among different uses for resources.

Drummond et al. (1997) describes full economic evaluations and partial economic evaluations. Studies with a the cost-effectiveness analysis and the cost-minimisation analysis can be stated as an full economic evaluation.. In a costeffectiveness analysis the costs are related to a single common effect. Results have to be stated as a cost per unit of effect or effect per unit of costs. If we identify that two interventions have the same outcome but at different costs, a cost minimisaton analysis is used.

The third category we identified is the partial economic evaluation. In this type of evaluation there was an comparison between two or more alternatives, both effects and costs are investigated but the link between costs and effects isn't described. 


\section{REFERENCES}

1. World Health Organization. The World Health Report, 2000 - Health Systems: Improving Performance. Geneva: World Health Organization 2000.

2. Buchan J, Dal Poz MR. Skill mix in the health care workforce: reviewing the evidence. Bulletin of the World Health Organisation 2002; 80 (7): 575-80.

3. Reay T, Golden-Biddle K, Germann K, Challenges and leadership strategies for managers of nurse practitioners. Journal of Nursing Management 2003; 11 (6): 396-403.

4. McKenna H, Richey R, Keeney S, Hasson F, Sinclair M, Poulton B, The introduction of innovative nursing and midwifery roles: the perspective of healthcare managers. Journal of Advanced Nursing 2006; 56 (5): 553-62.

5. Richardson G, Identifying, evaluating and implementing cost effective skill mix. Journal of Nursing Management 1999;7 (5): 265-70.

6. Kernick D, Scott A, Economic approaches to doctor/nurse skill mix: problems, pitfalls, and partial solutions. British Journal of General Practice 2002; 52 (474): 42-6.

7. American Academy of Nurse Practitioners (AANP). Nurse Practitioners - Providers of Quality Primary Care. Documentation of Cost Effectiveness. Washington DC: AANP, revised 2000. Available at: http://www.aanp.org/ (last accessed February 2007).

8. Laurant M, Reeves D, Hermens R, Braspenning J, Grol R, Sibbald B, Substitution of doctors by nurses in primary care.Cochrane Database of Systematic Reviews 2004; Issue 4. Art. No.: CD001271. DOI: 10.1002/14651858.CD001271.pub2.

9. Hoffman C, Graf von der Schulenberg JM, The influence of economic evaluation studies on decisionmaking: a European survey. Health Policy 2000; 52: 179-92.

10. Williams I, Bryan S, Understanding the limited impact of economic evaluation in health care resource allocation: a conceptual framework. Health Policy 2007; 80 (1): 135-43.

11. Canadian Nurse Association. Cost-effectiveness of the nurse practitioner role. Factsheet. Ottawa: CAN. Available at: http://www.can-nurses.ca/ (last accessed December 2006).

12. Drummond MF, O'Brien B, Stoddart GL, Torrance GW, Methods for the Economic Evaluation of Health Care Programmes, 2nd edn. New York: Oxford University Press, 1997.

13. Cochrane Effective Practice and Organisation of Care Review Group. The Cochrane Effective Practice and Organisation of Care Review Group Data Collection Checklist. Aberdeen, UK, University of Aberdeen, 1998.

14. French J, Bilton D, Campbell F, Nurse specialist care for bronchiectasis. Cochrane Database of Systematic Reviews, 2003; 3: CD004319.

15. Sharples LD, Edmunds J, Bilton D, Hollingworth W, Caine N, Keogan M, Exley A, A randomised controlled crossover trial of nurse practitioner versus doctor led outpatient care in a bronchiectasis clinic. Thorax 2002; 57 (8): 661-6.

16. De Broe S, Christopher F, Waugh N, The role of specialist nurses in multiple sclerosis: a rapid and systematic review. Health Technology Assessment 2001; 5 (17): $1-47$.

17. van den Hout WB, Tijhuis GJ, Hazes JM, Breedveld FC, Vliet Vlieland TP, Cost effectiveness and cost utility analysis of multidisciplinary care in patients with rheumatoid arthritis: a randomized comparison of clinical nurse specialist care, inpatient team care, and day patient team care. Annals of the Rheumatic Diseases 
2003; 62 (4): 308-15.

18. Tijhuis GJ, Zwinderman AH, Hazes JM, Breedveld FC, Vlieland PM,Two-year follow-up of a randomized controlled trial of a clinical nurse specialist intervention, inpatient, and day patient team care in rheumatoid arthritis. Journal of Advanced Nursing, 2003; 41 (1): 34-43.

19. Venning P, Durie A, Roland M, Roberts C, Leese B, Randomised controlled trial comparing cost effectiveness of general practitioners and nurse practitioners in primary care. British Medical Journal 2000; 320 (7241): 1048-53.

20. Richardson G, Maynard A, Cullum N, Kindig D, Skill mix changes: substitution or service development? Health Policy 1998; 45 (2): 119-32.

21. Caine N, Sharples LD, Hollingworth W, French J, Keogan M, Exley A, Hodgkins D, Bilton D, A randomised controlled crossover trial of nurse practitioner versus doctor-led outpatient care in a bronchiectasis clinic. Health Technology Assessment 2002; 6 (27): 1-71.

22. Kinley H, Czoski-Murray C, George S, et al. Extended scope of nursing practice: a multicentre randomised controlled trial of appropriately trained nurses and preregistration house officers in preoperative assessment in elective general surgery. Health Technology Assessment 2001; 5 (20): 1-87.

23. Richardson B, Shepstone L, Poland F, Mugford M, Finlayson B, Clemence N, Randomised controlled trial and cost consequences study comparing initial physiotherapy assessment and management with routine practice for selected patients in an accident and emergency department of an acute hospital. Emergency Medicine Journal 2005; 22 (2): 87-92.

24. Pioro MH, Landefeld CS, Brennan PF, Daly B, Fortinsky RH, Kim U, Rosenthal GE, Outcomes-based trial of an inpatient nurse practitioner service for general medical patients. Journal of Evaluation in Clinical Practice 2001; 7 (1): 21-33.

25. Kamps AW, Roorda RJ, Kimpen JL, Overgoor-van de Groes AW, van HelsdingenPeek LC, Brand PL (2004) Impact of nurse-led outpatient management of children with asthma on healthcare resource utilisation and costs. The European Respiratory Journal 2004; 23 (2): 304-9.

26. Harmsen M, Laurant M, van Achterberg T, Hulscher M, Wensing M, Wollersheim $\mathrm{H}$, Grol R, Taakherschikking in de gezondheidszorg: een systematisch literatuuroverzicht. WOK, Centre for Quality of Care Research, UMC, St Radboud Nijmegen, the Netherlands 2006. (In Dutch)

27. Glasgow, R. E. RE-AIMing research for application: ways to improve evidence for family medicine. Journal of the American Board of Family Medicine 2006; 19 (1):11-9.

28. Sidani S, Irvine D, A conceptual framework for evaluating the nurse practitioner role in acute care settings. Journal of Advanced Nursing 1999; 30 (1): 58-66.

29. Doran DI, Sidani S, Keatings M, Doidge D, An empirical test of the Nursing Role Effectiveness Model. Journal of Advanced Nursing 2002; 38 (1): 29-39. 


\section{Chapter}

\section{The value of nurse practitioners in Dutch general practices}

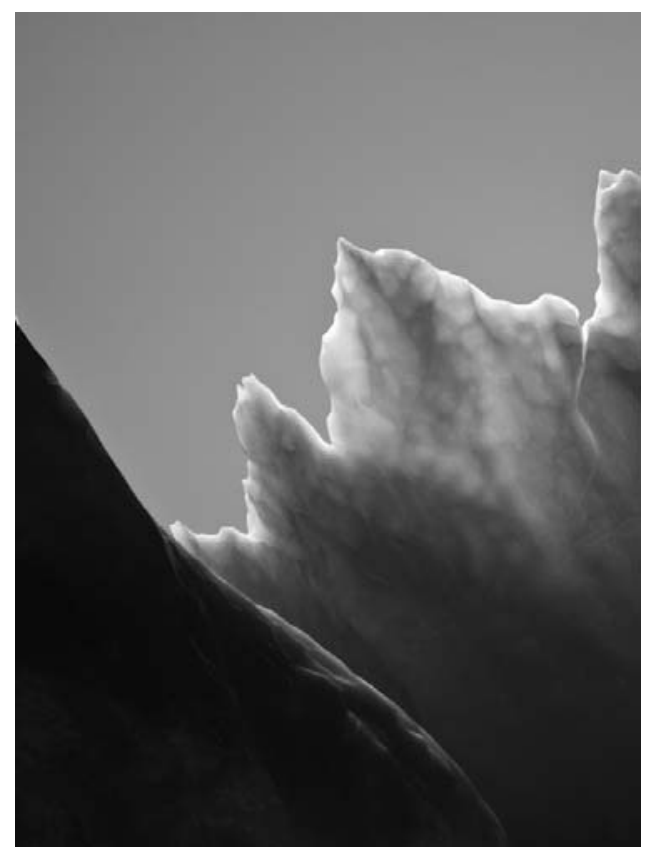

A.T.M. Dierick-van Daele, C. Spreeuwenberg, E.W.C.C. Derckx, Y. van Leeuwen, T. Toemen, M. Legius, J.J.M. Janssen, J.F.M. Metsemakers, H.J.M. Vrijhoef

Submitted for publication 


\section{Abstract}

Background. Health care systems are faced with a changing and increasing demand of care. Against the background of the need to increase service capacity and to improve access to primary care, a project was initiated to introduce the nurse practitioner (NP) role in Dutch general practices.

Objective. To explore the concordance of the NP roles with the initial concepts of the NP training program.

Methods. An observational longitudinal design, using mixed methods, was conducted between March 2004 and June 2008. A convenience sample of seven NPs and seven teaching general practitioners (GPs) together constituting seven experimental groups was used. Project documentation and data of consultations of NPs and GPs were collected. Twenty-nine interviews were performed, focussing on NP roles, competencies of and collaboration between professionals.

Results. As was intended, all NPs have patients with common complaints as main focus, as well as managing quality of care projects. Differences between NPs are reported in the percentages of their time spend to perform home visits, care for elderly, patient related activities, and non patient related activities.

Conclusion. NPs are functioning as formulated in the initial concepts with a main focus on the treatment of patients with common complaints. The adopted roles are influenced by practice needs and financial incentives. It is not clear to which degree NPs have to perform activities to improve the quality of care and further research is necessary to define the NP core competencies.

Keywords. nurse practitioner, general practice, substitution, collaboration, quality of care 


\section{INTRODUCTION}

Health care systems are faced with a changing and increasing demand of care. To guarantee the availability and accessibility of primary care for the nearby future, an adequate mix of health care personnel is one of the prior conditions. This requires a reflection on current roles and responsibilities of health personnel (WHO, 2000; Buchan and Dal Poz, 2002). Nurses and doctors have exchangeable skills which make it possible for one to substitute for the other within the area of overlap (Sibbald, 2008).

In British and Dutch general practices practice nurses are well known and they have a significant contribution in the care for chronically ill. Recently, strong interest has been shown in the concept of Nurse Practitioners (NPs) providing primary care particularly in the management of patients with minor health problems (Reay et al., 2003; Laurant et al., 2004). The term NP is generally used to identify registered nurses with additional education and training i.e. Master in Advanced Nursing Practice, who work within an expanded scope of practice that includes diagnosing, prescribing, and treating medical conditions within specific settings (Reay et al., 2003).

The majority of GPs recognize that NPs can undertake a wide range of clinical activities and are aware of their role to improve the quality and scope of practice (Redsell, 2006; Sibbald, 2008). Notwithstanding, wide divergence in autonomy and variations in activities exist in NP roles (Wilson et al., 2002; Furlong and Smith, 2005).

Against the background of the need to increase service capacity and to improve access to primary care, a project was initiated to introduce the NP in Dutch general practices. The aim of this study is to explore what the value is of the NP by exploring the concordance of the NP roles with the initial concepts of the NP training program.

\section{METHODS}

\section{Study design}

This study was part of an extensive evaluation study, which has been described in more detail elsewhere (Dierick et al., 2009). An observational longitudinal design was conducted between March 2004 and June 2008. We used mixed methods to maximize case completeness and validity (Munhall and Boyd, 1993; Yin, 1994).

\section{Participants}

A convenience sample of seven NPs and seven teaching GPs, together constituting seven experimental groups was used. NPs were trained and employed in ten participating practices: three solo practices, two duo practices, four group practices and one health care centre. The teaching GPs had an 
average work experience of 16 years $(\mathrm{SD}=10.1)$. Participating NPs had on average 12 years $(\mathrm{SD}=7.6)$ working experience as a (practice) nurse in general practice $(n=3)$, in hospital $(n=3)$ or an asylum seekers' centre $(n=1)$. Before they started to work as NP, the nurses followed the Higher Professional Education Master's degree in Advanced Nursing Practice (MANP). This training program started in March 2004 till February 2006. At the time of data collection all NPs worked part time (0.6 full time equivalent (FTE). More details of the job description and the training program are described in Box 1.

Box 1 The NP job description (project NP in Dutch general practices)

Target population: patients with common complaints

A specified set of common complaints was compiled for which patients seek medical attention. These common complaints will often lead to minor health problems. Patients have respiratory and throat complaints, ear and nose complaints, musculoskeletal complaints and injuries, skin injuries, urinary complaints, gynaecological complaints and geriatric problems.

Patient related activities

Based on triage by the practice assistant, patients with common complaints are referred to the NP. The NP works independent during consultations and home visits. The activities, according to practice guidelines derived by the Dutch College of General Practitioners are assessing symptoms, physical examinations where appropriate, diagnosing and making decisions for further treatment, prescriptions, referrals to primary or secondary services and clinical investigations. The NP has no full authority to prescribe medications, the GP is always available for consultation and to assign prescriptions. The NP has access to the electronic medical records and reported consultations.

\section{Non patient related-activities}

NPs perform activities to improve collaboration between health care professionals within general practice and external partners and activities related to education and quality care projects.

Training

A specific two year practice-oriented training program was developed, which consisted of the Higher Professional Education Master's degree in Advanced Nursing Practice (MANP), including general courses and medical courses on a specified set of managing common complaints. General courses were training of basic medical skills, role development, collaboration, context of care, and research.

Areas and competencies formulated in the training program

Patient care:

1. Analyzes and interprets patients'(and relatives') history, including presenting symptoms, physical findings, and diagnostic information to develop appropriate diagnoses (in a multidisciplinary way);

2. Diagnoses and manages conditions, prioritizes health problems and intervenes appropriately including initiation of effective emergency;

3. Formulates an action plan based on scientific rationale, evidence-based standards of care, and practice guidelines, provides guidance and counseling regarding management of the health/illness condition.

Collaboration:

4. Coordinates the patients' treatment, if necessary, initiates appropriate and timely consultation and/or referral when the problem exceeds the NP's scope of practice and/or expertise;

5. Initiates a professional collaboration with patients and other health care professionals. Quality Care:

6. Improves the quality of care by means of research and implementing evidence based practice;

7. Educates and coaches other professionals to improve their skills. 


\section{DATA COLLECTION}

Data from the project documentation were collected, to explore the initial concepts used for the development of the training program. Data of consultations and home visits by NPs and GPs, the patient's age and complaints and diagnoses were gathered, using the International Classification of Primary Care (ICPC) (Gebel and Lamberts, 2000). The ICPC-codes lower than 70 were labelled as symptoms and complaints and ICPC codes higher than 70 as diagnoses and diseases. These data were gathered retrospectively in five monthly measurements between March 2004 (T0) and October 2007 (T5). In each practice information was given about the relevance of systematically keeping records and registering data. Software was developed to extract data from computer systems. Extracted data were used during meetings per general practice to provide feedback and to test the reliability of documentation.

We conducted qualitative structured interviews in June 2005, November 2006 and June 2008. The structure of the interviews was focussed on NP roles, competencies and collaboration (Bryant-Lukosius et al., 2004). The output of the interview is a taxonomy (Bradley et al., 2007).

For the interviews, NPs and teaching GPs were selected by their mean rates of a developed job satisfaction questionnaire (McCranie, 1982; Tummers et al., 2002); two with the highest rates, one with a rate nearest to the mean and two with the lowest rates to ensure diversity among the informants. Items in the questionnaire $(\mathrm{N}=15)$ referred to patient care, organization characteristics, work characteristics and collaboration, measured by a Likert scale (score $1=$ very unsatisfied; score $5=$ very satisfied). The interviews were performed with openended questions and conducted by three authors, using the same instructions (AD, HV , CS) and debriefings. Informants were encouraged to speak freely and to raise issues of importance to them. Each interview lasted between 45 and 60 minutes.

\section{ANALYSIS}

The documentation of the initial concepts was explored and shared with the initiator (TT) of the training program, to validate the concepts. The SPSS software 15.0 (SPSS, Chicago, IL) was used to analyse quantitative data. Analyses were undertaken comparing the consultation rates of the NP group or GP group, based on 1 FTE. Descriptive statistics (percentage, mean, and standard deviation) were calculated. Consultation-units were calculated, based on the assumption that 'in-house' NP consultations take 12 minutes (Dierick et al., 2009), one home visit is in length of time comparable with three consultations (20 minutes per home visit and 16 minutes travel time). The interviews were tape recorded and transcribed verbatim and checked for accuracy. Two authors (AD, HV) read the transcription, coded the answers by using a taxonomy wherein competencies were grouped: patient related care, collaboration, and quality of 
care. The extent of agreement and variation between the three sets of coding was discussed. The authors reviewed and agreed the final broad coding taxonomy to be applied.

\section{RESUlts}

\section{Initial concepts}

In the development of the training program three basic concepts were formulated. First, the NPs should assess, diagnose, and treat the specified set of common complaints. Therefore, they need to possess medical knowledge and use practice guidelines on minor health problems derived from the Dutch College of General Practitioners. We expected that NP consultations are longer than GP consultations because they have less medical knowledge and they need time to learn assessing and diagnosing. No assumptions were made in assessing symptoms and complaints (ICPC code <70) or diagnoses and diseases (ICPC code $>70$ ). NPs should diagnose on the level of no doubt. Secondly, the NPs should act as professional communicators with patients and other professionals and reflect on their own and others functioning. NPs have, from their nursing discipline, a complementary expertise in health education and in assessing the impact of the complaints on patients' daily activities. As the NPs were also trained in the care for elderly with common complaints, medical and nursing competencies should also integrate in this specific care. Finally, NPs should be able to manage projects to improve the quality of care. Therefore, they develop skills related to education and research.

\section{Consultations and home visits}

Figure 1 shows the NP consultation rates in comparison with GP consultation rates (per 1.0 FTE) per month. During the training program (T0-T2), the NPs productivity increased from 0 to 225 consultations per month. In the period after graduation (T2-T5), consultation rates increased from 115 to 285 (147\%) consultations per month and the number of home visits increased from 1 to 26 (2500\%) per month. The GP consultation rates raised from 325 (T0) to 445 (T5) $(37,5 \%)$ per month and home visits from 15 (T0) to 33 (T5) (120\%) per month. 


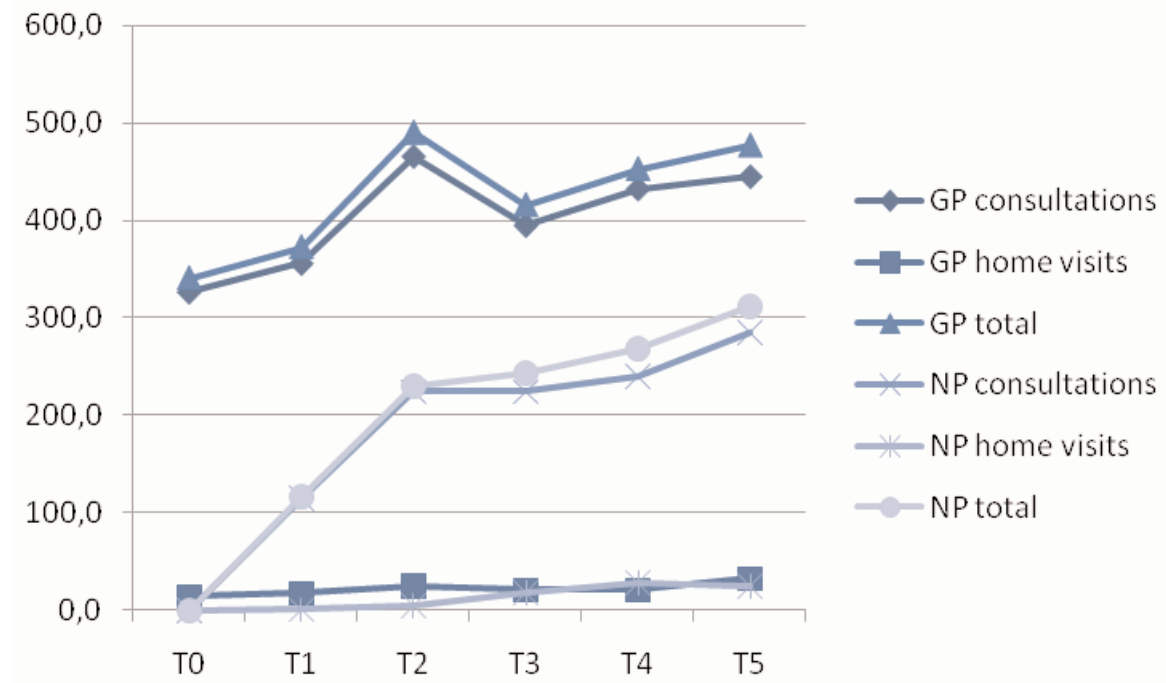

Figure 1 NPs' and GPs' consultations and home visits per month between March 2004 (T0) and October 2007 (T5), based on a calculation of 1 FTE.

(T0: March 2004, T1: March 2005; T2: March 2006; T3: October 2006; T4: March 2007; T5: October 2007).

Characteristics of the practices and interviewed professionals, including their individual coding, are described in Table 1. When looking at individual practices, in 2007 NP4 had on average the most consultations $(\mathrm{N}=338)$ and 0 home visits per month, NP1 the most home visits $(\mathrm{N}=76)$ per month, NP6 the least home visits $(\mathrm{N}=2)$ and relative less consultations per month $(\mathrm{N}=283)$. NP2 was excluded from the analysis, since data of October 2007 were not available. On average NPs had $324.31(\mathrm{SD}=38.64)$ consultation units per month in 2007. The NPs in EG 1 treated relatively more elderly people (12\%) than the GPs. In EG 5 and EG7 the NPs saw less elderly people than the GPs (resp. -17.6\%, -13.6\%). In 2007 the NPs assessed on average 2.3\% less ICPC codes $>70$ than GPs (mean $=59.33 \%, \mathrm{SD}=7.5 \%$ resp. mean $=61.61 \%, \mathrm{SD}=11.27$ ). 
Table 1 Characteristics of experimental groups

\begin{tabular}{|c|c|}
\hline Experimental group & Characteristics \\
\hline $\begin{array}{l}\text { Experimental group EG1 } \\
\text { Type of practice } \\
\text { Size (2006) } \\
\text { Staff (2006) } \\
\text { Interviewees } \\
\text { Interviewees' job satisfaction }\end{array}$ & $\begin{array}{l}\text { Group practice } \\
\text { Medium (list size } 3000-8000 \text { patients) } \\
5 \text { GPs, } 3 \text { practice nurses, } 3 \text { NPs } \\
\text { 2005: -- ; 2006: NP (NP1); 2008: NP (NP1, NP2), GP (GP1) } \\
\text { 2005: --; 2006: NP1 low; 2008: NP1 low, NP2 low; GP1 high }\end{array}$ \\
\hline $\begin{array}{l}\text { Experimental group EG2 } \\
\text { Type of practice } \\
\text { Size (2006) } \\
\text { Staff (2006) } \\
\text { Interviewees } \\
\text { Interviewees' job satisfaction }\end{array}$ & $\begin{array}{l}\text { Group practice } \\
\text { Medium (list size } 3000-8000 \text { patients) } \\
4 \text { GPs, } 2 \text { practice nurses, } 1 \text { NP } \\
\text { 2005: GP (GP2); 2006: GP (GP2); 2008: GP (GP2); } \\
\text { 2005: GP2 high; 2006: GP2 low; 2008: GP2 high }\end{array}$ \\
\hline $\begin{array}{l}\text { Experimental group EG3 } \\
\text { Type of practice } \\
\text { Size (2006) } \\
\text { Staff (2006) } \\
\text { Interviewees } \\
\text { Interviewees' job satisfaction }\end{array}$ & $\begin{array}{l}\text { Two duo practices } \\
\text { Both small (list size }<3000 \text { patients) } \\
\text { 2*2 GPs, } 1 \text { practice nurse, } 1 \text { NP, working in both practices } \\
\text { 2005: --; 2006: NP (NP3), GP (GP3); 2008: -- } \\
\text { 2005:--; 2006: NP3 high, GP3 high; 2008:-- }\end{array}$ \\
\hline $\begin{array}{l}\text { Experimental group EG4 } \\
\text { Type of practice } \\
\text { Size (2006) } \\
\text { Staff (2006) } \\
\text { Interviewees } \\
\text { Interviewees' job satisfaction }\end{array}$ & $\begin{array}{l}\text { Health care centre } \\
\text { Medium (list size } 3000-8000 \text { patients) } \\
3 \text { GPs, } 2 \text { practice nurses, } 1 \text { NP } \\
\text { 2005: NP (NP4); 2006: NP (NP4); 2008: NP (NP4), GP (GP4) } \\
\text { 2005: NP4 moderate; 2006: NP4 high; 2008: NP4 high, GP4 moderate }\end{array}$ \\
\hline $\begin{array}{l}\text { Experimental group EG5 } \\
\text { Type of practice } \\
\text { Size (2006) } \\
\text { Staff (2006) } \\
\text { Interviewees } \\
\text { Interviewees' job satisfaction }\end{array}$ & $\begin{array}{l}\text { Group practice } \\
\text { Medium (list size } 3000-8000 \text { patients) } \\
5 \text { GPs, } 1 \text { NP } \\
\text { 2005: NP (NP5), GP (GP5); 2006: GP (GP5); 2008: NP (NP5) } \\
\text { 2005: NP5 high, GP5 low; 2006: GP5 low; 2008: NP5 high }\end{array}$ \\
\hline $\begin{array}{l}\text { Experimental group EG6 } \\
\text { Type of practice } \\
\text { Size (2006) } \\
\text { Staff (2006) } \\
\text { Interviewees } \\
\text { Interviewees' job satisfaction }\end{array}$ & $\begin{array}{l}\text { Three solo practices } \\
\text { All: small (list size < } 3000 \text { patients) } \\
3 \text { GPs, } 1 \text { practice nurse, } 1 \text { NP } \\
\text { 2005: NP (NP6); 2006: NP (NP6), GP (GP6); 2008: -- } \\
\text { 2005: NP6 low; 2006: NP6 low, GP6 high; } 2008 \text {-- }\end{array}$ \\
\hline $\begin{array}{l}\text { Experimental group EG7 } \\
\text { Type of practice } \\
\text { Size (2006) } \\
\text { Staff (2006) } \\
\text { Interviewees } \\
\text { Interviewees' job satisfaction }\end{array}$ & $\begin{array}{l}\text { Group practice } \\
\text { Large (list size > } 11.500 \text { patients) } \\
5 \text { GPs, } 2 \text { practice nurses, } 1 \text { NP } \\
\text { 2005: NP (NP7), GP (GP7); 2006: NP (NP7) 2008: NP (NP7), GP (GP7) } \\
\text { 2005: NP7 high, GP7 low; 2006: NP7 moderate; 2008: NP7 moderate, } \\
\text { GP7 low }\end{array}$ \\
\hline
\end{tabular}

Experimental group (EG) is (a group of) practice (s) which (collaborate to) educate and employ a NP. Four interviews are excluded of professionals who had not an employed NP in practice: in 2005: two GPs (job satisfaction moderate and high) one NP (job satisfaction low) in 2006: 1 GP (job satisfaction moderate). 
We conducted 29 interviews, since one GP refused to participate in the interview in 2008 because of the high workload at that moment (job satisfaction low). We excluded four interviews with NPs from the analyses since the NPs were no longer employed in 2008.

\section{Patient care}

During the first two months of the training program all NPs joined the GPs during consultations. As soon as NPs finished a specific medical module successfully, they treat those patients with the corresponding complaint independently. Two NPs experienced having another mode for consultations than GPs. The combination of working and learning was experienced as difficult for NPs $(n=4)$, with the main reason being mentioned the combination of general courses and medical courses. NPs $(n=4)$ mentioned being very satisfied about the supervision of the GPs.

Three GPs experienced that NPs used another mode during consultations, focusing on education and stimulating self-management activities by patients. The NP's assessment was too elaborated to finish the diagnostic process, but they regarded this as a part of the learning process. The booking interval for a NP consultation was 15 minutes (e.g. 10 minutes for GP consultations). GPs experienced that the medical knowledge of NPs is less profound than GPs. In 2006 NPs ( $n=5$ ) would like to increase the set of common complaints, with complaints of hands, wrists and elbows, and care for patients with chronic diseases. GPs $(n=4)$ and NPs $(n=5)$ experienced that the NPs do their consultations in a responsible and careful way and they can comprehend the uncertain areas in diagnostic procedures.

In 2008 NPs treated on average 20 patients per day. Three NPs performed also small surgical interventions. The average proportion of patient-related activities versus non-patient related activities was $75 \%$ vs $25 \%$. The minimum percentage of patient-related activities was $60 \%$ (NP2). In this case, the NP spent much of her time on a quality care project related to care for the elderly. The maximum percentage of patient related activities was 90\% (NP7), the GP (GP7) mentioned as main reason the high productivity in this general practice. All GPs were very satisfied about the NPs as a new professional in general practice. From a medical point of view and related to common complaints, GPs have not noticed any differences in the way the NPs act during surgery hours. One NP (NP4, GP4) would change her booking interval to 10 minutes in the future, so she would have more time for other patient related activities. All other NPs remained 15 minutes.

From 2006 NPs had a role in care for elderly people but there are differences between NPs. One GP preferred to treat elderly patients himself (GP5, '06) and one GP experienced that national grants are insufficient for coordinating care for elderly when more than 20 GPs have to collaborate with each other (GP7 '08) (Box 2). 


\section{Box 2 Patient care}

NP5 '05:" Before I started the NP training program, I was a nurse in home care. For me it is difficult to do an assessment within 15 minutes. In home care I spent more time with the patient so I have more information about the context of the patient, how the patient lives and who the relatives are, is more clear."

NP6 '05: "Patients told me a NP consultation differs from a GP consultation. They were not unsatisfied about their GP, but I have more time, explore problems in a different way, which is influenced by my nursing background of course. I think I am more interested in exploring the problems very carefully, looking for themes behind the problems they came for, which might affect the complaints".

NP4 '05:"When GPs have the opinion that NPs only treat common complaints, I think the NP will not be implemented in primary care. I am a nurse and I focus also on self management of patients. They will have to get used to it, this is the a role."

NP4 '05:"The general part of the training program, is very theoretical and time consuming, but I prefer to do the medical courses, this knowledge I can practically use during my consultations."

NP4 '06: "Since a few months I have, in collaboration with a GP, also consultations of elderly with common complaints in nursing homes. I use my "new medical" knowledge and my nursing background. It is very interesting to combine these two into a new perspective. Further I coordinate and evaluate the patient care with the staff members of the nursing homes.

GP5 05: "I doubt about her empathic approach. Sometimes I think she goes too far in exploring the patient's experiences, so that she will loose her professional distance."

GP2 '06: "Sometimes I have patients, who come for their physical complaints, but I presume that these complaints are caused by some psychological factors. I ask the NP to explore the patient's complaints extensively. My experience is that her information is very useful in my diagnostic procedure."

GP3 '06:" We share home visits of patients with complex care (palliative care). It is comfortable and professional, when I do not have to do this all by myself. I feel that I have a new partner in this situations."

GP1 '08: "When a GP and NP collaborate pairwise, cure and care are become more close. This is especially important in the care for elderly people. Care for patients will be more adjusted on patient's needs and it affects the collaboration positively.

GP7 '08:"It is crucial that the NP has enough time to explore problems profound, this is quality of care."

\section{Collaboration}

In 2005 NPs ( $n=4)$ and GPs ( $=3$ ) reported that they were satisfied about the collaboration with patients and collaboration with all professionals working in general practice. No gaps in activities or job descriptions were reported. NPs $(n=4)$ stated to pay much attention to their collaboration with the practice assistants, and the triage process. In case problems with triage occurred, NPs reported to discuss these with the practice assistants. Further, they mentioned to stimulate GPs to adjust their modes and to use protocols.

In 2006, GPs ( $n=5)$ reported that the NP communication skills are good. As their role is new in the team, they succeed in make their role transparent and colleagues also accept the new role. Three NPs integrate also in the patient care for elderly in the nursing homes, in collaboration with GPs. They have patient consultations and evaluate the patient care with staff members. One NP (NP4 
'08) mentioned that the group of NPs in primary care is still very small. Public relation and communication inside and outside the practice about the new role remain very important (Box 3).

\section{Box 3 Collaboration}

NP5 '05: "The practice assistants conducted triage, they booked patients with common complaints for a NP consultation. They have notes of the common complaints I can treat. Sometimes I change the rank, because otherwise I will treat only patients with ears, noses or throat complaints. In the beginning there were some problems and they planned patients with complaints, which I could not treat. So we have discussed this. For practice assistants it is sometimes difficult to do a triage or to introduce the NP to patients as a new type of professional who can also treat common complaints."

NP7 '05: "I have worked with assistants to see what their activities are, so now I can understand their questions better. And they have learned me also some activities such as a cervical smear or to test urine sediments."

NP4 '06: "My role is very clear. Some activities which I have learned in the training program, are performed by practice assistants. There are no indications to take over these activities. In this cases we'll make our consents."

GP2 '06: "The NP indicates the gaps in care, delivered by me and my colleagues. She also noticed differences in treatment and discusses what is evidence based practice or best practice. The way she discusses this is very professional and we also accept that she is doing this. She stimulates us to reflect on our patient care and discusses uniformity between GPs."

GP7 '08: "From the beginning she was very clear about her role to all professionals, especially to the practice assistants on a friendly manner: "Sometimes I will ask you something to do and I will give you feedback or we will look how we get things solved". She took care for stability in this team. I can imagine that another personality would not succeed in this."

GP2 '08: "The GPs in this village had some problems in the collaboration with the nursing home, which affected the care for the elderly. Our NP took a leading role to improve this collaboration. She explored the problems by means of questionnaires for the staff members of the nursing home, the GPs and the practice assistants in all general practices. Then she developed protocols to structure the collaboration between the general practices and the nursing home. The result is that the NP treats all the elderly with minor complaints who live in the nursing home, she coordinates the care and consult the patient's GP if necessary. She is now the mediator between the nursing home and the 11 GPs and evaluates the patient care frequently. Patients and the staff member of the nursing homes are all very satisfied. We, GPs, have now less interruptions and the collaboration between GPs and the staff members of the nursing home has been strongly improved. The NP works now for 18 hours per week for all the GPs and six hours per week in my practice."

\section{Quality of care}

NPs ( $\mathrm{n}=5)$ in 2005 participated in quality improvement projects. All GPs recognized that with the introduction of the NP quality improvement has been realized, by the development of standards and protocols. They also have a role in the education of practice assistants and projects to improve the quality of care. In 2008, five NPs and four GPs had experiences with the role of the NP in quality care projects: the development and implementation of protocols based on evidence, the accreditation of Dutch national guidelines, and the introduction 


\section{8| Chapter 3}

\section{of care-pathways for elderly people. In Box 4 examples of these activities are described.}

\section{Box 4 Quality of care}

GP7 '05:"Thinking about quality gives an impuls in our practice. It is a typical phenomenon when educating a professional. Educating a NP is a stimulus for practice assistants, practice nurses and GPs. We discuss a lot what is best practice and which protocols do we need."

NP6 '06: I work very systematically. "My impression is that GPs like to innovate, but they do this often without a well-considered plan. I think that a NP could have an important role in such innovative or implementation projects, because we have learned how to structure these kind of processes and how to implement evidence based practice."

NP4 '06: "Practice assistants ask patients about their complaints. Based on this data they decide if they can give the patient some instructions, or the patient should have a consultation with a GP or NP. Frequently I organize a triage training for practice assistants. The purpose is to improve their communication with patients. In this training I educate them about a specific complaint, how to explore patients' complaints and what advices or instructions they can give to patients. Practice assistants appreciate my trainings.

By giving this training I realized practice assistants are doing things, because they were told to do it. But the reason is not clear for them. I use some simple anatomy and pathology and explain the effects of an intervention (evidence based) the accent lies on the reasons behind the patient's instructions. Then they will able to motivate to improve the patients' self management."

NP7 '06: "We have noticed that a number of patients came back with otitis externa, after they had an ear irrigation, provided by the practice assistants. As part of my master thesis I investigated ear irrigation to reduce the risk on complications. First I conducted a literature review on the complications (probably) caused by ear irrigation. Based on the results I conducted a checklist to detect the risk factors in our practice. As a result we had to improve three elements: the assessment by patients / the contra-indications of ear irrigation; adapt our intervention by using a wad of cotton wool to dry the ear canal, and we had to improve the patient's instructions, whether patients had to come back for a follow up consultation. The next phase of the master thesis was to develop a new evidence based protocol for ear irrigation, and I organized a training for practice assistants about the anatomy and physiology of the ear and ear irrigation. After three months we evaluated the new protocol with the general practitioners and the practice assistants and we conducted the observation study for a second time six months after the implementation of the protocol, to measure the effect of our interventions."

NP2 '08: "I give also education in the training program for NPs. I would like to do more activities in quality care projects, such as implementation of evidence based practice and research, but I have not the time to do this."

NP1 '08: "Our practice is involved in several quality care projects (NP care for homeless persons, NP care related to mental health care, emergency care, etc). I perform activities related to these projects during leisure time."

GP4 '08: "Our NP gave us a scientific article about the use of a type of contraception-medication and the risk on thrombosis. The NP suggested that we could inform patients who take this medication and give an advice for an alternative. So we accomplished that. She also developed the protocol for endocarditis profylaxe." 


\section{Discussion}

This study lends clarity about the role of NPs in general practices. NPs are functioning as formulated in the initial concepts with a main focus on the treatment of patients with common complaints. In this way the value is that NPs contribute to the accessibility and availability of primary care, but also to the improvement of quality of care in general practice. The learning curve of NPs substituting for GPs is visible by the increase of productivity rates. The increase after graduation is partly influenced by incentives to make the NP economic viable and partly attributed to the modification in the Dutch health insurance system. Differences between productivity rates of NPs and GPs can arguably be explained by differences in the booking interval.

Differences between NPs are reported in the percentage of home visits, the care for elderly and the percentage patient related activities versus non patient related activities between practices. These results are attributed to the preference of GPs to perform certain consultations by themselves, the economic attainability to coordinate care for the elderly by means of allowances from Health insurers and the specific needs of practices to perform non patient related activities. Consequently, the way NPs perform their roles is a result of their collaboration with other professionals in general practice and financial incentives. Offredy and Townsend (2000) found similar results related to the variation in clinical freedom and autonomy of the NPs work at practice level.

From a medical point of view, GPs have not noticed any difference in the way NPs act during the treatment of patients with common complaints compared with themselves, which is also reported in earlier publications (Bond et al., 1999; Laurant et al., 2004; Dierick et al., 2009). As NPs treat mainly patients with common complaints this might also lead to GPs having more time for patients with chronic diseases or multi morbidity.

NPs are hybrids, synthesizing nursing and medical skills (Bond et al., 1999). The Master training program is one of the major prior conditions to make the autonomous role of the NP successful. In the curriculum NPs experienced a tension between medical and general courses. For NPs the patient population is new, which make medical courses crucial to perform effectively in practice. Otherwise general courses related to role development, collaboration and research are crucial to perform activities in the improvement of (evidence based) patient care (Bryant-Lukosius et al., 2004; Grumbach and Bodenheimer, 2004; Barrett et al., 2007). Ashworth et al. (2001) categorized characteristics attributed to master's graduates under cognitive and practice-related competencies, research orientation and personal dynamism, which are also visible in this study. To understand and to create the current and intended values of NPs by GPs, it is recommendable to develop collaborative models for education (Wilson et al., 2002).

Several studies postulate the development of non patient related activities, to challenge traditional values and transform clinical practice in an ever changing 
health care system (Furlong and Smith, 2005), but these activities are mostly not reimbursed. Researchers, professionals and Health insurers should debate the importance of these activities and quantify them to indicate potential cost savings. Additional robust research is needed to operationalize the core competencies of NPs in general practice.

\section{Strengths and limitations}

One of the most important advantages in using mixed methods is that this can lead to theoretical and substantive insights into the multidimensional nature of health care systems (Bradley et al., 2007). This study was also facing limitations. Descriptive studies do not report full range of responses. Issues have to be identified and considered for a certain level of evidence (Daly et al., 2007). Further, not all the data of consultation rates of the NP in EG2 were available for the researchers, since she worked for a group of GPs who did not participate in the project. Bias might have occurred because the evaluation setting was not anonymous. Further, the interviewers had a different background. By using the same instructions and debriefings, the authors assume the variation in interviewing has been limited. In our analyses we have not used data of four interviews with professionals, because in these practices the NPs finished their job before 2007. These controls are lacking, but it was the intention to focus on general practices with four years of experience.

\section{Conclusion}

NPs are functioning as defined in the initial concepts with a main focus on the treatment of patients with common complaints. In this way, the value is that NPs contribute to the accessibility and availability of primary care but also to the improvement of quality of care. Differences in roles are mostly influenced by specific needs in practices and financial incentives. Additional research is needed to validate the results and to operationalize the core competencies of NPs in general practice. 


\section{REFERENCES}

1. Ashworth PD, Gerrish K, McManus M. Whither nursing? Discourses underlying the attribution of master's level performance in nursing. Journal of Advanced Nursing 2001; 34: 5 621-8.

2. Barrett J, Curran V, Glynn L. Godwin M. CHRSF Synthesis: Interprofessional Collaboration and Quality Primary Healthcare. Canadian Health Services Research Foundation. Ottawa, Ontario 2007.

3. Bond S. et al. Training nurse practitioners for general practice, the EROS project. British Journal of General Practice 1999; 49: 531-5.

4. Bradley EH, Curry LA, Devers KJ. Qualitative Data Analysis for Health Services Research: Developing taxonomy, themes and theory. Health Service Research 2007; 42 (4): 1758-72.

5. Bryant-Lukosius D, DiCenso A, Browne G, Pinelli J. Advanced practice nursing roles: development, implementation and evaluation. Journal of Advanced Nursing 2004; 48 (5): 519-29.

6. Buchan J, Dal Poz MR. (2002) Skill mix in the health care workforce: reviewing the evidence. Bulletin of World Health Organization 2002; 80: 575-80.

7. Dierick-van Daele ATM, Metsemakers JFM, Derckx EWCC, Spreeuwenberg C, Vrijhoef HJM. Nurse practitioners substituting for general practitioners; randomised controlled trial. Journal of Advanced Nursing 2009; 65(2): 391-401.

8. Daly J, Willis K, Small R, Green J, Welch N, Keally M, Hughes E. A hierarchy of evidence for assessing qualitative health research. Journal of Clinical Epidemiology 2007; 60: 43-69.

9. Furlong E, Smith R. Advanced nursing practice: policy, education and role development. Journal of Clinical Nursing 2005; 14: 1059-66.

10. Gebel RS, Lamberts H. Dutch College of General Practitioners- International Classification of Primary Care (NHG-ICPC - 1). Dutch College of General Practitioners 2000, fourth and revised Edition. (In Dutch)

11. Grumbach K, Bodenheimer T. Can health care teams improve primary care practice. JAMA 2004; 291 (10): 1246-51.

12. Laurant M, Reeves D. all. E. Substitution of doctors by nurses in primary care. The Cochrane Database of Systematic Reviews Collaboration, 2004 (4).

13. McCranie EW, Hornsby JL, Calvert JC. Practice and career satisfaction among residency trained family physicians; a national survey. Journal of Family Practice 1982; 14: 1107-14.

14. Munhall PL, Boyd CO. Nursing Research; a qualitative perspective. National league for Nursing Press. New York 1993.

15. Offredy M, Townsend J. Nurse practitioners in primary care. Family Practice 2000; 17 (6): 564-69.

16. Reay T, Golden-Biddle K,. Germann K. Challenges and leadership strategies for managers of nurse practitioners. Journal of Nursing Management 2003; 11: 396-403.

17. Redsell S, Stokes T, Jackson C, Hastings A, Baker R. Patients' accounts of the differences in nurses' and general practitioners' roles in primary care. Journal of Advanced Nursing 2007: 57; 172-80.

18. Sibbald B. Should primary care be nurse led? British Medical Journal 2008; 337: 658-59.

19. Tummers G, Landeweerd JA., Merode GG. van. Workorganisation, work 
characteristics and their physiological effects on nurses in the Netherlands. International Journal of stressmanagement 2002; 9(3): 183-206.

20. Wilson A, Pearson D, Hassey A. Barriers to developing the NP role in primary care. Family Practice 2002; 19 (6): 641-6.

21. WHO The World Health Report 2000. Health systems: improving performance. Geneva: World Health Organization 2000.

22. Yin R. Case Study Research: Design and Methods. Thousand Oaks, California: Sage Publications 1994. 


\section{Chapter}

Nurse practitioners substituting for general practitioners in the care for patients with common complaints; a randomised controlled trial

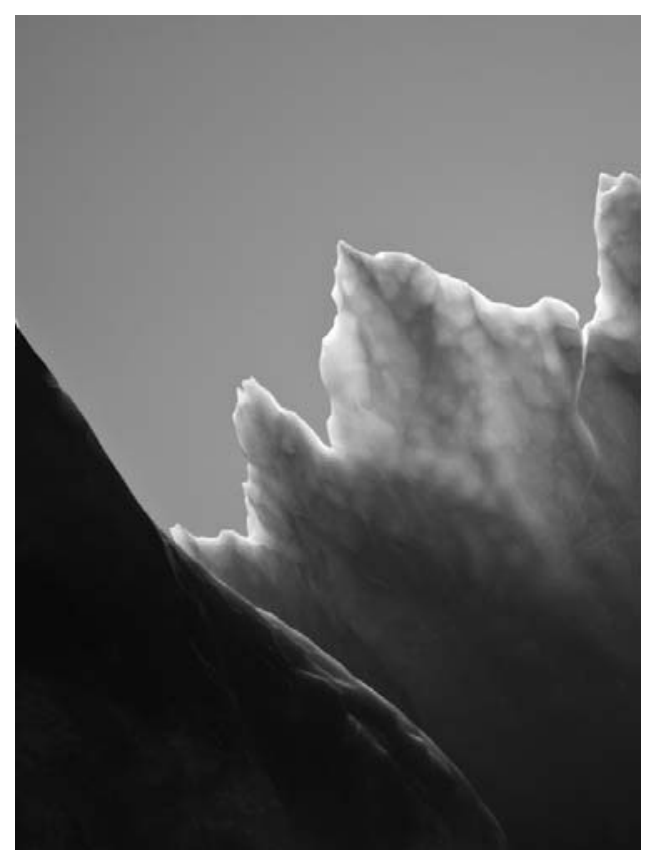

A.T.M. Dierick-van Daele, J.F.M. Metsemakers, E.W.C.C. Derckx, C. Spreeuwenberg, H.J.M. Vrijhoef

Published in Journal of Advanced Nursing 2009; 65(2): 391-401. 


\section{Abstract}

Title. Nurse practitioners substituting for general practitioners in the care for patients with common complaints; a randomised controlled trial.

Background. Studies in the USA and Great Britain reported that substituting general practitioners for nurse practitioners results in higher patient satisfaction and higher quality of care. As the American and British health care system and settings differ from that in the Netherlands, a Dutch trial was conducted.

Aim. To evaluate process and outcomes of care provided by specially trained nurse practitioners (intervention group) or general practitioners (reference group) for patients at first point of contact.

Design. 1,501 patients were randomized for a consultation by a general practitioner or a nurse practitioner, working in 15 general practices. Data were collected over a 6-month period in 2006 by means of questionnaires, extracting medical records from the practice computer systems, and recording length of consultations.

Findings. In both groups patients highly appreciated the quality of care. No significant differences were found in health status, medical consumption, and compliance of practical guidelines. Patients in the intervention group were more invited to re-attend, had more follow up consultations and their consultations took significantly more time.

Conclusion. Nurse practitioners and general practitioners provide comparable care. These findings support an increased involvement of specially trained nurse practitioners in the Dutch primary care and contribute to the knowledge on the effectiveness of care provision by nurse practitioners from a national and international perspective.

Keywords. randomised controlled trial, nurse practitioner, general practitioner, substitution, process and outcomes, quality of care 


\section{INTRODUCTION}

Against the background of the need to increase service capacity, to meet a rising demand, and to improve access to primary care, a project was initiated to introduce the nurse practitioner (NP) in Dutch general practices. This project was financially supported by the Dutch Ministry of Health, Welfare, and Sport and the Health Insurance Companies CZ and VGZ. At the start of the project in 2004, only five NPs worked in a general practice nationwide.

\section{Background}

In achieving an adequate mix of health personnel (Buchan Dal Poz, 2002; WHO 2000) a need for NPs is being reported in the USA, Europe, Canada, Australia and the Far East (Reay et al., 2003; McKenna et al., 2006). These developments contribute to an increase of the service capacity that is needed to meet a rising demand, to overcome a shortage of physicians in particular settings, to improve the quality of care, to advance the career of nurses, and to lower health care costs by employing the 'lowest cost provider'.

Recently, strong interest has been shown in the concept of NPs providing primary care. In this way, NPs may potentially substitute for doctors particularly in the management of patients with minor health problems. The term NP is generally used to identify registered nurses with additional education and training - i.e. Master in Advanced Nursing Practice -, who work within an expanded scope of practice that includes diagnosing, prescribing, and treating medical conditions within specific settings (Reay et al., 2003).

Moreover, a systematic review of studies in primary care (Horrocks et al., 2002), found evidence that NP consultation is likely to lead to high levels of patient satisfaction and high quality of care. Other studies found that nurse(s) (practitioners) give more information (Shum et al., 2000) and more advice on self care and management (Shum et al., 2000; Kinnersley et al., 2000). Similar results were found regarding health status ( Kinnersley et al., 2000; Mundinger et al., 2000; Lenz et al., 2004) the number of prescriptions ordered, (Venning et al., 2000; Kinnersley et al., 2000), and health services utilisation (Mundinger et al., 2000; Lenz et al., 2004).

However, these results mostly present the practice in Great Britain and the USA. Since the introduction of the NP in 1965 in the USA, the role has been expanded and diversified. Considering differences like the variability in autonomy of NPs (Offredy and Townsend, 2000), the level of education of NPs, and characteristics of health care systems, there is a need for more research findings about NPs from other countries. In this Dutch trial the effectiveness of NPs and general practitioners (GPs) in providing primary care, as first point of contact, was evaluated. 
66| Chapter 4

\section{Methods}

Aim

The aim was to evaluate process and outcomes of care provided to patients with common complaints by GPs or specially trained NPs as first point of contact.

\section{Design}

A randomised controlled trial was conducted over a 6-month period from May 2006 in 15 general practices in the southern region of the Netherlands. With NPs being appointed on a part-time base, the trial took place on the days when GPs and NPs were both working in the practice.

\section{Samples/Participants}

A convenience sample was used and 12 NPs and 50 GPs participated in the trial. Table 1 shows the type of practice, their location, list size, and the number of GPs in the 15 practices recruited.

Table 1 Characteristics of the recruited general practices $(n=15)$

\begin{tabular}{|l|l|}
\hline $\begin{array}{l}\text { Degree of urbanization } \\
<5000\end{array}$ & No of practices \\
$5000-30.000$ & 1 \\
$30.000-100.000$ & 4 \\
$>100.000$ & 4 \\
No of general practitioners & 6 \\
1 & 3 \\
2 & 2 \\
3 & 3 \\
4 & 2 \\
5 & 5 \\
Practice list size & $(\mathrm{n}=79310)$ \\
$2.000-4.000$ & 5 \\
$4.000-6.000$ & 4 \\
$6.000-8.000$ & 2 \\
$8.000-10.000$ & 1 \\
$10.000-12.000$ & 3 \\
\hline
\end{tabular}

At the start of this project the role of the NP in the treatment of patients with common complaints was new for the Dutch setting. Therefore, a specific two year practice-oriented training programme was developed, which consisted of the Higher Professional Education Master's Degree Advanced Nursing Practice (MANP) including an academic course on managing common complaints. During the training programme, the NPs were employed and facilitated by, and educated in general practices. This trial took place two months after the NPs successfully completed their training programme.

A specified set of common complaints was compiled, for which patients seek medical attention. These common complaints will often lead to minor health 
problems. The NP sees patients with respiratory and throat problems, ear and nose problems, musculoskeletal problems and injuries, skin injuries, urinary problems, gynaecological problems, and geriatric problems. The role of the NP involves assessing symptoms, including physical examinations where appropriate, diagnosing and making decisions for further treatment, including prescriptions, referrals to primary or secondary services and clinical investigations. The NP has no full authority to prescribe medications, so the GP is always available for consultation and to assign prescriptions and referrals.

Before they started the NP training programme, the NPs were all senior nurses with on average 12 years ( $\mathrm{SD}=7.6$ years) working experience as a (practice) nurse in general practice $(n=4)$, in a hospital $(n=3)$, home care $(n=2)$, a criminal relief for addicts $(n=1)$, or an asylum seekers centre $(n=2)$. The GPs have an average work experience of 16 years $(\mathrm{SD}=10.1)$. The NPs work part-time (0.6 full time equivalent).

Patients who attended in general practice for an appointment during the study period were assessed for inclusion by the practice assistant. Patients, aged over 16 years and coming for an initial consultation, were invited to participate in the trial, if they asked for an appointment on a day the NP was present and had time available in the schedule. The patients were randomised and allocated to either the intervention group (NP-led care) or the reference group (GP-led care). Sequentially numbered sealed envelopes containing randomized assignments to the two groups were provided by an independent person. The codes were generated from random numbered tables.

In each practice, a research assistant explained the project to patients as they arrived for their appointment and informed consent was obtained. Patients were excluded from the study if one or more of the following criteria applied: patients who were not registered in the practice, any patients with language or reading problems, children under 16 years of age, patients who came for a follow up consultation, and patients who did not provide information about the reason for the appointment to the practice assistant.

\section{Data collection}

Data were collected by means of three questionnaires, and from the computer systems of the practices. Patients filled in their own questionnaire before the consultation (T0), directly after the consultation (T1) and two weeks after the consultation (T2). The first and second questionnaire (T0, T1) were administered by patient prior to leaving the practice. The third questionnaire (T2) was send and returned by post. It took the patients approximately five minutes (T0) to ten minutes ( $\mathrm{T} 1$ and $\mathrm{T} 2$ ), to complete the questionnaires.

Demographic information and data of diagnoses, prescriptions, referrals, and investigations were extracted from the computer systems. The questionnaires were coded in a manner that the data could be merged with the data obtained from the computer system. Patients were assured that only the researcher would see data on the level of individuals. 


\section{Demographic information and bealth status}

Demographic data, such as sex, age and diagnoses, were derived after recruitment of patients. At T1 patients were asked per questionnaire if they have (had) any (chronic) diseases. These were enlisted according to the Health and Labour Questionnaire (van Roijen et al., 1996).

\section{Patient perceptions of quality of care}

A self-completion patient measurement tool was used to measure patient perceptions of quality of care. The 12 items, which were partly derived from a validated instrument (Wensing et al., 1997) and a questionnaire developed for patients seeking "same day" consultations (Kinnersley et al., 2000), were related to communication, attitude, provision of information, and overall satisfaction. Responses were scored on a Likert-type scale; 6 was "excellent" and 1 was "poor". The patients reported if the practitioner, they were assigned to, was the right professional to treat their illness (T1).

\section{Effectiveness of the consultation and follow up consultations}

At baseline (T0) and two weeks after the consultation (T2), patients were asked to recorded the burden of their illness and their current level of concern on Likert-type scales (scale 0-10) (Kinnersley et al., 2000). Data about the patients' health status were derived by the EQ-5D, which the patient completed at T0 and T2. The EQ-5D is a multi-attribute health status classification system to measure preferences for five attributes: mobility, self care, usual activity, pain/ discomfort and anxiety/ depression. The EQ5-D scores range between 0.00 (dead) and 1.00 ( "full health") (Drummond et al., 2003).

Patients were asked in the questionnaire if they have had the advice to re-attend (T1) and whether they have had a follow up consultation (T2). Patients reported how they would deal with similar illnesses in the future: self managing the illness, consulting a GP, consulting a NP, or having no preference for GP or NP (T2).

\section{Time of duration of consultation}

The research-assistant recorded the length of each consultation using a stopwatch, starting from the moment the patient went into the room of the NP or GP and stopping when the patient left the room. The length includes the time to prescribe drugs and interruptions. This objective timing of each individual consultation is regarded as the golden standard for measuring the time of duration of consultation (Wilson and Childs, 2002).

\section{Compliance with practice guidelines for general practitioners}

To assess whether the quality of care was conform professional standards, a selection of 21 practice guidelines on minor health problems, derived by the Dutch College of General Practitioners (Braspenning and Schellevis, 2004), was applied. These guidelines refer to the definition of the problem, the relevant 
history questions, clinical investigations, use of prescriptions and referrals. We investigated to what extent NPs and GPs followed the guidelines during the consultations and, where applicable, during follow-up consultations. The list of practice guidelines is available upon request from authors.

\section{Medical consumption}

Data were obtained about the consultations and the patient's presenting illness, prescriptions issued, investigations ordered, and referrals to other professionals in health care. For this, every patient participating in the trial was identified from the practice computer system and corresponding clinical notes were searched. Finally, patients registered (T2) if they had a follow up consultation, how many consultations they had for the same problem, how many days they reported illness by their (paid) job, and how many days they were disabled to perform daily activities.

\section{Validity and reliability}

To assure the content validity, the composed questionnaires were discussed with two GPs with a background in scientific research. Then, the questionnaires were tested amongst a group of 40 patients. This resulted in two textual refinements and asking the name of the practitioner instead of asking the type of practitioner (NP or GP) consulted by patients.

Special attention was paid to ensure the reliability of documentation by professionals. In each practice information was given about the relevance of systematically registering medical records. Software was developed to extract data from the computer systems. Extracted data were used during meetings per general practice to provide feedback and for testing the reliability of their documentation. As a result, in one practice the software for data extraction was adapted.

\section{Ethical considerations}

Ethical approval for the study was obtained from the local Medical Ethical Judgment Committee.

\section{Data-analysis}

Data from the questionnaires were coded and entered into a Microsoft Access 2000 database created for the study. The SPSS software 11.5 (SPSS, Chicago, IL) was used to analyse the data.

No power was calculated since the number of participating practices was defined at the start of the project. This number was defined by the number of NPs being enrolled in the training programme.

Analyses were undertaken to compare patients within and between the groups (NP led care or GP led care) to which they were originally assigned to. Any patient who was not initially seen by the GP or the NP at the moment of 
randomization or who was seen by both professionals, was excluded from the final analysis.

Descriptive statistics (percentage, mean, and standard deviation, median, interquartile ranges, values of kurtosis and skewness) were calculated for all variables, and histograms with normal curves were plotted to ensure that the data were normally distributed. The two tailed t-test was applied for continuous variables. For categorical variables the chi-squared test for independent samples was used. An analysis of covariance (ANCOVA) was used to examine whether the co-variable "practice" has an effect on patient perceptions on the quality of care. The results are presented as treatment differences and 95\% confidence intervals. A 5\% significance level was used throughout.

\section{Results}

It is estimated that 2,000 patients attended to the practice assistant for a consultation; 499 met one or more exclusion criteria, declined to participate, had no interest, or were too ill (Figure 1). After randomisation, 58 patients who were allocated to the intervention group and 47 patients to the reference group did not attended to the appointment which they had booked, or refused to participate because of being too ill or not having interest. Enrolled for randomisation were 1,501 patients. Allocated to the NP were $817(54.4 \%)$ patients and $684(45.6 \%)$ patients to the GP. The two initial questionnaires (T0, T1) were completed by $1,306(87.0 \%)$ patients and 1,009 patients $(67.2 \%)$ completed the postal questionnaire at T2. Data from medical records were available from 1,397 patients $(93.1 \%)$ 


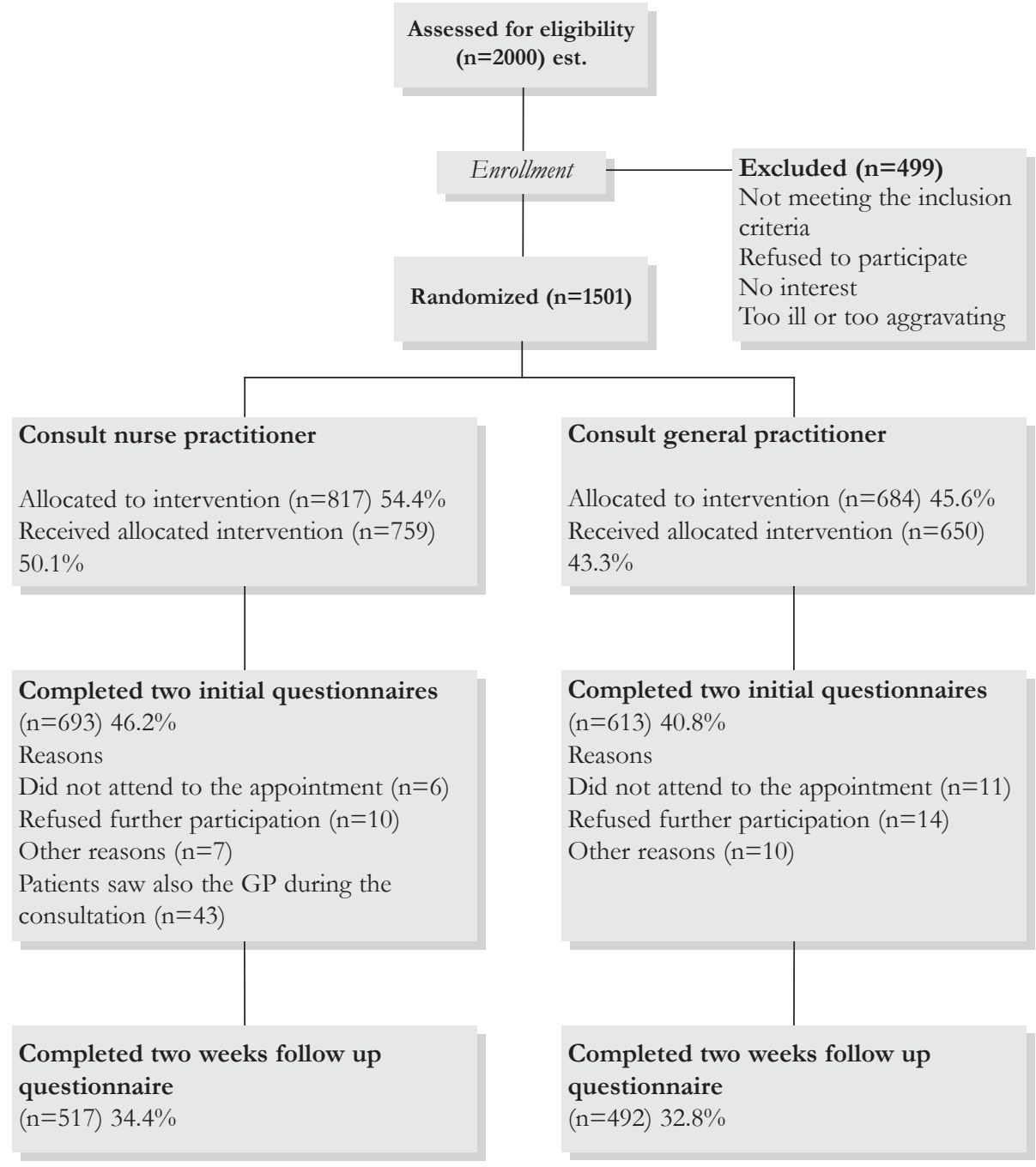

Figure 1 Flowchart

The demographic characteristics of the patients and the main categories of diagnoses are shown in table 2. Most patients in the intervention group are aged between 26 and 45 years $(41.5 \%)$ and in the reference group most patients are aged between 46 and 65 years $(36.9 \%)$. Patients randomised to the GP were significant older (mean=46.1, $\mathrm{SD}=16.6)$ than those in the intervention group (mean $=42.8, \mathrm{SD}=16.5 ; \mathrm{p}<0.001)$.

Most frequently reported diagnoses were conditions of throat, nose and ears/ respiratory system $(30.8 \%)$ and skin injuries $(29.2 \%)$. Groups were comparable for the reported number of diagnoses.

Patients who returned all questionnaires were significant older (mean $=48.74$, $\mathrm{SD}=16.8)$ than those who did not (mean $=42.75, \mathrm{SD}=16.4 ; \mathrm{p}<0,001)$. There 
were no significant differences in sex and type of diagnoses between patients with or without complete data.

No significant differences were notable between patients in the intervention group and the reference group in terms of other (chronic) diseases. In the intervention group a higher prevalence of minor injuries $(+3.6 \%)$, migraine $(+3.1)$, chronic skin injuries $(+2.9 \%)$, emotional distress $(+2.4 \%)$ was registered than in the reference group. In the reference group a higher prevalence was notable for hypertension $(+6.1 \%)$, diabetes $(+3.0 \%)$, varix $(+2.7 \%)$, back injuries $(+2.6 \%)$ than among patients in the intervention group. No significant differences in health status were measured between groups at baseline.

Table 2 Demographic information and the presenting diagnoses

\begin{tabular}{|c|c|c|c|c|c|c|}
\hline Demographic information $\dagger$ & \multicolumn{2}{|c|}{$\begin{array}{l}\text { Total } \\
\mathrm{N}=1,397(\%)\end{array}$} & \multicolumn{2}{|c|}{$\begin{array}{l}\text { Nurse practitioner } \\
\mathrm{N}=747(\%)\end{array}$} & \multicolumn{2}{|c|}{$\begin{array}{l}\text { General practitioner } \\
\mathrm{N}=650(\%)\end{array}$} \\
\hline $\begin{array}{l}\text { Age (years): } \\
<25 \\
26-45 \\
46-65 \\
>65 \\
\text { Sex: } \\
\text { Male } \\
\text { Female }\end{array}$ & $\begin{array}{l}184 \\
543 \\
488 \\
182 \\
\\
545 \\
852\end{array}$ & $\begin{array}{l}(13.2) \\
(38.9) \\
(34.9) \\
(13.0) \\
\\
(39.0) \\
(61.0)\end{array}$ & $\begin{array}{l}110 \\
310 \\
248 \\
79 \\
\\
285 \\
462\end{array}$ & $\begin{array}{l}(14.7) \\
(41.5) \\
(33.2) \\
(10.6) \\
(38.2) \\
(61.8)\end{array}$ & $\begin{array}{r}74 \\
233 \\
240 \\
103 \\
\\
260 \\
390\end{array}$ & $\begin{array}{l}(11.4) \\
(35.8) \\
(36.9) \\
(15.8) \\
(40.0) \\
(60.0)\end{array}$ \\
\hline Diagnoses $¥ *$ & $\begin{array}{l}\text { Tota } \\
N=1\end{array}$ & $32(\%)$ & $\begin{array}{l}\text { Nur } \\
N=6\end{array}$ & $\begin{array}{l}\text { practitioner } \\
3(\%)\end{array}$ & $\begin{array}{l}\text { Gen } \\
\mathrm{N}=5\end{array}$ & $\begin{array}{l}\text { al practitioner } \\
9(\%)\end{array}$ \\
\hline $\begin{array}{l}\text { Categories: } \\
\text { Conditions throat, nose and ears / } \\
\text { respiratory system } \\
\text { Skin injuries } \\
\text { Musculoskeletal system } \\
\text { Sexually transmitted diseases } \\
\text { Contraceptive } \\
\text { Urinary tract infection } \\
\text { Other }\end{array}$ & $\begin{array}{l}379 \\
360 \\
294 \\
47 \\
20 \\
9 \\
123\end{array}$ & $\begin{array}{l}(30.8) \\
(29.2) \\
(23.9) \\
(3.8) \\
(1.6) \\
(0.7) \\
(10.0)\end{array}$ & $\begin{array}{l}210 \\
223 \\
137 \\
24 \\
16 \\
7 \\
56\end{array}$ & 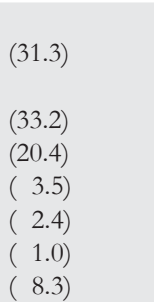 & $\begin{array}{l}169 \\
137 \\
157 \\
23 \\
4 \\
2 \\
67\end{array}$ & 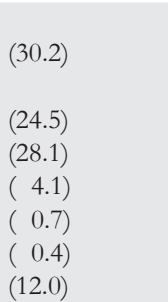 \\
\hline
\end{tabular}

† based on complete case analysis; missing data: 12 patients in the intervention group 0 patients in the reference group.

$\ddagger$ based on complete case analysis; missing data: 86 patients in the intervention group 78 patients in the reference group.

*209 patients had more than one diagnosis

From Table 3 it can be found that the items, related to communication, attitude, and provision of information (scored on a Likert-type scale 1-6), were highly appreciated by patients from both groups ( $\min =5.46, \max =5.61)$. Comparable results were found in groups for the items related to the provision of information. $(\min =5.13, \max =5.42)$. No significant difference in overall satisfaction was reported: the intervention group scored a mean of 8.19 $(\mathrm{SD}=1.18)$, the reference group a mean of $8.20(\mathrm{SD}=1.26)$. Patients $(n=583)$ who reported at least one other (chronic) disease, were significantly more 
satisfied with a consultation of the NP (mean=8.35, SD=1.07). Patients in the reference group scored a mean of $8.11(\mathrm{SD}=1.32 ; \mathrm{p}=0.02)$. The co-variable "practice" had no significant effect on the patient perceptions of the quality of care.

Table 3 Satisfaction after the consultation

\begin{tabular}{|c|c|c|c|c|c|c|c|}
\hline & \multicolumn{3}{|c|}{$\begin{array}{l}\text { Nurse } \\
\text { practitioner }\end{array}$} & \multicolumn{2}{|c|}{$\begin{array}{l}\text { General } \\
\text { practitioner }\end{array}$} & \multirow[b]{2}{*}{$\begin{array}{l}\text { Mean } \\
\text { difference }\end{array}$} & \multirow[b]{2}{*}{$\mathrm{p}$} \\
\hline & $\mathbf{N}$ & Mear & (SD) & $\mathbf{N}$ & Mean (SD) & & \\
\hline $\begin{array}{l}\text { Communication/ attitude* } \\
\text { Did he/ she showed that he/ she understood } \\
\text { your problem? }\end{array}$ & 690 & 5.49 & $(0.88)$ & 611 & $5.53(0.79)$ & -0.04 & 0.41 \\
\hline How clear he/ she told you what the plan was? & 689 & 5.48 & $(0.88)$ & 610 & $5.50(0.84)$ & -0.02 & 0.74 \\
\hline $\begin{array}{l}\text { How clear was the explanation of the goals and } \\
\text { procedure of the treatment? }\end{array}$ & 692 & 5.51 & $(0.87)$ & 612 & $5.52(0.83)$ & -0.01 & 0.76 \\
\hline $\begin{array}{l}\text { Are you convinced about the importance of the } \\
\text { given advices? }\end{array}$ & 692 & 5.46 & $(0.95)$ & 611 & $5.53(0.91)$ & -0.07 & 0.17 \\
\hline $\begin{array}{l}\text { Have you spoken about your problems with all } \\
\text { the attention that was needed? }\end{array}$ & 689 & 5.61 & $(0.83)$ & 613 & $5.60(0.80)$ & 0.01 & 0.78 \\
\hline Provision of information* & & & & & & & \\
\hline Causes of problems/ illness. & 688 & 5.13 & $(1.17)$ & 612 & $5.21(1.16)$ & -0.08 & 0.21 \\
\hline Relief of symptoms & 687 & 5.33 & $(1.04)$ & 614 & $5.37(1.07)$ & -0.04 & 0.47 \\
\hline Duration of illness & 683 & 5.20 & $(1.31)$ & 608 & $5.28(1.41)$ & -0.09 & 0.25 \\
\hline Reduce chance of recurrence & 685 & 5.27 & $(1.53)$ & 607 & $5.42(1.62)$ & -0.15 & 0.08 \\
\hline What to do if your problem/ illness persists & 684 & 5.36 & $(1.24)$ & 610 & $5.30(1.51)$ & 0.06 & 0.45 \\
\hline Overall satisfaction about this consultation** & 683 & 8.19 & $(1.18)$ & 609 & $8.20(1.26)$ & -0.015 & 0.83 \\
\hline
\end{tabular}

* Likert-scale 1-6

** Likert-scale 0-10

Patients from both groups equally regarded the NP or GP the right professional to treat their illness $(p=0.35)$, equally reported to visit their practitioner in the future $(p=0.67)$, and recommend their professional to other patients if asked for $(\mathrm{p}=0.41)$.

Two weeks after the consultation, patients in the intervention group reported that their symptoms had improved (mean=-1.77, SD=3.18), and that their concerns were reduced (mean $=-1.51, \mathrm{SD}=3.20$ ). Patients assigned to the GP reported on a Likert-type scale (0-10) also an improvement of the symptoms (mean $=-1.50, \mathrm{SD}=2.63$ ) and a reduction of concerns (mean=-1.40, SD=2.97). Between groups no significant differences were noticed in de degree of burden $(p=0.16)$ or concerns related to the illness $(p=0.60)$. A small change was noticed in health status, measured with the EQ5-D. At T0 the mean score between the two groups did not significantly differ (mean $=0.82, \mathrm{SD}=0.19$ vs mean $=0.80$, $\mathrm{SD}=0.19)$ The intervention group showed an improvement of $0.05(\mathrm{SD}=0.17)$ and the reference group an improvement of $0.04(\mathrm{SD}=0.15, \mathrm{p}=0.20$ at $\mathrm{T} 2)$. 
The NPs were more likely to ask patients to re-attend $(50.3 \%, \mathrm{p}=0.001)$, whilst those patients seemed to return significantly more than the patients in the reference group $(23.5 \%, \mathrm{p}=0.04)$. Patients in the intervention group mentioned to return because of consisting health problems or illness $(59.6 \%$ vs $46.9 \%$, $\mathrm{p}=0.01)$.

Table 4 Effectiveness of the consultation

\begin{tabular}{|c|c|c|c|c|c|c|}
\hline & \multicolumn{2}{|c|}{ Nurse practitioner } & \multicolumn{2}{|c|}{ General practitioner } & \multirow[b]{2}{*}{$\begin{array}{l}\text { Mean } \\
\text { difference }\end{array}$} & \multirow[b]{2}{*}{$\mathrm{p}$} \\
\hline & $\mathbf{N}$ & Mean (SD) & $\mathbf{N}$ & Mean (SD) & & \\
\hline $\begin{array}{l}\text { Before the consultation: } \\
\text { - Burden of the illness* } \\
\text { - Concerns about the illness * } \\
\text { - EQ5-D } \\
\text { Difference between before and two } \\
\text { weeks after the initial consultation: } \\
\text { - Burden of the illness* } \\
\text { - Concerns about the illness* } \\
\text { - EQ5-D }\end{array}$ & $\begin{array}{l}745 \\
744 \\
723\end{array}$ & $\begin{array}{l}-1.77(3.18) \\
-1.51(3.20) \\
+0.05(0.17)\end{array}$ & $\begin{array}{l}622 \\
622 \\
595\end{array}$ & $\begin{array}{l}-1.50(2.63) \\
-1.40(2.97) \\
+0.04(0.15)\end{array}$ & $\begin{array}{l}0.21 \\
0.13 \\
0.01\end{array}$ & $\begin{array}{l}0.17 \\
0.35 \\
0.41\end{array}$ \\
\hline
\end{tabular}

* Likert-scale (0-10)

Of the 492 patients who consulted a GP and returned the follow up questionnaire after two weeks, $19.8 \%$ stated that they would self manage similar illness in the future, $42.1 \%$ would consult a GP for a similar illness in the future, $1.3 \%$ indicated that they would consult the nurse practitioner and $25.1 \%$ had no preference for type of practitioner. Of the 517 patients who consulted a NP and returned the questionnaire, $19.4 \%$ stated that they self manage the illness in the future, $27.3 \%$ would consult a GP, $8.1 \%$ would consult a NP and $38.4 \%$ had no preference for type of practitioner. There was no significant difference between the intervention group and the reference group for these statements.

The NP spent on average 12.22 minutes $(\mathrm{SD}=5.7)$ face to face contacts with patients, compared by 9.20 minutes $(\mathrm{SD}=4.8)$ by the GP $(\mathrm{p}<0.001)$.

From NPs, 179 consultations and from GPs 126 consultations were identified for analysing the compliance in using the selected practical guidelines from the Dutch College of General Practitioners. No significant differences were found in compliance: the NP adhered to the guidelines in $79.8 \%$ of cases and the GP in $76.2 \%$. The median (middle score) in the intervention group was $86.6 \%$ versus $93.6 \%$ in the reference group. The interquartile ranges (represent the limits around the median) 25/ 75 was 45,8/100 in the intervention group and $50,0 / 100$ for the reference group. 
Table 5 Medical consumption

\begin{tabular}{|l|l|l|l|l|l|}
\hline & \multicolumn{2}{l}{ Nurse practitioner } & \multicolumn{2}{l|}{ General practitioner } & p \\
\hline & No of patients & \% & No of patients & \% \\
\hline 1 prescription & $411 / 747$ & 55.0 & $352 / 650$ & 54.2 & 0.75 \\
\hline prescriptions & $126 / 747$ & 16.9 & $127 / 650$ & 19.5 & 0.20 \\
$\geq 3$ prescriptions & $66 / 747$ & 8.8 & $51 / 650$ & 7.8 & 0.51 \\
\hline Investigations carried out & $18 / 747$ & 2.4 & $19 / 650$ & 2.9 & 0.55 \\
Referrals & $90 / 747$ & 12.0 & $92 / 650$ & 14.2 & 0.24 \\
Asked to return & $340 / 676$ & 50.3 & $250 / 604$ & 41.3 & $0.001^{*}$ \\
\hline Actually returned for the same problem & $121 / 515$ & 23.5 & $89 / 487$ & 18.3 & $0.04^{*}$ \\
\hline
\end{tabular}

*significant p-value

No significant difference between groups occurred in the percentage of prescriptions given $(p=0.75)$, the investigations $(p=0.55)$, and referrals $(p=0.24)$ carried out (Table 5).

Of the number of the patients who had a follow up consultation $(n=210)$, patients from the intervention group returned on average 1.71 times for the same problem $(\mathrm{SD}=0.82)$, and patients from the reference group 1.66 times $(\mathrm{SD}=0.89)$. These results were not significantly different.

Patients from both groups reported absence from their paid job due to illness with an average of 1.11 days (intervention group: $\mathrm{SD}=0.32$, reference group: $\mathrm{SD}=0.31$ ). Finally, there was no significant difference between groups in the mean number of days patients reported being unable to perform their daily activities because of their illness (intervention group: mean $=2.53, \mathrm{SD}=2.89$, reference group: mean $=2.69, \mathrm{SD}=2.90)$.

\section{Discussion}

This study evaluated process and outcomes of care provided by Dutch GPs or specially trained NPs as first point of contact. The results can be used for an international comparison with similar studies (Mundinger et al., 2000; Venning et al., 2000; Kinnersley et al., 2000). In these studies no information was provided about the work experience of the GP. Work experience of the NPs ranged from 1 to 5 years (Venning et al.; 2000, Kinnersley et al., 2000). In our study newly graduated NPs are compared with GPs; an obvious, but inequivalent comparison. NPs who finished their education programme two months before the start of the study are compared with GPs, who have an average work experience of 16 years $(\mathrm{SD}=10.1)$ and have build confidential relationships with their patients.

Furthermore, patients in the reference group were significant older. As patients were randomized, no explanation can be given for this result. Patients who returned all the questionnaires were significantly older, than those patients who did not. A possible explanation is that more participating patients do not have a paid job and/or experienced more time to participate in the trial. 
Patients value the care as provide by NPs equivalent to that by GPs. Patient perceptions of the quality of care were in both groups equal and patients highly appreciated the communication, attitude and the provision of information. In these items and in the overall satisfaction about the consultation no significant differences between groups were notable. Other studies found that patients are more satisfied with consultations by NPs (Mundinger et al., 2000; Venning et al., 2000; Kinnersley et al., 2000). Differences in educational level and/or work experience as NP may possibly explain the findings from this study.

Also no significant differences were found in patients' health status, medical consumption, and in practitioners' compliance in using practical guidelines. As the NP role in Dutch general practices is new and will develop in the future, these results are comparable with other studies conducted in different settings and different health care systems, published several years ago (Shum et al., 2000; Mundinger et al., 2000; Venning et al., 2000; Kinnersley et al., 2000).

NPs were more likely to ask patients to return. This can be clarified, as in the training programme the NPs are educated to ask every patient to return when the problem persists or aggravates. Patients in the intervention group had significantly more follow up consultations. Patients might feel less confident with a NP than with a GP and as a result would like to have extra checks for their complaints.

Among those who had seen a doctor, $26.4 \%$ had a preference for a NP or no preference if they would deal with a similar illness in the future. Among those who had seen a NP, $46.5 \%$ had a preference for a NP or no preference for a GP or NP. This suggests that once patients have consulted a NP, they return to this type of practitioners for future complaints. Regarding the results of patient satisfaction, the effectiveness of the consultation and the medical consumption, it might be expected that this percentage will grow, when the NP is more known in general practice, and develops herself in terms of work experience.

The consultations of the NP were significant longer, but no difference was notable in the provision of information. This may be attributable to the fact of the booking interval, which is 15 minutes for a consultation of the NP and ten minutes for a consultation of the GP, and the fact that the NP is newly graduated and has less experience than the GP. This study gives no results whether the NP has a more holistic approach, which was found in other studies (Reveley, 1998; Seale et al., 2006). They concluded that NPs show more social, emotional and patient-centred talk. The GPs, on the other hand, confine themselves more to the gathering of information directly relevant to diagnosing and treatment (Redsell et al., 2007). Williams and Jones (2006) and Shum (2000) found that time matters partly to patients when they consult on their health, whether it is time to discuss problems or time saved as a result of having issues resolved. Factors associated with the style and emphasis of consultations were also important. 


\section{Policy implications}

This study lends support to an increased involvement of NPs in primary care, treating patients with common complaints at first point of contact. The NPs provide care of equal quality as GPs do and an expanding continuity of care would be expected when the NPs work fulltime.

These results are achieved by NPs, who have followed a training programme, which equip them in making both diagnostic and treatment decisions, additional to the regular training programme Master in Advanced Nursing Practice. This differentiation in training programme is recommendable to prepare the NPs for their specific role in primary care.

It cannot be assumed that similar results will be obtained by nurse practitioners working in different settings, with different groups of patients, with another education or experience level.

The results of this research are one of the first steps to accept the NP as a new professional in treating common complaints. How primary care is provided, is an important policy question and depends on the extent wherein NPs gain authority. The process for implementing and evaluating APN roles is as complex and dynamic as the roles themselves (Bryant-Lukosius and Dicenso, 2004). Policy texts indicate support for advanced practice and the autonomy of NPs. The process for authorization (for example to write prescriptions) however, has constraints which support nurses' progress but also hinders it. (Turner et al., 2007). A national and international widespread debate about appropriate mix of skills in primary care is needed, to develop a greater understanding of the potential value of the NP role (Roodbol, 2005) and in particular the NP in general practice (Laurant, 2006; Wilson et al., 2002).

\section{Study limitations}

This study gives an overall view of the NP employed in different type of practices, with a different degree of urbanization. We have not investigated the influence of the particular characteristics of practices on the results, for example the workload. The practices were comparable in their vision to educate and employ a NP, and in the receiving facilitation during the project (2004-2006). Finally the study did not have sufficient power to detect a difference in rare or serious events.

The strengths of this study are the big sample size and the ability to randomize patients to equivalent providers. However, there were also several limitations. In all practices the practice assistants mentioned that on the moments they experienced a very high workload, it was not always possible to assess patients for inclusion. Four practices did not register accurately the patients, who were asked to participate in the trial. From the other practices the mean percentage and standard deviation were calculated of those patients, who refused to participate, which was $25 \%(\mathrm{SD}=10.0)$. This percentage was extrapolated to the total group of 1,501 included patients, so it was estimated that 2,000 patients 
were assessed for eligibility, on the days that the NP and GP were both available. Because most of the patients knew the practitioners, working in practice, personally, it was not possible to blind the patient for the intervention. Finally, the study had some characteristics that limit the generalizability of the results. The trial took place in one region, the NPs were senior nurses, newly graduated and the trial was conducted in general practices, which joined in a project to educate the NP as a new professional in primary care. Those GPs can be seen as early adopters of innovations.

\section{ConClusion}

NPs have been evaluated in other countries for more than 30 years now, but until now no evaluations studied NPs in Dutch general practices using a large scale, randomized controlled design. This study lends support to an increased involvement of specially trained NPs in the Dutch primary care, treating common complaints, and contributes to the knowledge of the effectiveness of the NP as first point of contact in primary care from a national and international point of view. 


\section{REFERENCES}

1. Braspenning J, Schellevis F. Tweede Nationale studie naar ziekten en verrichtingen in de huisartsenpraktijk. Kwaliteit huisartsenzorg belicht. NIVEL / WOK. Utrecht/ Nijmegen, the Netherlands, 2004. (In Dutch)

2. Bryant-Lukosius D, Dicenso A. A framework for the introduction and evaluation of advanced practice nursing roles. Journal of Advanced Nursing 2004; 48: 530-40.

3. Buchan J, Dal Poz MR. Skill mix in the health care workforce: reviewing the evidence. Bulletin of World Health Organisation 2002; 80: 575-80.

4. Drummond MF, O'Brien B, Stoddart GL, Torrance GW. Methods for the economic evaluation of health care programmes, second edition., Oxford, Oxford University Press, 2003.

5. Horrocks S, Anderson E, Salisbury C. Systematic review of whether nurse practitioners working in primary care can provide equivalent care to doctors. British Medical Journal 2002; 324: 819-23.

6. Kinnersley P, Anderson E, Parry K, Clement J, Archard L, Turton P, Stainthorpe A, Fraser A, Butler CC, Rogers C. Randomised controlled trial of nurse practitioner versus general practitioner care for patients requesting "same day" consultations in primary care. British Medical Journal 2000; 320: 1043-8.

7. Laurant M. Changes in skill mix. The impact of adding nurses to the primary care team. Nijmegen, the Netherlands, 2006.

8. Lenz ER, Mundinger MO, Kane RL, Hopkins SC, Lin S. X. Primary care outcomes in patients treated by nurse practitioners or physicians: two-year follow-up. Medical Care Research and Review 2004; 61: 332-51.

9. McKenna H, Richey R, Keeney S, Hasson F, Sinclair M, Poulton B. The introduction of innovative nursing and midwifery roles: the perspective of healthcare managers. Journal of Advanced Nursing 2006; 56: 553-62.

10. Mundinger MO, Kane RL, Lenz ER, Totten AM, Tsai WY, Cleary PD, Friedewald WT, Siu AL, Shelanski ML. Primary care outcomes in patients treated by nurse practitioners or physicians: a randomized trial. JAMA 2000; 283, 59-68.

11. Offredy M, Townsend J. Nurse practitioners in primary care. Family Practice 2000; 17: 564-9.

12. Reay T, Golden-Biddle K, Germann K. Challenges and leadership strategies for managers of nurse practitioners. Journal of Nursing Management 2003; 11: 396-403.

13. Redsell S, Stokes T, Jackson C, Hastings A, Baker R. Patients' accounts of the differences in nurses' and general practitioners' roles in primary care. Journal of Advanced Nursing 2007; 57: 172-80.

14. Reveley $\mathrm{S}$. The role of the triage nurse practitioner in general medical practice: an analysis of the role. Journal of Advanced Nursing 1998; 28: 584-91.

15. Roodbol P. Dwaallichten, struikeltochten, tolwegen en zangsporen : onderzoek naar taakherschikking tussen verpleging en artsen. Groningen, the Netherlands, 2005. (In Dutch)

16. Seale C, Anderson E, Kinnersley P. Treatment advice in primary care: a comparative study of nurse practitioners and general practitioners. Journal of Advanced Nursing 2006; 54: 534-41.

17. Shum C, Humphreys A, Wheeler D, Cochrane MA, Skoda S, Clement S. Nurse management of patients with minor illnesses in general practice: multicentre, randomised controlled trial. British Medical Journal 2000; 320: 1038-43. 
18. Turner C, Keyzer D, Rudge T. Spheres of influence or autonomy? A discourse analysis of the introduction of Nurse Practitioners in rural and remote Australia. Journal of Advanced Nursing, 2007; 59: 38-46.

19. van Roijen L, Essink-Bot ML, Koopmanschap MA, Bonsel G, Rutten FF. Labor and health status in economic evaluation of health care. The Health and Labor Questionnaire. International Journal of Technology Assessment in Health Care 1996; 12: 405-15.

20. Venning P, Durie A, Roland M, Roberts C, Leese B. Randomised controlled trial comparing cost effectiveness of general practitioners and nurse practitioners in primary care. British Medical Journal 2000; 320: 1048-53.

21. Wensing M, Grol R, Asberg J, van Montfort P, van Weel C, Felling A. Does the health status of chronically ill patients predict their judgements of the quality of general practice care? Quality of Life Research 1997; 6: 293-9.

22. WHO The World Health Report 2000. Health systems: improving performance. Geneva: World Health Organization, 2000.

23. Williams A, Jones M. Patients' assessments of consulting a nurse practitioner: the time factor Journal of Advanced Nursing 2006; 53(2): 188-195.

24. Wilson A, Childs S. The relationship between consultation length, process and outcomes in general practice: a systematic review. British Journal of General Practice 2002; 52: 1012-20.

25. Wilson A, Pearson D, Hassey A. Barriers to developing the nurse practitioner role in primary care-the GP perspective. Family Practice 2002; 19: 641-6. 


\section{Chapter}

\section{Economic evaluation of substituting}

nurse practitioners for general practitioners in the care for patients with common complaints

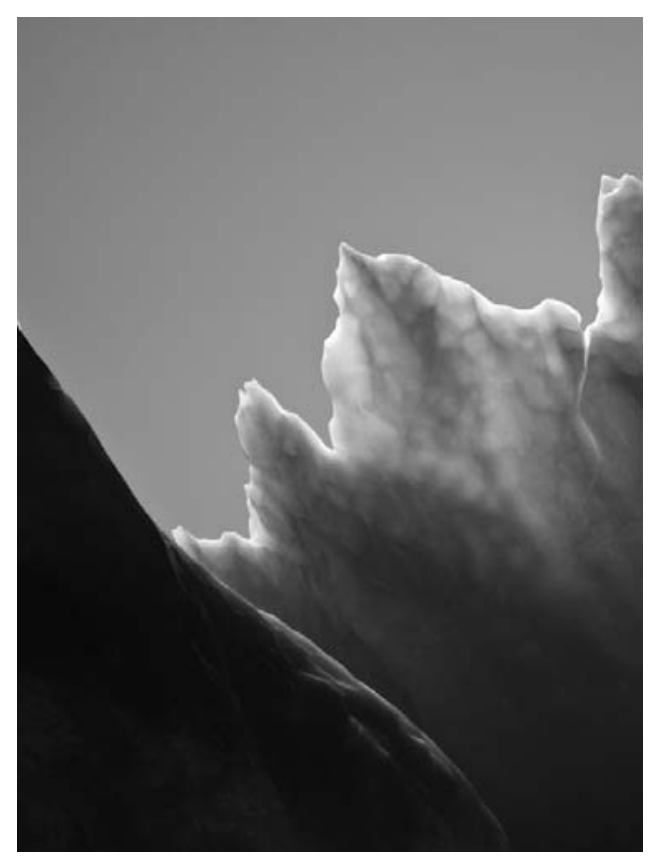

A.T.M. Dierick-van Daele, Steuten L.M.G., J.F.M. Metsemakers, E.W.C.C. Derckx, C. Spreeuwenberg, H.J.M. Vrijhoef

Based on the paper in British Journal of General Practice 2010; (60) 570: 28-35 


\section{Chapter 5}

\section{Abstract}

Title. Economic evaluation of substituting nurse practitioners for general practitioners in the care for patients with common complaints.

Background. Studies wherein substitution of care has been evaluated revealed only limited evidence on cost-effectiveness. Given the concerns about generalizability, a trial was conducted to evaluate nurse practitioners (NPs) in Dutch general practices as first point of contact.

Aim. to estimate costs of general practitioner (GP) or NP consultations from a practice and societal perspective.

Design. an economic evaluation was conducted alongside a randomised controlled trial between May and October 2006, wherein 12 NPs en 50 GPs working in 15 general practices (NPGP-practices) participated. Consultations by NPGP-practices were also compared with a second external reference group, with 17 GPs working in five general practices without the involvement of NPs. Methods. Direct costs within the health care sector included resource use, followup consultations, length of consultations and salary costs. Costs outside the health care sector were productivity losses. Sensitivity analyses were performed. Results. Direct costs were significant less for NP consultations than for GP consultations within NPGP-practices. This was also the case for direct costs plus costs from a societal perspective for patients aged below 65 years. Direct costs of consultations by NPGP-practices were significant less than those by reference practices while practices did not differ for direct costs plus costs from a societal perspective for patients aged below 65 years. Cost differences are mainly caused by the differences in salary.

Conclusion. By involving NPs, substantial economic "savings" could be used for redesigning primary care, to optimize the best skill mix and to cover the full range of primary care activities.

Keywords. nurse practitioner, general practitioner, cost minimization, economic evaluation, randomized controlled trial 


\section{INTRODUCTION}

At the background of scarce health care budgets, skill mix changes are being introduced to ensure health services are used efficiently. Substitution of care results in at least equivalent quality of care than usual care (AANP, 2000; Vrijhoef et al., 2000; Buchan and Dal Poz, 2002; Horrocks et al., 2002; Laurant et al., 2004). Simultaneously, studies wherein a "new type" of health care worker has been evaluated in terms of costs and consequences, revealed only limited evidence on cost-effectiveness, while methodological limitations were stressed regarding the validity and generalizability of these studies (Laurant et al., 2004; Dierick et al., 2008).

One of these new roles is the nurse practitioner (NP). Recent interest in substituting NPs for general practitioners (GPs) may be driven by a goal to reduce costs while achieving similar outcomes (Richardson and Maynard, 1995; Williams, 1999; Sibbald, 2008). Given the limited number of similar studies and the concerns about their generalizability, there was also a need to perform research in Dutch general practices. By means of a randomised controlled trial it was recently demonstrated, that NP consultations for patients with common complaints result in the same high patient satisfaction and high quality care as GP consultations (Dierick et al., 2009).

In the current paper, the authors report on health care utilisation and health care costs when patients are treated for common complaints by specially trained NPs. This study aims to estimate costs of GP or NP consultations dealing with patients with common complaints from two perspectives: general practice and societal. Provided equivalence in quality of care, a cost minimisation analysis was regarded suitable for this purpose.

\section{Methods}

\section{Design and participants}

An economic evaluation was conducted alongside a randomised controlled trial between May and October 2006, wherein a convenience sample of 12 NPs and 50 GPs working in 15 general practices (NPGP-practices) participated. Patients of NPGP-practices were also compared with those in a second reference group, referred to as external reference group, who received treatment of 17 GPs working in five general practices without the involvement of a NP.

Comparisons are made between NPGP-practices and external reference practices, and between NP consultations and GP consultations both within NPGP- practices. The general practices range in size from solo practices (1 GP) to health centres (5 GPs). The general practices in the external reference group range from duo practices (2 GPs) to group practices (4 GPs). Details about the design are described in the appendix (Dierick et al., 2009). The job description of the NP is further described in Appendix 1. 
Box 1 Nurse practitioner: a job description

\section{General definition Nurse practitioner (NP):}

"A registered nurse with additional education and training, who works within an expanded scope of practice that includes diagnosing, prescribing and treating medical conditions within specific settings"(Reay 2003)

\section{NP in the Dutch NPGP-project:}

Target population: patients with common complaints

A specified set of common complaints was compiled for which patients seek medical attention. These common complaints will often lead to minor health problems. Patients have respiratory and throat complaints, ear and nose complaints, musculoskeletal complaints and injuries, skin injuries, urinary complaints, gynaecological complaints and geriatric problems

\section{Tasks performed}

Based on triage by the practice assistant, patients with common complaints are referred to the NP. The NP works independent during consultations and home visits. The activities, according to practice guidelines derived by the Dutch College of General Practitioners are assessing symptoms, physical examinations where appropriate, diagnosing and making decisions for further treatment, prescriptions, referrals to primary or secondary services and clinical investigations. The NP has no full authority to prescribe medications, the GP is always available for consultation and to assign prescriptions. The NP has access to the electronic medical records and reported consultations.

\section{Training}

Before they started the NP training programme, NPs have a work experience with an average of 12 years $(\mathrm{SD}=7.6$ years). A specific two year practice-oriented training programme was developed, which consisted of the Higher Professional Education Master's Degree Advanced Nursing Practice (MANP) which includes also a medical course on managing common complaints. During the training program the NP was supervised by a general practitioner.

A specified set of common complaints and related international classification of primary care (ICPC) diagnoses was compiled, for which patients seek medical attention (Lamberts and Wood, 1987; Gebel and Lamberts, 2000). Patients, aged over 16 years, who attended in general practice for an appointment and visiting for an initial consultation related to common complaints were included. Patients were randomly allocated to a NP consultation or GP consultation. In the external reference group, data were retrospectively gathered from patients with common complaints.

\section{Data collection}

Demographic characteristics and data of diagnoses (ICPC codes), prescriptions, referrals and investigations were extracted from the health information systems of the general practices. The ICPC-codes were classified as symptons and complaints (code $<70$ ) or diagnoses and diseases (code $\geq 70$ ). Special attention was paid to ensure the reliability of documentation by professionals. In each practice, information was given about the relevance of systematically keeping records and registering data. Software was developed to extract data from the computer systems. Extracted data were used during meetings per general practice to provide feedback and for testing the reliability of their documentation.

Because of pragmatic reasons data for follow-up consultations, length of 
consultations, and number of days of absence were only gathered in NPGPpractices. It was assumed that these data were the same for the external reference group.

\section{Valuation of resource use}

All costs related to the consultations were split into costs which occurred within the health care sector and those that occurred outside. Direct costs within the health care sector included costs of prescriptions, diagnostic procedures, and referrals, ordered in the following two weeks after the initial consultations; follow-up consultations, length of consultations (Dierick et al., 2009) and salary costs.

We calculated one initial consultation for each referral. Costs of follow-up consultations were based on percentages of patients who consulted a NP or a GP and had a follow-up consultation in the following two weeks (Dierick et al., 2009) (Table 1).

The costs of clinical time were valued as salary plus expenses of superannuation and national insurance (Oostenbrink et al., 2004). Costs of GP time were calculated at $€ 47.72$ per hour, and costs of NP time at $€ 25.43$ per hour. The direct health care costs were calculated using current prices, if ever available, or tariffs.

Costs outside the health care sector were productivity losses measured in terms of sick leave days and calculated using the age-dependent friction cost method (Oostenbrink et al., 2004).

To derive unit costs for the year 2006, the price index was used of Statistics Netherlands (www.cbs.nl/Statline, accessed June 26 2008). Table 1 shows the key unit standardised costs per type of resource and by its reference.

\section{Analyses}

Mean costs were calculated for each group, treating each cost separately and then adding up the total costs. Data were analysed using SPSS software 15.0 (SPSS, Chicago, IL). We adopted the cost minimisation form of economic analysis (Drummond et al., 2003), as the RCT showed no significant differences in outcome (Dierick et al., 2009). Analyses were performed according to the intention to treat principle. As cost data were highly skewed, estimates for costs were compared with estimates based on non-parametric clustered bootstrap (1,000 replications) to check the robustness of the analysis (Barber and Thompson, 1998; Thompson and Barber, 2000). Both estimates gave similar results and so only the direct estimates are presented. Differences in clinical characteristics and health care utilisation were analysed using the Students t-test (two-sided; $\alpha=0.05$ ) and chi-square, where appropriate. Univariate linear regression and mixed model analysis were used to determine whether there were significant effects between the intervention group and control group upon the different scores after controlling for potential confounding variables. 
86| Chapter 5

Table 1 Price indexed unit costs (in $€$ ) in 2006

\begin{tabular}{|c|c|c|c|}
\hline Resource use & Unit & Cost $(€)$ & Reference \\
\hline Prescriptions & consultation & variable & $\begin{array}{l}\text { Dutch Pharmacotherapeutic } \\
\text { Compass }\end{array}$ \\
\hline Referrals* & consultation & variable & Dutch Manual for Costing \\
\hline Diagnostic procedures & consultation & variable & CTG National tariffs 2006 \\
\hline Salary costs NP & year & $41,160.00$ & $\begin{array}{l}\text { Collective labour agreement } \\
\text { general practices }\end{array}$ \\
\hline Salary costs GP & year & $94,475.92$ & Standard income (LHV) \\
\hline Follow up costs NP† & consultation & 2.12 & RCT (Dierick et. al., 2009) \\
\hline Follow up costs GP† & consultation & 1.65 & RCT (Dierick et al., 2009) \\
\hline $\begin{array}{l}\text { Indirect costs for paid } \\
\text { work } \ddagger\end{array}$ & consultation & variable & Dutch Manual for Costing \\
\hline
\end{tabular}

*based on one initial consultation

tbased on costs of one consultation: $€ 9.00$ and percentage of follow up consultations (NP: $€ 9.00 * 23.5 \%=€ 2.12$; GP: $€ 9.00 * 18.3=€ 1.65$ )

$\ddagger$ Indirect costs for paid work are based on mean income of Dutch population according to age and sex.

A sensitivity analysis was performed to test several assumptions in the cost analysis. The impact of salary was assessed by using two scenarios. The first scenario was the salary of "GP in employment", working 38 hours weekly, and the second was based on the salary of a GP who is employed by GPs in partnership, working 40 hours weekly.

A subgroup analysis for patients younger than 65 years old was performed, since for this group productivity costs were calculated.

\section{REsults}

Considering the background characteristics, patients within NPGP-practices and randomised to the GP were significant older (mean=46.1, SD=16.6) than those in the intervention group (mean=42.8, $\mathrm{SD}=16.5 ; \mathrm{p}<0.001)$. No significant differences between groups were notable in gender or complexity of diagnoses. There was no significant difference between patients of the NPGP-practices and external reference practices in gender (Table 2). Most patients were female (61.0\% vs. 60.6\%). Patients in external reference practices were on average more than two years older $(p=0.001)$ than those in NPGP-practices. Patients in NPGP-practices had on average more complex diagnoses than patients in external reference practices. 
Table 2 Patient characteristics

\begin{tabular}{llll} 
& NPGP-practices & \multicolumn{2}{c}{ External reference practices } \\
& $\mathbf{N}=1,397$ & $\mathbf{N}=1,350$ & p \\
Sexe Male / Female (\%) & $39.0 / 61.0$ & $39.4 / 60.6$ & 0.83 \\
Age; years mean (SD) & $45.1(16.7)$ & $47.2(18.2)$ & 0.001 \\
Complexity of the diagnose; & & & \\
low/ high (\%) & $40.6 / 59.4$ & $47.0 / 53.0$ & 0.001
\end{tabular}

Within NPGP-practices, there was no significant difference in resource use by patients treated by NP or GP. Patients in the NPGP-practices had significant less prescriptions $(\mathrm{p}<0.001)$ and diagnostic procedures $(\mathrm{p}=0.04)$ than patients in the external reference practices (Table 3).

Table 3 Resource use (percentages)

\begin{tabular}{llll} 
& NPGP-practices & \multicolumn{2}{l}{ External reference practices } \\
N=1,397 & N=1,350 & $\mathbf{p ~}$ \\
& $\mathbf{n}(\mathbf{0} \%)$ & $\mathbf{n}(\mathbf{0})$ & \\
& $763(54.6)$ & $889(65.9)$ & $<0.001$ \\
1 Prescription & $253(18.1)$ & $307(22.7)$ & 0.003 \\
2 Prescriptions & $117(8.4)$ & $93(6.9)$ & 0.14 \\
$>3$ Prescriptions & $37(2.6)$ & $55(4.1)$ & 0.14 \\
Diagnostic procedures & $182(13.0)$ & $187(13.9)$ & 0.53 \\
Referrals & & &
\end{tabular}

† based on resource use, costs of follow up consultations, length of consultations and salary costs

Results of the economic analyses are shown in table 4. Within NPGP-practices a significant difference in direct costs appeared between the NP consultations and GP consultations: a mean difference in direct costs of $€ 8.21$ in favor of the NP consultations was found $(p=0.001)$. No significant difference in direct costs and productivity costs was found between NP consultations and GP consultations within NPGP-practices. 
Table 4 Cost analysis (in $€$ ) per NP consultation and GP consultation within NGGP

\begin{tabular}{|c|c|c|c|c|c|}
\hline & \multicolumn{2}{|c|}{$\begin{array}{l}\text { NP consultations(I) } \\
N=747\end{array}$} & \multicolumn{3}{|c|}{$\begin{array}{l}\text { GP consultations }(\mathrm{R}) \\
\mathrm{N}=650\end{array}$} \\
\hline & Mean (SD) & Mean (SD) & Mean dif $\triangle I-R(\%)$ & $95 \% \mathrm{CI}$ & $\mathrm{p}$ \\
\hline $\begin{array}{l}\text { Direct costs } † \\
\text { Based on salary GP in }\end{array}$ & $31.94(36.29)$ & 40.15 (49.94) & $-8.21(-20.45)$ & $3.56-12.85$ & 0.001 \\
\hline $\begin{array}{l}\text { Employment } \\
\text { Based on GP emploved }\end{array}$ & $31.94(36.29)$ & 38.33 (49.94) & $-6.39(-16.67)$ & $1.74-11.03$ & 0.007 \\
\hline by other GPs & $31.94(36.29)$ & 37.45 (49.94) & $-5.53(-14.76)$ & $0.88-10.16$ & 0.02 \\
\hline $\begin{array}{l}\text { Direct costs and } \\
\text { productivity costs } \\
\text { Based on salary GP in }\end{array}$ & $144.40(53.18)$ & $145.87(67.15)$ & $-1.48(-1.01)$ & $-4.94-7.90$ & 0.65 \\
\hline Employment & $144.40(53.18)$ & $144.05(67.15)$ & $0.34(0.24)$ & $-6.77-6.08$ & 0.92 \\
\hline by other GPs & $144.40(53.18)$ & $143.17(67.15)$ & $1.20(0.84)$ & $-7.63-5.22$ & 0.71 \\
\hline \multirow[t]{2}{*}{ Patients $<65$ year } & \multicolumn{2}{|c|}{$\begin{array}{l}\text { NP consultations(I) } \\
N=666\end{array}$} & \multicolumn{2}{|c|}{$\begin{array}{l}\text { GP consultations }(\mathrm{R}) \\
\mathrm{N}=542\end{array}$} & \\
\hline & Mean (SD) & Mean (SD) & Mean dif $\triangle I-R(\%)$ & $95 \% \mathrm{CI}$ & $\mathrm{p}$ \\
\hline $\begin{array}{l}\text { Direct costs and } \\
\text { productivity costs } \\
\text { Based on salary GP in }\end{array}$ & 161.57 (33.98) & $170.75(46.58)$ & $-9.18(-5.38)$ & $4.48-13.88$ & $<0.001$ \\
\hline $\begin{array}{l}\text { Employment } \\
\text { Based on GP employed }\end{array}$ & 161.57 (33.98) & $170.10(46.58)$ & $-8.52(-5.01)$ & $3.83-13.23$ & $<0.001$ \\
\hline by other GPs & $161.57(33.98)$ & $168.90(46.58)$ & $-7.33(-4.34)$ & $2.63-12.03$ & 0.002 \\
\hline
\end{tabular}

Table 5 Cost analysis (in $€$ ) per consultation in NPGP-practices and external reference practices

\begin{tabular}{|c|c|c|c|c|c|}
\hline & \multicolumn{2}{|c|}{$\begin{array}{l}\text { NPGP-practices }(\mathrm{I}) \\
\mathrm{N}=1,397\end{array}$} & \multicolumn{3}{|c|}{$\begin{array}{l}\text { External Reference practice }(\mathbf{R}) \\
\mathbf{N}=1,350\end{array}$} \\
\hline & Mean (SD) & Mean (SD) & Mean dif $\triangle \mathrm{I}-\mathrm{R}(\%)$ & $95 \% \mathrm{CI}$ & $\mathrm{p}$ \\
\hline $\begin{array}{l}\text { Direct costs } \dagger \\
\text { Based on salary GP in }\end{array}$ & $35.76(43.35)$ & $39.21(42.99)$ & $-3.45(-8,80)$ & $0.22-6.68$ & 0.04 \\
\hline Employment & $34.92(43.27)$ & $37.39(42.99)$ & $-2.47(-6,60)$ & $-0.75-5.70$ & 0.13 \\
\hline $\begin{array}{l}\text { Based on GP employed } \\
\text { by other GPs }\end{array}$ & $34.50(43.24)$ & $36.51(42.99)$ & $-2.01(-5.50)$ & $-1.21-5.24$ & 0.22 \\
\hline $\begin{array}{l}\text { Direct costs and } \\
\text { productivity costs } \\
\text { Based on salary GP in }\end{array}$ & $145.08(60.07)$ & 141.09 (63.03) & $4.00(2,83)$ & $-8.61-0.61$ & 0.09 \\
\hline Employment & $144.24(60.07)$ & $139.26(63.03)$ & $4.98(3,58)$ & $-9.58--0.36$ & 0.04 \\
\hline $\begin{array}{l}\text { Based on GP employed } \\
\text { by other GPs }\end{array}$ & $143.82(60.07)$ & 138.39 (63.03) & $5.43(3,92)$ & $-10.04-0.82$ & 0.02 \\
\hline \multirow[t]{2}{*}{ Patients $<65$ year } & \multicolumn{2}{|c|}{$\begin{array}{l}\text { NPGP- practices }(\mathrm{I}) \\
\mathrm{N}=1,208\end{array}$} & \multicolumn{3}{|c|}{$\begin{array}{l}\text { External Reference practice (R) } \\
N=1,089\end{array}$} \\
\hline & Mean (SD) & Mean (SD) & Mean dif $\triangle \mathrm{I}-\mathrm{R}(\%)$ & $95 \% \mathrm{CI}$ & $\mathrm{p}$ \\
\hline $\begin{array}{l}\text { Direct costs and } \\
\text { productivity costs } \\
\text { Based on salary GP in }\end{array}$ & $165.69(40.37)$ & $168.25(40.48)$ & $-2.60(-1.55)$ & $-0.74-5.88$ & 0.13 \\
\hline $\begin{array}{l}\text { Employment } \\
\text { Based on GP employed }\end{array}$ & $165.39(40.33)$ & $167.60(40.48)$ & $-2.21(-1.31)$ & $-1.10-5.52$ & 0.19 \\
\hline by other GPs & $164.86(40.27)$ & $166.40(40.48)$ & $-1.55(-0.93)$ & $-1.76-4.86$ & 0.36 \\
\hline
\end{tabular}

† based on resource use, costs of follow up consultations, length of consultations and salary costs 
Between NPGP-practices and reference practices a significant difference was found in the direct costs within health care (Table 5). The mean difference in direct costs was $€ 3.45$ per consultation in favor of the NPGP-practices $(p=0.04)$. Regarding the direct costs and productivity costs, the consultations in external reference practices cost less $(€ 141.09)$ than the consultations in NPGPpractices $(€ 145.08 ; \mathrm{p}=0.09)$, although not statistically significant.

Univariate linear regression revealed that direct costs were significantly associated with patients' gender $(F 4.13 ; \mathrm{p}=0.042)$, age $(F 24.24 ; \mathrm{p}=0.001)$, and the classification of ICPC codes (F 63.67; $\mathrm{p}<0.001)$. The variable practice (i.e. patients nested within general practices) was not significantly associated. These variables explained $16.06 \%$ of the total variance (adj. R-squared 0.40 ).

\section{Sensitivity analysis}

Adjusting the salary of the GP (in salary of a GP being employed and in a GP being employed by GPs in partnership) affects the results to some degree. The significant difference in directs costs remained comparing NP consultations and GP consultations within NPGP-practices. Also, no significant difference was noticed regarding direct costs and productivity costs between consultations within NPGP-practices (Table 4). Impact of salary was found in the analyses between NPGP-practices and external reference practices; in direct costs no longer a significant difference appeared, while in direct costs and productivity costs significant difference did appear between practices (Table 5).

With patients in the reference groups being significantly older, a sensitivity analysis was performed for patients younger than 65 years of age. In so doing, it was found that within NPGP-practices the mean direct costs and productivity costs for NP consultations were $€ 161.57$ (SD=33.98) and for GP consultations $€ 170.75$ (SD=46.58; $\mathrm{p}<0.001)$ (Table 4). Furthermore, mean costs for consultations in NPGP-practices were $€ 165.69$ (SD=40.37) and $€ 168.25$ for consultations in the external reference practices $(\mathrm{SD}=40.48 ; \mathrm{p}=0.13)$ (Table 5).

\section{Discussion}

This study evaluated costs of care provided by Dutch GPs or specially trained NPs as first point of contact for patients with common complaints. From a general practice perspective direct costs of NP consultations were significant less than of GP consultations. Same results were found when comparing NPGP-practices with external reference practices, showing direct costs of consultations in favor of NPGP-practices. Given there were differences in the age of people both within the NPGP-practices as well as between NPGPpractices and external reference practices, we looked at the impact of age on the direct costs plus productivity costs. This revealed that amongst those aged younger than 65 years of age direct costs plus productivity costs were significant lower for NP consultations than for GP consultations within NPGP-practices. 
Between NPGP-practices and external reference practices no differences were found for direct costs plus productivity costs of consultations amongst those younger than 65 years of age. Cost differences are mainly caused by the difference in salary between NPs and GPs.

As the external reference practices also implemented triage, the difference in costs related to the allocation of patients between NPGP-practices and external reference practices is assumed as marginal.

We were unable to gather data for follow-up consultations, length of consultations, number of days of absence in the external reference practices, because of pragmatic reasons. As we were not able to collect data on the follow up after a referral, for each referral one initial consultation was calculated in order not to leave this type of events out of the calculation.

We are aware of the preference for cost-effectiveness analyses and cost effectiveness planes as a valuable tool in the interpretation of both costs and effects (Drummond et al., 2003; Bosmans and De Bruijne, 2007). The use of cost minimization analysis is in most cases regarded as inappropriate in studies designed to compare two interventions on their cost-effectiveness (Bosmans, 2007; Briggs and Brien, 2001). However, in comparing NP or GP consultations no significant differences in outcome or process measures were found (Dierick et al., 2009). Consequently, we considered that the sum of these measures represents equivalence between the intervention group and reference group within the NPGP-practices. As a result, we did not conduct a cost-effectiveness analysis. If we would have done so, it is very unlikely this would have altered our findings on costs, given the equivalence in effectiveness.

Earlier reviews, mainly based on British studies (Laurant et al., 2004; Dierick et al., 2008) found no significant differences in costs between NP consultations and GP consultations. Hollinghurst et al. (2006) included training costs and advice time in the analyses. Other factors that could explain differences between studies are type of diagnoses being addressed (e.g. chronic disease versus common complaints), specific competencies or consulting styles (e.g. no prescriptive authority), and work experience, as well as training programs followed by providers. The training of nurses and GPs is funded through a variety of mechanisms, which may not accurately reflect the true costs (Hollinghurst et al., 2006) and makes an international comparison unclear.

Most decisions of health policy makers will not be about whether services should be delegated or substituted, but about the degree to which existing services should change (Kernick, 2003). We found a cost difference of $€ 2.01$ per consultation, based on a mix of GP consultations and NP consultations and the salary of a GP who is employed by GPs in partnership. To illustrate the impact of such a difference on national level, we calculated a scenario wherein all consultations of common complaints would be performed by NPs instead of GPs. Taking account for one full time equivalent NP employed per 4 GPs, 8400 employed GPs (www.LHV.nl), 20 NP consultations per day (Dierick et al., 
2008a), a cost reduction of $€ 19$ million per year can be realized. This amount should not be considered as a pure economical saving. When involving the NP in the care for patients with common complaints, this substantial amount should be used partly for redesigning primary care (Sibbald, 2008). As a result, GPs should have longer consultations for an increasing number of patients with complex diagnoses or multi morbidity, more time for coordination between professionals, and more time for their supervisor role to other professionals. When common complaints are extracted from the repertoire of GP consultations, the GP role of coordinator and supervisor will be very important to manage less complex care. Such redesign requires the health care system to take a long term perspective, which may be difficult to achieve in practice (Williams and Sibbald, 1999). It is important to continue the debate between policymakers and researchers about the meaning of results from economic evaluations (Eddama and Coast, 2008; Graf von der Schulenburg, 2000) to optimize the best skill mix (effective and efficient) and to cover the full range of primary care activities.

Consultations were considered during two weeks after the initial consultation. This study was not powered to either determine the impact on adverse events (and related costs) nor to explore additional consultations.

Since the regression analysis resulted in a model explaining only a marginal amount of the variance in results, more research is needed. Finally, we recommend more research to cost-effectiveness of innovations in health care over a long term period i.e. beyond the time horizon of a trial.

\section{Appendix 1}

\footnotetext{
Studies in the USA and Great Britain reported that substituting general practitioners for nurse practitioners results in higher patient satisfaction and higher quality of care. As the American and British health care system and settings differ from that in the Netherlands, a Dutch trial was conducted.

The aim of the study was to evaluate process and outcomes of care provided by general practitioners or specially trained nurse practitioners for patients with minor complaints at first point of contact.

1501 patients were randomized for an initial consultation by a general practitioner or a nurse practitioner, working in 15 general practices. Data were collected by means of questionnaires, extracting medical records from the practice computer systems, and recording length of consultations.

In both groups patients highly appreciated the quality of care. No statistically significant differences were found patient satisfaction, the provision of information, communication and attitude, in health status (including burden of illness and concerns regarding the illness), compliance of practical guidelines, and medical consumption: prescriptions (NP 55.0\%; GP 54.2\%: $\mathrm{p}=0.75$ ), investigations ordered (NP 2.4\%; GP 2.9\%: $\mathrm{p}=0.55$ ) and referrals (NP 12.0\%; GP 14.2\%; $\mathrm{p}=0.24)$ Patients in the intervention group were more invited to re-attend (NP 50.3\% GP 41.3\%; $\mathrm{p}=0.001$ ), had more follow up consultations (NP 23.5\%; GP $18.3 \%$; $=0.04)$ and their consultations took significantly more time (NP mean=12.22 (SD=5.7); GP mean=9.20 (SD=4.8): $\mathrm{p}=0.001)$.

It was concluded that nurse practitioners and general practitioners provide comparable care. These findings support an increased involvement of specially trained nurse practitioners in Dutch primary care and contribute to the knowledge on the effectiveness of care provision by nurse practitioners from a national and international perspective.
} 


\section{REFERENCES}

1. American Academy of Nurse Practitioners. Nurse Practitioners - providers of quality primary care. Documentation of cost effectiveness. Washington DC: AANP revised 2000. http://www.aanp.org/. (latest access November 2008)

2. Barber JA, Thompson SG. Analysis and interpretation of cost data in randomised controlled trials: review of published studies. British Medical Journal 1998; 317:1195-200.

3. Bosmans JE, de Bruijne MC. Practical Guidelines for Economic Evaluations Alongside Equivalence Trials. International Society for Pharmacoeconomics and Outcomes Research 2007; 11 (2): 251-8.

4. Briggs AH, O'Brien BJ. The death of cost minimization analysis? Health Economics 2001; 10: 179-84.

5. Buchan J, Dal Poz MR. Skill mix in the health care workforce: reviewing the evidence. Bulletin World Health Organization 2002; 80(7): 575-80.

6. Capacity rates in general practices. htpp://www.LHV.nl/zorgcijfers. (latest access 9th december 2008) (In Dutch)

7. Dierick- van Daele ATM, Spreeuwenberg C, Derckx EWCC, Metsemakers JFM, Vrijhoef HJM Critical appraisal of the literature on economic evaluations of substitution of skills between professionals: a systematic literature review. Journal of Evaluation in Clinical Practice 2008; 14: 481-92.

8. Dierick-van Daele ATM, Spreeuwenberg C, Derckx EWCC, Metsemakers JFM, Vrijhoef HJM. The nurse practitioner in general practice, the research report. De Nurse practitioner in de huisartsenpraktijk, het onderzoeksrapport Maastricht, Maatricht University Medical Centre 2008a. (In Dutch)

9. Dierick-van Daele ATM, Metsemakers JFM, Derckx EWCC, Spreeuwenberg C, Vrijhoef HJM. Nurse practitioners substituting for general practitioners in the care for patients with common complaints; a randomised controlled trial. Journal of Advanced Nursing 2009; 65(2): 391-401.

10. Drummond MF, O'Brien B, Stoddart GL, Torrance GW. Methods for the economic evaluation of health care programmes, second edition. Oxford, Oxford University Press 2003.

11. Eddamaa O, Coast J. A systematic review of the use of economic evaluation in local decision-making. Health Policy 2008; 86:129-141

12. Gebel RS, Lamberts H. NHG-ICPC-1. (Dutch College of General Practitioners ICPC1). Dutch College of General Practitioners. Fourth Edition Utrecht, Netherlands 2000. (In Dutch)

13. Graf von der Schulenburg JM. The influence of economic evaluation studies on bealth care decision making. A European survey. Amsterdam: IOS Press 2000.

14. Hollinghurst $S$, Horrocks $S$, et al. Comparing the cost of nurse practitioners and GPs in primary care; modelling economic data from randomised trials. British Journal of General Practice 2006; 56: 530-35.

15. Horrocks S, Anderson E, Salisbury C. Systematic review of whether nurse practitioners working in primary care can provide equivalent care to doctors. British Medical Journal 2002; 324: 819-23.

16. Kernick DP. Developing intermediate care provided by general practitioners with a special interest: the economic perspective. British Journal of General Practice 2003; 53: 553-6. 
17. Linden MW van der, Westert GP, Bakker DH de, Schellevis FG. Tweede Nationale Studie naar ziekten en verrichtingen in de buisartspraktijk. Klachten en aandoeningen in de bevolking en in de buisartspraktijk. (Second national Study of diseases and treatments in general practices. Complaints and illnesses in the Dutch population and in general practice. Dutch Insitute for Health Services Research (NIVEL)/National Institute for Public Health and Environment (RIVM).Utrecht/Bilthoven 2004. (In Dutch)

18. Lamberts H, Wood M. ICPC. International Classification of Primary Care. Oxford: Oxford University. Press 1987.

19. Laurant M, Reeves D, et al., Substitution of doctors by nurses in primary care. The Cochrane Database of Systematic Reviews Collaboration 2004; (4).

20. Lilford RJ, Braunholtz DB. Who is afraid of Thomas Bayes? Journal of Epidemiology Community Health 2000; 54:731-39.

21. Reay T., Golden-Biddle K, Germann K. Challenges and leadership strategies for managers of nurse practitioners. Journal of Nursing Management 2003; 11: 396-403.

22. Richardson G, Maynard A. Fewer doctors? More nurses? A review of the knowledge base of doctor-nurse substitution. Discussion paper 135. York: University of York 1995.

23. Sibbald B. Should primary care be nurse led? British Medical Journal 2008; 337: 658-9.

24. Oostenbrink JB, Koopmanschap MA, Rutten FF. Handleiding voor kostenonderzoek, methoden en richtlijmprijzen voor economische evaluaties in de gezondheidszorg (Handbook for cost studies, methods and guidelines for economic evaluation in health care) Hague, Netherlands; Health care Insurance Councel 2004. (In Dutch)

25. Pharmotherapeutic Compass. Health Care Insurance Board (CVZ). http://www.fk.cvz.nl/. (latest access October 2008).

26. Price index rates. Central Bureau of Statistics. http://www. cbs.nl/Statline. (latest access June 26 2008).

27. Thompson SG, Barber JA. How should cost data in pragmatic randomized trials be analyzed British Medical Journal 2000; 320: 1197-200.

28. Vrijhoef HJM, Diederiks JP, Spreeuwenberg C. Effects on quality of care for patients with NIDDM or COPD when the specialised nurse has a central role: a literature review. Patient Education and Counseling. 2000; 41(3):243-50.

29. Williams A, Sibbald B. (1999) Changing roles and identities in primary health care: exploring a culture of uncertainty. Journal of Advanced Nursing 1999; 29: 737-45. 


\section{Chapter}

\section{Is it economically viable to employ the nurse practitioner in general practice?}

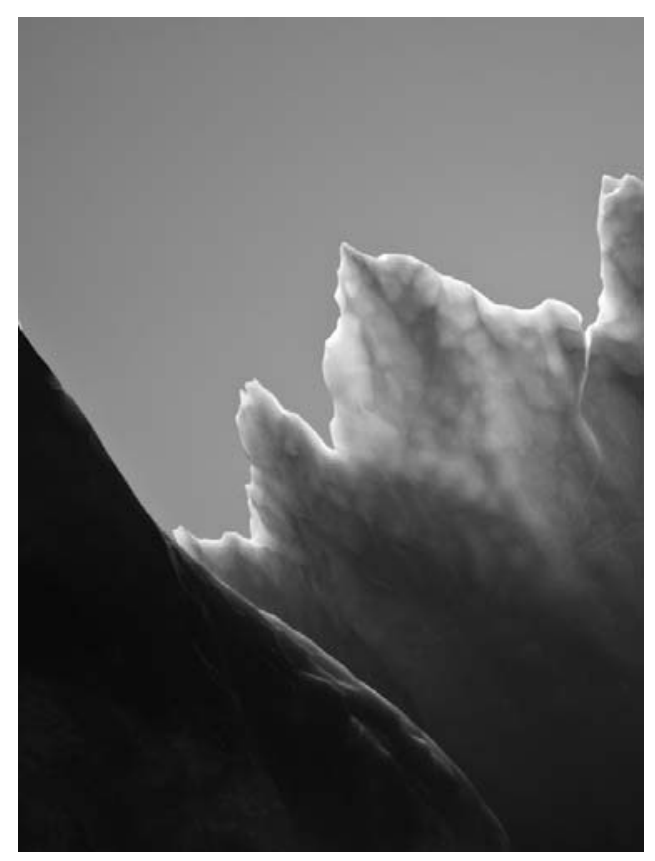

A.T.M. Dierick-van Daele, L.M.G. Steuten, A. Romeijn, E.W.C.C. Derckx, H.J.M. Vrijhoef 


\section{Abstract}

Background and objective. General practitioners face the challenging task of finding the most efficient and effective mix of professionals in general practice to accommodate future care demands within scarce health care budgets. To enable informed decision making about skill mix issues, economic information is needed. This article provides insight in the potential economic viability of nurse practitioner (NP) employment in Dutch general practices.

Discursive paper. A descriptive and explorative design was chosen to study the economic viability of nurse practitioner employment in general practice. The conditions under which the nurse practitioner is able to earn back his/her own cost of employment, were identified. Preferences and expectations of general practitioners and Health insurers about nurse practitioner reimbursement were made transparent.

Results. Although general practitioners and Health insurers acknowledge the importance of the nurse practitioner in accommodating primary care demands, they have polarized views about reimbursement. The employment of nurse practitioners is seldom economically viable. It requires a reallocation of ( $80 \%$ of) the general practitioner's freed up time towards practice growth (12\% patients). Conclusion. The economic viability of the NP has proven difficult to achieve in every day health care practice. This study provided insight into the complex interaction of the (cost-) parameters that result in economic viability and feeds a further discussion about the content of the NP role in general practice based on optimal quality of care versus efficiency.

Relevance to clinical practice. Effective and efficient health care can only be provided if the actual care needs of a population provide the basis for deciding which mix of professionals is best equipped to deal with the changing and increasing demand of care. A macro level intervention is needed to help a broad scale introduction of the NP in general practice.

Keywords. Economic perspective, nurse practitioner, general practice, substitution, skill mix. 


\section{INTRODUCTION}

A large variety of health care professionals are working in the health care system. History and tradition over the years have determined how tasks and responsibilities are divided between these professionals. However, the increased pressure on health care services due to major demographic, epidemiological, socio-cultural, societal, scientific and technological developments have led to a rearrangement of traditional role boundaries between staff groups. A recent example is the nurse practitioner (NP). NPs have been working within the Dutch health care context since 1997. The large majority of them are employed in hospitals. The NP has only recently been introduced to primary care in the Netherlands, with the purpose to increase service capacity and improve access to primary care.

To create an evidence base for the efficiency and effectiveness of this new professional in primary care, an extensive 5 year evaluation study (NPGP study; NP in general practice) was set up (Derckx, 2005, 2006). This article, as part of the NPGP study, focuses on questions concerning the economic viability of NP employment in general practice (from a general practice perspective). As general practitioners increasingly face the challenging task of finding the most efficient and effective mix of professionals in general practice to accommodate future care demands within scare health care budgets, economic information is needed to support informed decision making.

The aim of this article is to identify the conditions under which the NP is able to earn back his/her own cost of employment through productivity (consultations) or capacity (patients) increase. A second aim was to clarify perceptions and expectations of central stakeholders - GPs and Health insurers with respect to this topic.

\section{Background}

Many studies have focussed on the effectiveness of the NP. A systematic review of studies in primary care (Horrocks et al., 2002), found evidence that NP consultation is likely to lead to high levels of patient satisfaction and high quality of care. Other studies found that nurse(s) (practitioners) give more information (Shum et al., 2000) and more advice on self care and management (Shum et al., 2000; Kinnersley et al., 2000). Similar results were found regarding health status (Kinnersley et al.; 2000, Mundinger et al. 2000; Lenz et al., 2004) the number of prescriptions ordered (Venning et al., 2000; Kinnersley et al., 2000), and health services utilisation (Mundinger et al., 2000; Lenz et al., 2004). These results mostly represent health care practices in Great Britain and the US, where the NP role has been expanded and diversified, since its introduction in the sixties. Given the considerable differences between countries in autonomy of NPs (Offredy and Townsend, 2000), level of education of NPs, and characteristics of health care systems, there is a need for more comparative research about the role and potential value of NPs from other countries. 
The NPGP study was the first of its kind in the Netherlands. The study entailed an evaluation of process and outcomes of care provided to patients with common complaints by GPs or specially trained NPs as first point of contact. It confirmed previous study outcomes that in treating patients with common complaints, NPs provide equal quality of care as GPs (Dierick et al., 2009). Questions surrounding efficiency, however, remained. Previously, several authors (McGrath, 1990; Richardson, 1999; Horrocks et al., 2002; Laurant et al., 2004; Dierick et al., 2008) emphasized the lack of attention for the economic viability of NPs and stressed the methodological limitations of studies concerned. One recent economic analysis concluded that employing a NP in primary care in the United Kingdom (UK) is likely to cost much the same as employing a salaried GP (Hollinghurst et al., 2006). Yet, the inconsistent use of the term 'NP', the different contexts in which the studies took place, the variety in case mix, tasks, education and experience of the NPs, as well as the differences in economic methods used, hamper direct comparability and broader generalizability of these study's outcomes. In the Dutch context the NPGP study was the first to compare NP versus GP costs (Dierick et al., 2010). The authors concluded that NPs can provide care at lower costs.

When focusing on the introduction of the NP in general practice from an economic perspective, it is important to know whether or not the NP is used as a replacement for a doctor and/ or if the NP is added to an existing general practice team. If, given the growing and changing demands in health care, general practices are faced with a decision which professional to add to their practice, economic information is needed to unveil under which specific conditions it is economically viable to employ such a professional. Such information has been lacking and should go beyond the "standard" costeffectiveness comparison of NP versus GP costs. In the NPGP study, the main prerequisite has always been that the NP should be able to earn back his/her own cost of employment by means of an increase in production (number of consultations) and/or capacity (number of patients) in general practice (Derckx, 2005, 2006). From a general practice perspective, adding a NP should result in at least cost-neutral employment.

Several stakeholders play a role in the introduction of NPs in general practice. The triangular relationship between health care consumer, health care provider and health care insurance company (Van der Maas and Mackenbach, 1999) was identified as the main framework for describing the cost and reimbursement of NP employment in Dutch general practice (Figure 1). The Dutch Ministry of Health has a steering role when it comes to new developments in health care. Yet, despite the Ministry's responsibility for adequate quality, accessibility and affordability of care, no particular initiatives have been taken so far to tackle problems related to reimbursement of new professionals in health care. 


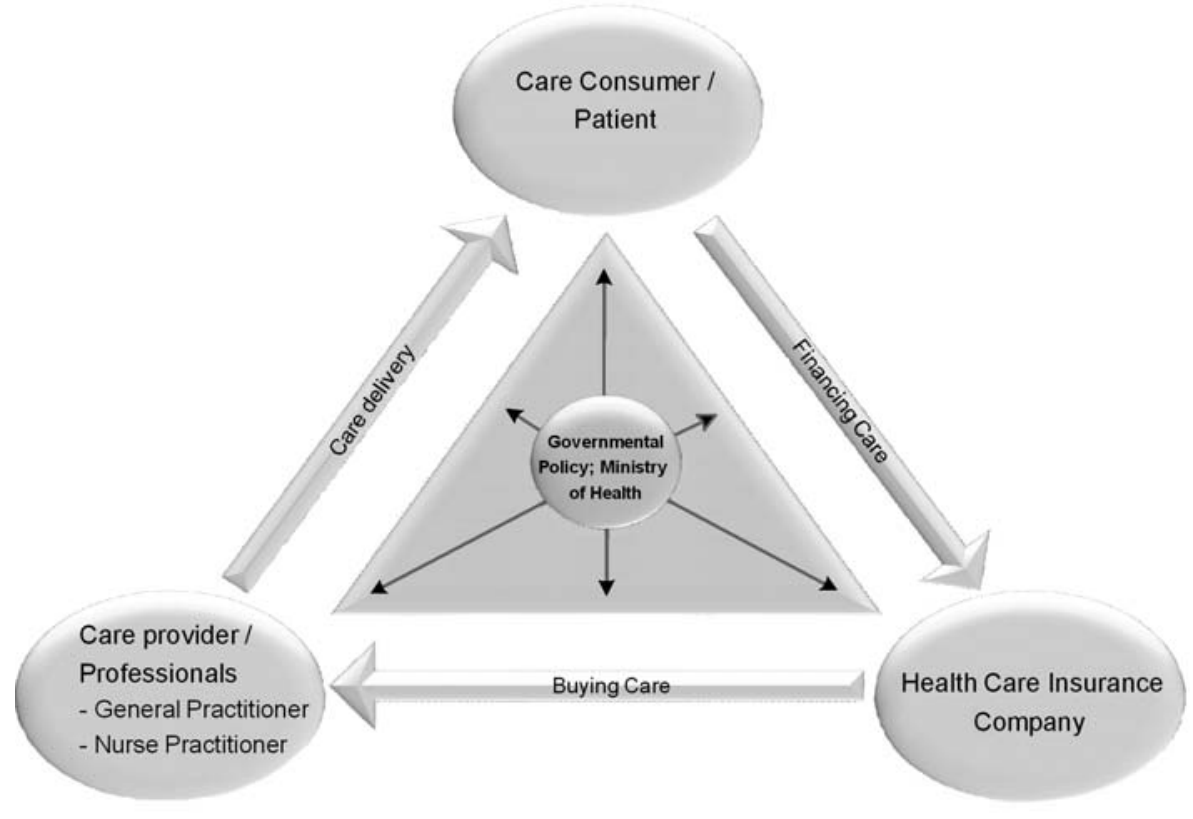

Figure 1 The Stakeholdermodel (Van der Maas and Mackenbach, 1999)

\section{THE PRESENT PAPER}

Given the nature of the study objectives, a descriptive, explorative, study design was chosen and carried out in 2008. Data collection and data analysis were of a quantitative nature. The full operational population of GPs employing a NP $(\mathrm{N}=132)$ and Health insurers $(\mathrm{N}=12)$ in the Netherlands received the first questionnaire asking for their preferences and expectations of NP employment and reimbursement. To calculate the economic viability of NP employment, the conditions under which the NP would be able to earn back his/her own cost of employment, i.e. by increasing productivity (consultations) or capacity (patients), were identified by using parameter inputs as collected from the first questionnaire. A second questionnaire confronted both GPs and Health insurers with the most relevant outcomes. The questions were related to the respondent's acceptability of the study outcomes and the perceived feasibility of the percentage of practice growth that is suggested.

Questionnaire data were analysed in SPSS software 16.0 (SPSS, Chicago, IL)(descriptive statistics; t-tests, $\mathrm{p} \leq 0.05$; and Pearson's chi-square tests). Respondents with more than $10 \%$ missing values were excluded from the analysis. For those cases with less than $10 \%$ missing values, the missing value was replaced by an average item score of the applicable respondent group. 
When estimating the economic viability of the NP, several parameters need to be taken into account. The perspective taken in any economic evaluation determines the (cost-) parameters that need to be considered. In this study, a general practice perspective was taken, which means that costs of training are excluded as these are considered to be only relevant when taking a societal perspective (Hollinghurst et al., 2006). A literature review accomodated the identification of the parameters to be included in the economic model in order to estimate the economic viability of NP employment (Table 1).

Table 1 Parameters included in the economic model

\begin{tabular}{|c|c|c|c|c|}
\hline Parameter & Input value (\#) & Source & $\begin{array}{l}\text { Range initial } \\
\text { 1-way sensitivity } \\
\text { analysis }(\wedge)\end{array}$ & $\begin{array}{l}\text { Final model } \\
\text { sensitivity } \\
\text { analysis/test range }\end{array}$ \\
\hline $\begin{array}{l}\text { FTE (Full-time } \\
\text { equivalent) general } \\
\text { practitioner, and } \\
\text { working hours per } \\
\text { FTE }\end{array}$ & $\begin{array}{l}1 \text { FTE GP }=45 \text { hrs / } \\
\text { week; Hours on call duty } \\
=5 \text { hrs / week; Working } \\
\text { weeks }=45 \text { / year } \\
\text { FTE GP in average } \\
(\mathrm{n}=10) \text { practice: } 2,8 \text { FTE }\end{array}$ & $\begin{array}{l}\text { (van de Berg et } \\
\text { al., 2004) } \\
\text { Questionnaire }\end{array}$ & Fixed & Fixed \\
\hline $\begin{array}{l}\% \text { Patient related } \\
\text { hours of general } \\
\text { practitioner }\end{array}$ & $70 \%$ & Questionnaire & Fixed & Fixed \\
\hline $\begin{array}{l}\text { Gross revenue } \\
\text { general practice } \\
\text { (Euro) per year } \\
\text { (excl. standard } \\
\text { practice cost) }\end{array}$ & $\begin{array}{l}\text { Total gross revenue: } € \\
760,029 \text { / year } \\
\text { Estimated gross practice } \\
\text { cost: } 51 \% \text { of total gross } \\
\text { revenue }\end{array}$ & $\begin{array}{l}\text { Questionnaire } \\
\text { (www.ctg-zaio.nl) }\end{array}$ & Fixed & Fixed \\
\hline $\begin{array}{l}\text { Number of patients } \\
\text { in general practice } \\
\text { (based on the mean } \\
\text { of } 2,8 \text { FTE general } \\
\text { practitioner per } \\
\text { practice) }\end{array}$ & 6,603 patients & Questionnaire & Fixed & Fixed \\
\hline $\begin{array}{l}\% \text { Substitution } \\
(\% \text { of patient } \\
\text { related + non- } \\
\text { patient related tasks } \\
\text { from general } \\
\text { practitioner to } \\
\text { nurse practitioner ) }\end{array}$ & $15 \%$ & Questionnaire & Range $10-60 \%$ & Fixed \\
\hline $\begin{array}{l}\% \text { Supervision } \\
\text { needed }\end{array}$ & $5 \%$ & Questionnaire & Range $4-15 \%$ & Fixed \\
\hline $\begin{array}{l}\text { Inefficiency } \% \\
\text { (consultation times } \\
\text { of nurse } \\
\text { practitioner are } \\
\text { longer than that of } \\
\text { general practitioner) }\end{array}$ & $33 \%$ & Questionnaire & $20-100 \%$ & Fixed \\
\hline $\begin{array}{l}\% \text { ratio of total } \\
\text { tasks of NP that } \\
\text { consists of } \\
\text { substituted tasks } \\
\text { and complementary } \\
\text { tasks }\end{array}$ & $\begin{array}{l}\text { Substitution tasks: } 77 \% \\
\text { Complementary tasks: } \\
23 \%\end{array}$ & $\begin{array}{l}\text { Questionnaire } \\
\text { Questionnaire }\end{array}$ & $\begin{array}{l}50-100 \% \\
0-50 \%\end{array}$ & Fixed \\
\hline
\end{tabular}


Table 1 Continued

\begin{tabular}{|c|c|c|c|c|}
\hline Parameter & Input value (\#) & Source & $\begin{array}{l}\text { Range initial } \\
\text { 1-way sensitivity } \\
\text { analysis }\left({ }^{\wedge}\right)\end{array}$ & $\begin{array}{l}\text { Final model } \\
\text { sensitivity } \\
\text { analysis/test range }\end{array}$ \\
\hline $\begin{array}{l}\text { NP Salary cost per } \\
\text { year (per } 1 \text { FTE = } \\
38 \text { hrs/week in } \\
\text { Euros) }\end{array}$ & $€ 59,426$ & Questionnaire & Fixed & Fixed \\
\hline $\begin{array}{l}\text { FTE and working } \\
\text { hours of NP }\end{array}$ & $\begin{array}{l}1 \text { FTE NP }=38 \text { hrs } \\
\text { /week; Vacation: } \\
166 \text { hrs; National } \\
\text { holidays = } 7 \text { days; } \\
\text { Sickness absence: } 5 \% \\
\text { FTE NP in average } \\
(\mathrm{N}=10) \text { practice: } 0,6 \\
\text { FTE }\end{array}$ & $\begin{array}{l}\text { Questionnaire } \\
\text { (Collective } \\
\text { Employment } \\
\text { Agreement } \\
\text { General } \\
\text { Practitioners } \\
\text { 2005) }\end{array}$ & Fixed & Fixed \\
\hline $\begin{array}{l}\text { Use of freed up } \\
\text { time by general } \\
\text { practitioner, split in: } \\
\% \text { patient related } \\
\text { tasks, (regular } \\
\text { complexity and } \\
\text { higher complexity), } \\
\% \text { non-patient } \\
\text { related tasks, } \\
\% \text { free time }\end{array}$ & $\begin{array}{l}\% \text { time patient related } \\
\text { tasks, regular complexity: } \\
27 \% \\
\% \text { time patient related } \\
\text { tasks, higher complexity: } \\
15 \% \\
\% \text { time non-patient } \\
\text { related tasks: } 45 \% \\
\% \text { free time: } 13 \%\end{array}$ & Questionnaire & $0-100\left(^{*}\right)$ & $\begin{array}{l}\text { Threshold } \\
39-100 \%\left(^{*}\right)\end{array}$ \\
\hline
\end{tabular}

(\#) Questionnaire results represent average score based on $\mathrm{N}=10$ (general practices)

$(\wedge)$ Range based on literature data and actual questionnaire outcomes.

(*) Patient related tasks (with same complexity)

Five main assumptions underlie the economic model: 1) growth of the general practice is possible. This assumption allows for calculating what percentage of growth is necessary for the NP to earn back his/her cost of employment; 2) the employment of the NP does not generate a significant structural increase of expenditure of the amount of the yearly general practice cost; 3) the NP's availability in general practice is guaranteed (available when needed); 4) the quality of care of the NP is equal to that of the GP (Dierick et al., 2009); 5) resource utilization of the NP in terms of the number of return visits, prescriptions, additional diagnostic tests, referrals, is equal to that of the GP (Dierick et al., 2009).

The starting point of the economic model is a general practice for which the total number of GPs (full-time equivalent; FTE GP), number of patients and general practice gross revenue is described, based on the price year 2007. The revenue is then re-estimated to represent a value of gross revenues as if the NP was not yet employed in this practice. Based on the percentage of patient related tasks performed by the GP, the total time that is spent on patient care is estimated, as well as revenues per patient. Next, based on data found in the questionnaire with respect to substitution of tasks (sum of both patient related and non-patient related tasks), it is estimated how much patient related time 
could be transferred to a NP if the GP should decide to employ this professional in his/her practice. Taking into account the time needed for supervision, the inefficiency ratio of the NP (the NP's consultation time is longer than that of the GP) as well as the fact that the NP does not spend $100 \%$ of his/her time on patient related tasks, an estimation is made of the actual hours that a NP can spend on patient related tasks and the full-time equivalent (FTE) NP that is needed for these activities. Subsequently, the cost of the NP in terms of annual salary is introduced into the model. Finally, the fact that not all GPs dedicate the freed up time, as accrued by substituting tasks to the NP, for $100 \%$ to patient care is taken into account. This is a crucial factor, since it affects the possible growth of the general practice. The model outcome is the difference between the growth in revenue of the practice, minus the cost of the NP. This metric indicates the percentage of general practice growth that is currently achieved and the net gain or loss associated with this.

To deal with uncertainty in relation to data inputs, and to attempt to increase the generalizability of the study, the economic viability was estimated by means of a one way sensitivity analysis and a threshold analysis in Excel 2003 (Briggs et al., 1994).

First, a one way sensitivity analysis was performed to identify the parameters that influence the economic viability of the NP the most. The variables of importance, as well as the variety range applied in the one way sensitivity analysis, were chosen based on what literature considers to be relevant and feasible. These variables were, percentage of substitution (Richardson, et al., 1998; Bussemakers 2005a/b), percentage of supervision (Mc. Grath, 1990; Richardson et al., 1998; Bussemakers 2005a/b), the percentage of inefficiency (Laurant et al., 2004; Richardson, 1999; Dierick et al., 2009), \% ratio of total tasks of NP that can truly be considered substituted tasks and/or complementary tasks (Richardson et al., 1998) and the use of freed up time by GPs (Richardson, 1999; RVZ, 2002).

Next a threshold analysis was performed. Goal variables were practice growth in terms of patients and subsequent reallocation of GP's freed up time needed to achieve both a cost-neutral (NP is economic viable) or revenue scenario. By setting the net added result to zero we simulated the necessary practice growth and the needed allocation of freed up GP time (in terms of patient care, same complexity). To calculate the maximum potential revenue, we set the reallocation of freed up GP time to $100 \%$ (all of the freed up time goes towards practice growth) and we simulated the assumed practice growth.

Data-analysis showed the following outcomes relevant in the discussion about the economic viability of the NP. Response rates for the first questionnaire were 46\% among GPs and 58\% among Health insurers. Under the current financial structure, three out of 17 general practices are able to fully earn back the cost of NP employment. In all other practices, NP employment is not (yet) economically viable. In those practices, either no additional reimbursements are available 
$(n=4)$, practice nurse reimbursements are used for NPs employment $(n=7)$ or some other form of reimbursements are used such as a partial replacement of GP ( $n=3)$. The preferences and expectations of GPs $(\mathrm{N}=61)$ and Health insurers $(\mathrm{N}=7)$ regarding NP employment and reimbursement are shown in Table 2.

Table 2 Average scores GPs and Health insurers per statement

\begin{tabular}{|c|c|c|}
\hline Item* & $\begin{array}{l}\text { Health } \\
\text { insurers } \\
\mathrm{N}=7 \\
\text { Mean (SD) }\end{array}$ & $\begin{array}{l}\text { GPs } \\
\begin{array}{l}\mathrm{N}=61 \\
\text { Mean (SD) }\end{array}\end{array}$ \\
\hline I see possibilities for NP reimbursement by using additional practice income & $-0.43(1.62)$ & $-0.11(1.27)$ \\
\hline $\begin{array}{l}\text { I think that Health insurers will reimburse NP if NP can't fully earn back own } \\
\text { employment cost }\end{array}$ & $-0.43(0.98)$ & $-0.03(1.15)$ \\
\hline I am willing to contribute to NP reimbursement within my own practice $\dagger$ & $0.86(0.69)$ & $0.03(1.33)$ \\
\hline There should be a separate tariff for the NP & $0.71(1.38)$ & $0.25(1.36)$ \\
\hline $\begin{array}{l}\text { Sufficient growth of my practice is possible so that NP can earn back } \\
\text { employment cost }\end{array}$ & $0.14(0.69)$ & $0.26(1.18)$ \\
\hline $\begin{array}{l}\text { I do not object to growth of my practice, to allow NP to earn back employment } \\
\text { cost }\end{array}$ & $0.57(1.27)$ & $0.34(1.45)$ \\
\hline $\begin{array}{l}\text { The government should play a more active role in solving issues related to NP } \\
\text { reimbursement }\end{array}$ & $-0.14(1.57)$ & $0.75(0.98)$ \\
\hline $\begin{array}{l}\text { NP reimbursement can best be realized by letting NP earn back own } \\
\text { employment cost }\end{array}$ & $1.43(1.13)$ & $0.90(1.11)$ \\
\hline It is the responsibility of Health insurers to reimburse the NP $\dagger$ & $0.00(1.29)$ & $0.97(1.02)$ \\
\hline $\begin{array}{l}\text { I would welcome the idea to use the additional practice income originally meant } \\
\text { for practice nurses, for NP employment/reimbursement }\end{array}$ & $0.71(0.95)$ & $1.02(1.15)$ \\
\hline Other GPs will employ a NP, if it leads to financial benefits & $0.71(0.95)$ & $1.18(0.70)$ \\
\hline $\begin{array}{l}\text { A broad budgeting system should allow general practices to select personnel } \\
\text { based on care demand } \dagger\end{array}$ & $-1.00(1.15)$ & $1.49(0.72)$ \\
\hline $\begin{array}{l}\text { The NP has a role in creating primary care that is able to deal with future care } \\
\text { demands }\end{array}$ & $1.43(0.79)$ & $1.51(0.83)$ \\
\hline
\end{tabular}

*5- points Likert-scale: -2 : totally disagree; 2 : totally agree

† Significant differences Health insurers versus GPs $(\mathrm{p}<0.05)$

Both stakeholders indicate that the NP has an important role in accommodating future care demands in primary care and that the NP could best be financed by making sure that the NP is able to (at least) earn back his/her own cost of employment. GPs further indicated that they would like the existing reimbursements for practice nurses to be extended to NPs. Table 2 also shows that GPs perceive Health insurers to be responsible for the reimbursement of the NP if they want this professional to become a structural provider of primary care. Health insurers have a significantly different $(p=0.023)$ opinion on this topic and meanwhile overestimate GPs' willingness to contribute to NP reimbursement $(\mathrm{p}=0.021)$. Furthermore, whereas GPs would welcome a general budget, allowing them to decide for themselves which type of professional to employ based on the demand of care; Health insurers are united in their opinion against this. $(\mathrm{p}<0.001)$.

Table 3 shows the estimated economic viability of NP employment, based on 
data from ten general practices, including small (solo/duo) general practices $(n=4)$ and (group) general practices $(n=6)$. The current situation as well as the practice growth conditions needed to achieve a cost-neutral or revenue generating scenario are presented.

Table 3 Economic viability NP employment

\begin{tabular}{|c|c|c|c|}
\hline & $\begin{array}{l}\text { Average general } \\
\text { practice }(\mathrm{N}=10)\end{array}$ & $\begin{array}{l}\text { Small(solo/duo) } \\
\text { general practice } \\
(\mathrm{N}=4)\end{array}$ & $\begin{array}{l}\text { Large(group) } \\
\text { general practice } \\
(\mathrm{N}=6)\end{array}$ \\
\hline \multicolumn{4}{|l|}{ Current situation } \\
\hline Net added result variable general practice revenue & $€ 27,342-$ & $€ 7,706-$ & $€ 43,603-$ \\
\hline Allocation freed up time practice towards growth $(*)$ & $27 \%$ & $25 \%$ & $28 \%$ \\
\hline Assumed practice growth (in terms of patients) & $4 \%$ & $4 \%$ & $4 \%$ \\
\hline \multicolumn{4}{|l|}{ Neutral net added result for revenues } \\
\hline Net added result variable general practice revenue & $€,-$ & $€,-$ & $€,-$ \\
\hline Allocation freed up time practice towards growth $(* *)$ & $80 \%$ & $56 \%$ & $92 \%$ \\
\hline Assumed practice growth (in terms of patients) & $12 \%$ & $8 \%$ & $13 \%$ \\
\hline \multicolumn{4}{|l|}{ Maximal net added result revenues } \\
\hline Net added result variable general practice revenue & $€ 9,975$ & $€ 11,074$ & $€ 5,355$ \\
\hline Allocation freed up time practice towards growth $\left({ }^{* *}\right)$ & $100 \%$ & $100 \%$ & $100 \%$ \\
\hline Assumed practice growth (in terms of patients) & $15 \%$ & $15 \%$ & $14 \%$ \\
\hline
\end{tabular}

$\left(^{*}\right)$ Reallocated towards patient care (same complexity), reallocation towards more complex patients not included

(**) Calculated in terms of patient care with same complexity only

On average, NP employment is currently not economically viable. This is expressed by the negative value of the gross revenue. The initial one way sensitivity analysis, followed by the threshold analysis, showed that this economic loss is mainly due to the relatively low allocation of freed up time of GPs towards practice growth. In the average general practice, $27 \%$ of the freed up time is used for practice growth. Furthermore, 15\% of the freed up time is used for quality improvement (treating more complex patients). A relatively high percentage of the freed up time $(45 \%)$ is allocated towards more non-patient related activities, and $13 \%$ towards leisure time.

In an average-sized practice, NP employment would be cost-neutral when 12\% practice growth is realised in terms of number of registered patients. To achieve this, $80 \%$ of the freed up time should be allocated towards practice growth. The required practice growth however depends on the size of the general practice and is lower in small (solo/duo) practices and higher in group practices. In small practices a growth of $8 \%$ would suffice to arrive at a cost-neutral employment of the NP. For this $56 \%$ of GP freed up time should be allocated towards practice growth. In group practices, a growth of $13 \%$ in number of registered patient is required to pay-off NP employment, which demands a reallocation of $92 \%$ of freed up time towards practice growth only.

In an ideal situation, in which the general practices allocate $100 \%$ of the freed up time towards practice growth, the net added revenue achieved amounts to an 
average of $€ 9,975$ Euro. This scenario translates in $15 \%$ practice growth in terms of registered patients.

Although the small $\mathrm{N}(\mathrm{N}=10)$ calls for caution in drawing conclusions, further analysis was performed to try to explain the difference in outcomes between small (solo/duo practices $\leq 2$ FTE GP) versus larger (group practices; $>2$ FTE GP). This analysis showed that the average gross revenue per FTE GP (after deduction of cost for practice personnel; NP, general practice nurse, general practice assistant) is higher in small versus larger practices. A crude correlation analysis confirms that smaller practices (in terms of FTE GPs) seem to economically perform better than larger practices. The practice revenue minus salary cost of practice personnel per FTE GP correlates significantly and negatively (corr: -0.752, sign 2-tailed: 0.012) with FTE GP.

The general practices that economically perform better than others, do so without a significant difference in consultations per patient (mean: 3 consultations per patient per year). Correlation analysis also shows that the number of consultations per FTE NP is negatively correlated to the number of patients (corr: -0.641, sign. 2-tailed: 0.046) in general practice and positively correlated to the revenue per patient (corr: 0.719, sign. 2-tailed: 0.019). To summarize; smaller general practices are able to generate more revenue per patient without a significant higher number of consultations.

Finally, when looking at the production parameters of the NP, the following picture emerges. In the average practice $(n=10), 77 \%$ of the NP's time is spend on substituted tasks, $23 \%$ on complementary tasks. In smaller practices this differs, a higher percentage of NP tasks consists of substituted tasks (85\%), leaving less room for complementary tasks (15\%). In group practices this ratio of substituted versus complementary tasks is $72 \%$ versus $28 \%$. Inefficiency of the NP (longer consultation time of NP versus GP) is lower in smaller practices (on average $30 \%$ in smaller practices versus 34\% in larger practices), the number of consultations per FTE NP is higher (on average 4329,6 per FTE NP per year in small practice versus 3003,2 per FTE NP per year in larger practices).

When confronting GPs and Health insurers with the main study outcomes and requesting their comments (response rates: 35\% GPs; 58\% Health insurers) both stakeholder groups acknowledge that the cost-neutral scenario for NP employment is currently seldom achieved in general practice. The estimation that $80 \%$ of the GP's freed up time should be reallocated towards practice growth in order to achieve such a cost-neutral scenario, is accepted as accurate by the majority of the respondents. GPs tend to be slightly more negative than Health insurers about the feasibility of the required $12 \%$ practice growth for achieving a cost-neutral employment scenario. GPs would also like to see all NP tasks reimbursed. Currently $23 \%$ of NP tasks are complementary; these include tasks that are not previously performed by the GP, but are considered important to improve the quality of the care. These activities are often related to education, 
quality improvement projects or research. Health insurers significantly disagree $(p<0.001)$ with this opinion.

\section{Discussion}

As GPs increasingly face the challenging task of finding the most appropriate mix of professionals for their general practice, questions about the economic viability and reimbursement of the NP in general practice can no longer be ignored. Although GPs and Health insurers argue that, ideally, the NP should be able to earn back his/her own cost of employment, this is seldom the case. This study has shown that NP employment can be economically viable, if the majority of GP freed up time (i.e. $80 \%$ on average) is reallocated to achieve the $12 \%$ practice growth needed to pay-off NP employment costs. This study has also shown some indications that smaller general practices economically perform better than larger practices, but more research is needed to confirm these findings.

The model for estimating economic viability, was based on the hypothesis that practice growth is possible. Nevertheless, practice growth is variable and depends on many factors such as practice characteristics, demand of care and the number of general practices situated in the same region. GPs are sceptic towards the growth potential of their general practice. Their scepticism is geared by doubts as to the actual growth of care demands that can be expected in their region. In addition, not all GPs are willing to increase practice size, regardless of increased demand. Health insurers do not perceive practice growth to be such an obstacle. The national estimations (Capacity group, 2008) suggest that the overall demand of care in general practice will increase in the next decade with $16 \%$ to $32 \%$. Although the broad range of the estimations leaves room for uncertainty, the required increase of on average $12 \%$ to break-even on NP employment costs is well beyond the lower limit of this estimation. Moreover, the maximum estimated practice growth achievable by NP-employment of $15 \%$ (i.e. when $100 \%$ of freed up time is reallocated to practice growth), would be insufficient to meet the lowest estimate of increased care demand. Nevertheless, whenever for any reason sufficient growth is not (yet) realized, then stakeholders' willingness to contribute to some form of additional reimbursement becomes relevant. Both GPs and Health insurers have different views about each others' responsibility in this matter. GPs would welcome a reimbursement system allowing them the freedom to choose for themselves which professionals to employ. Ideally, they would like all NPs activities to be integrated in the reimbursement system. Currently, only substituted patient related tasks generate income for the general practice. Furthermore, differences found in economic revenue and use of the NP in smaller versus larger general practices (higher NP production, higher percentage of substituted and lower percentage of complementary NP tasks in smaller practices), prompts a 
discussion about what the tasks and responsibilities of the NP ideally should be both from a quality and efficiency perspective. From an economic perspective a narrow focus on only substituted tasks might be preferred, as it generates income. However, we have seen that on average a large proportion of the NP tasks consists of complementary tasks (23\%), which are currently not reimbursed. These tasks are often tasks that GPs feel are of importance, in order to enhance quality of care in their practice, but which they themselves were unable to take on due to their demanding workload. If primary care wants to be prepared for the growing demand for care, it might just be that sustaining the quality of this care is largely linked to upfront investment in these complementary tasks. On the other hand, the study results provide some indication that in some general practices more efficiency can be achieved without a loss of quality by taking a closer look at the current mix of nursing/supportive staff available.

GPs have indicated that they would like differences in reimbursements between professionals in general practice resolved. The fact that Health insurers offer additional reimbursement for practice nurses but not for NPs, might provide a false incentive for GPs in their choice for a new professional. Unless this is resolved, primary care might find itself insufficiently equipped with a suboptimal mix of professionals for dealing with future care demands. Health insurers overestimate the GPs' willingness to contribute to NP reimbursement and are reluctant to adjust the current reimbursement system to allow for additional NP reimbursement.

\section{CONCLUSION}

The economic viability of the NP has proven difficult to achieve in every day health care practice. Yet, our model estimations indicate that NP employment can be economically viable, if the majority of GP freed up time (i.e. $80 \%$ on average) is reallocated to achieve the $12 \%$ practice growth needed to pay-off NP employment costs. This study provided insight into the complex interaction of the (cost)parameters that result in economic viability and feeds a further discussion about the content of the NP role in general practice based on optimal quality of care versus efficiency as well as a need to look at the optimal mix of professionals in general practice.

\section{Relevance to clinical practice}

The challenges that the Dutch primary health care system faces with respect to the introduction of the NP in general practice are not unique. Internationally innovations with respect to skill mix and disease management are often met with enthusiasm but broad scale implementation is hampered because a clear implementation policy on a national scale is lacking. Now that more and more scientific evidence about both efficiency and effectiveness of the NP in general 
practice is becoming available, questions about implementation, task contents and reimbursement of new professionals should be resolved. Effective and efficient health care can only be provided if the actual care needs of a population provide the basis for deciding what mix of professionals is best equipped to deal with the changing and increasing demand of care. Against this background, existing reimbursement structures and skill mix policies have to be evaluated and if necessary reformed. The British context, for example, is not that different from the Dutch. Their financial incentive structure for GPs (i.e. the Quality and Outcomes Framework) is geared towards encouraging higher quality care for patients (Ashworth and Millet, 2008). This policy can be an example for the Dutch health care system. Those GPs who have demonstrated to be successful in employing optimal skill mix to achieve an efficient and effective care, should be considered for a remuneration (Leatherman et al., 2003).

With stakeholders' polarized views on the topic of NP reimbursement, a macro level intervention from policy makers such as the Department of Health seems into place. The Department of Health should translate its acknowledgement of the importance of the NP role in primary care (Ministry of Health, 2008) into action. In order to secure affordability, accessibility and uniformity in quality of care, the government should urge stakeholders on a national level (National GP Association and Dutch Association of Health insurers) to try to come to a uniform policy, including stimuli to organize patient care efficiently and effectively, and a long term vision with respect to skill mix in relation to demand of care. With the increasing complexity of general practice, attention is needed to improve the management of general practice (e.g. training of management skills). If not, local differences with respect to both quality of care and reimbursement of skill mix will increase and unjustified reimbursement differences between nursing staff in general practice will continue to exist. To facilitate a change process, dissemination of research evidence, as provided by our study, and best practices is necessary.

The descriptive and explorative nature of this study calls for additional research, so that the results found in this study can be validated. Future research with a larger sample size and in different contexts is needed to confirm these results and to identify potential covariates that influence this preliminary finding. Given the complexity of this type of research, as well as the variety of interests of the stakeholders involved, a combination of both quantitative and qualitative studies might be the best way forward.

Finally, we recommend future research and international comparisons -e.g. United Kingdom and the Netherlands-, where the role of GPs, is comparable, to see whether these findings sustain in a larger sample size and over a longer period of time. Such a study should focus on identifying the most efficient and effective mix of professionals in general practice, to accommodate present and future care demands (Bussemakers, 2007; Hollinghurst et al., 2006). 


\section{REFERENCES}

1. Ashworth M, Millett C. Quality improvement in the UK Primary Care, the role of financial incentives. Journal of Ambulatory Care Management 2008; 31 (3): 220-25.

2. van den Berg MJ, Kolthof ED, de Bakker DH, van der Zee J. The Second National Study related to diseases and interventions in health care; the worklouad of general practitioners. Tweede Nationale Studie naar ziekten en verrichtingen in de huisartspraktijk. De werkbelasting van huisartsen. Utrecht: NIVEL. 2004. (In Dutch)

3. Briggs A, Sculpher M, Buxton M. Uncertainty in the economic evaluation of health care technologies: the role of sensitivity analysis. Health Economics 1994; 3: 95-104.

4. Bussemakers HJJM. Substitution of skills in general practice. The effects of substitution on the need of (para-) medics and nurses. Leiden: STG 2005a. (In Dutch)

5. Bussemakers HJJM. Practice exceeds expectations, the nurse practitioner decreases the scarceness of general practitioners. Medisch Contact 2005b; 60, 763-66. (In Dutch)

6. Bussemakers HJJM. Skillmix. Interprofessional substitution and collaboration in general practices. Medisch Contact, 2007; 62, 1216-8. (In Dutch)

7. Capacitygroup. Capacity Plans 2008 for the Medical, Dental, Clinical technological, and Related Specialty Training Programs. Utrecht 2008. (In Dutch)

8. Derckx EWCC. Between Cure and Care. NP in general practice is economic viable. Medisch Contact 2005; 60, 1992-5. (In Dutch)

9. Derckx EWCC. The first NPs with a specialisation in primary care. TVZ 2006; 116: 26-30. (In Dutch)

10. Dierick- van Daele ATM, Spreeuwenberg C, Derckx EWCC, Metsemakers JFM, Vrijhoef HJM. Critical appraisal of the literature on economic evaluations of substitution of skills between professionals: a systematic literature review. Journal of Evaluation in Clinical Practice 2008; 14: 481-92.

11. Dierick- van Daele ATM, Metsemakers JFM, Derckx EWCC, Spreeuwenberg C, Vrijhoef HJM. NPs substituting for GPs in the care for patients with common complaints; a randomised controlled trial. Journal of Advanced Nursing 2009; 65: 391-401.

12. Dierick- van Daele ATM, Steuten LMG, Metsemakers JFM, Derckx EWCC, Spreeuwenberg C, Vrijhoef HJ. Economic evaluation of substituting NPs for GPs. British Journal of General Practice 2010; (60) 570: 28-35.

13. Hollinghurst S, Horrocks S, Anderson A, Salisbury C. Comparing the cost of NPs and GPs in primary care: modelling economic data from randomised trials. British Journal of General Practice 2006; 56: 530-5.

14. Horrocks S, Anderson E, Salisbury C. Systematic review of whether NPs working in primary care can provide equivalent care to doctors. British Medical Journal 2002; 324: 819-23.

15. Kinnersley P, Anderson E, Parry K, Clement J, Archard L, Turton, P, Stainthorpe A, Fraser A, Butler C, Rogers C. Randomised controlled trial of NP versus GP care for patients requesting "same day" consultations in primary care. British Medical Journal 2000; 320: 1043-8.

16. Leatherman S, Berwick D, Iles D, Lewin LS, Davidoff F, Nolan T, Bisognano M. The Business Case For Quality: Case Studies And An Analysis. Health Affairs 2003; 
22 (2): 17-30.

17. Laurant M, Reeves D, Hermens R, Braspenning J, Grol R, Sibbald B. Substitution of doctors by nurses in primary care. The Cochrane Database of Systematic Reviews. 2004 Issue 4.

18. Lenz ER, Mundinger MO, Kane RL, Hopkins SC, Lin SX. (2004) Primary care outcomes in patients treated by NPs or physicians: two-year follow-up. Medical Care Research and Review 2004; 61: 332-51.

19. McGrath S. The cost-effectiveness of NPs. Nurse Practitioner 1990; 15: 40-2.

20. Mundinger MO, Kane RL, Lenz ER, Totten AM, Tsai WY, Cleary PD, Friedewald WT, Siu AL, Shelanski ML. (2000) Primary care outcomes in patients treated by NPs or physicians: a randomized trial. JAMA, 2000; 283: 59-68.

21. Offredy M, Townsend J. Nurse practitioners in primary care. Family Practice 2000; 17:564-9.

22. Richardson G, Maynard A, Cullum N, Kindig D. Skill mix changes: substitution or service development? Health Policy 1998; 45: 119-32.

23. Richardson G. Identifying, evaluating and implementing cost-effective skill mix. Journal of Nursing Management 1999; 7: 265-70.

24. RVZ (Council for Public Health and Health Care). Substitution of skills in bealth care. Recommendations to the Ministry of Health. Zoetermeer: RVZ 2002. In Dutch)

25. Shum C, Humphreys A, Wheeler D, Cochrane, MA, Skoda S, Clement S. Nurse management of patients with minor illnesses in general practice: multicentre, randomised controlled trial. British Medical Journal 2000; 320: 1038-43.

26. Van der Maas PJ, Mackenbach JP. Public Health and Health Care. Maarssen: Elsevier Gezondheidszorg 1999. (In Dutch)

27. Venning P, Durie A, Roland M, Roberts C, Leese B. Randomised controlled trial comparing cost effectiveness of GPs and NPs in primary care. British Medical Journal 2000; 320: 1048-53.

28. Consulted websites

Ministry of Health. Reaction Minister of VWS, Ab Klink on Capacity Plan 2008. The Hague. www.minvws.nl/kamerstukken/meva/. (In Dutch) www.ctg-zaio.nl (website of the Dutch Health Care Authority) (In Dutch) www.nvnp.nl (website of the Dutch Nurse Practice Association) (In Dutch) 


\section{Chapter}

General Discussion

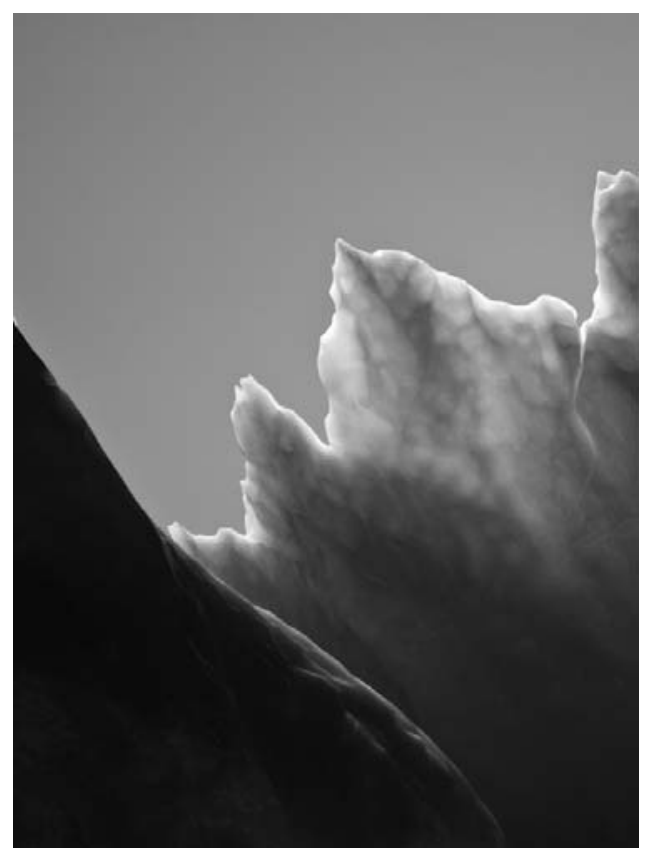


112 Chapter 7 


\section{INTRODUCTION}

The overall objective of this thesis was to evaluate the implementation of the Nurse Practitioner (NP) in the care for patients with common complaints. The study is divided in a process evaluation and an effect evaluation. The process evaluation aimed to explore the feasibility of the implementation of the NP in the care for patients with common complaints and the conditions needed (structure and process). The focus of the effect evaluation was to assess the quality and the (cost-) effectiveness of care provided by the NP in general practice.

This chapter summaries the main findings from the particular studies and the methodological strengths and limitations of the presented studies are discussed. The results from the patients perspective, providers perspective, organizational perspective, and from the perspective of policymakers are interpreted and finally recommendations for practice, policy and further research are described.

\section{GENERAL CONCLUSIONS}

The objectives and the main study results are described in this paragraph.

Objective 1: to identify economic evaluations of substitution between professionals, to assess the quality of the study methods applied and to value the evaluation results for decision making.

Main conclusion: eleven studies were included of 7,605 studies: three cost effectiveness studies, three cost minimisation studies, and five studies related to partial economic evaluations. Small numbers of participating professionals and several limitations in the cost valuation and the measurement of costs were identified. These limitations influence the validity and generalisability of the results. The relationship between structural, process and outcome variables when evaluating the cost-effectiveness of substitution of care is not sufficient investigated in the literature. For meaningfully placing the costs and consequences of substitution of skills in the context of health care and generating relevant data for decision making, it is strongly recommended to combine an economic evaluation (RCT) with an observational longitudinal study.

Objective 2: to explore the concordance of the NP roles with the initial concepts of the NP training program.

Main conclusion: all NPs provide care to patients with common complaints as main focus, as well as managing quality of care projects. The NP roles are in this way in concordance with the NP training program. Differences between NPs are reported in the percentages of their time spend to perform home visits, care for elderly, patient related activities, and non patient related activities. NPs contribute to the accessibility and availability of primary care as well as to the 
collaboration in and quality of primary care. The adopted roles are influenced by practice needs and financial incentives.

Objective 3: to evaluate the impact on process and outcomes of care provided by GPs and specially trained NPs for patients at first point of contact.

Main conclusion: patients assigned to NP care (intervention group) and patients assigned to GP care (reference group) highly appreciated the quality of care. No significant differences between the two groups were found in the quality of care in terms of health status, medical consumption and compliance with practical guidelines. Patients in the intervention group were more invited to re-attend, had more follow up consultations and their consultations took significantly more time. These findings support an increased involvement of specially trained nurse practitioners in the Dutch primary care and contribute to the knowledge on the effectiveness of care provision by NPs from a national and international perspective.

Objective 4: to estimate the costs of consultations by GPs or NPs from a practice perspective and a societal perspective.

Main conclusion: direct costs were significant less for NP consultations than for GP consultations within NPGP-practices. Direct costs of consultations by NPGP-practices were also significant less than those by external reference practices. By involving NPs in the care for patients with common complaints, substantial economic "savings" could be used for redesigning primary care, to optimize the best skill mix and to cover the full range of primary care activities.

Objective 5: to describe and explore the economic viability of NPs employed in general practices.

The conditions under which the nurse practitioner is able to earn back his/her own cost of employment, were identified. Preferences and expectations of general practitioners and Health insurers about nurse practitioner reimbursement were made transparent.

Main Conclusion: Although general practitioners and Health insurers acknowledge the importance of the nurse practitioner in accommodating primary care demands, they have polarized views about reimbursement. The employment of nurse practitioners is seldom economically viable. It requires a reallocation of ( $80 \%$ of) the general practitioner's freed up time towards practice growth $(12 \%$; patients). The economic viability of the NP has proven difficult to achieve in every day health care practice. This study provided insight into the complex interaction of the (cost-) parameters that result in economic viability and feeds a further discussion about the content of the NP role in general practice based on optimal quality of care versus efficiency. 


\section{Overall conclusion}

From this study it is concluded that care delivered by specially trained NPs for patients with common complaints is feasible and effective and costs less than usual care. With the transfer of these care activities being justified, the availability and accessibility of primary care can be safeguarded for the nearby future by the introduction of the NP in general practice in the Netherlands. However, the economic viability of the NP has proven difficult to achieve and a macro level intervention is needed to help a broad scale introduction of the NP in general practice.

\section{Conceptual framework}

For this study a conceptual framework (Sidani and Irvine, 1999) was chosen that represents the complex system of interrelated factors in the NP practice situation. By means of the study results we are able to elucidate and validate the original framework, taking into account the characteristics of practices and other, existing professionals and their levels of role formalization (Figure 1). The introduction of a new professional, like the NP, affects the roles of other professionals in general practice and the adjustment between roles have to be reconsidered to achieve an effective collaboration between professionals. Therefore, all patient related activities and non-patient related activities have to be described (process). To achieve effective and efficient care provided by a team of professionals in general practice, process and structure variables should be redesigned and evaluated in terms of the quality of care and (cost-) effectiveness. The government, health insurers and professional organizations are responsible for creating prior conditions in achieving an effective and efficient care in Dutch health care. In this dynamic context nursing roles will further develop. 


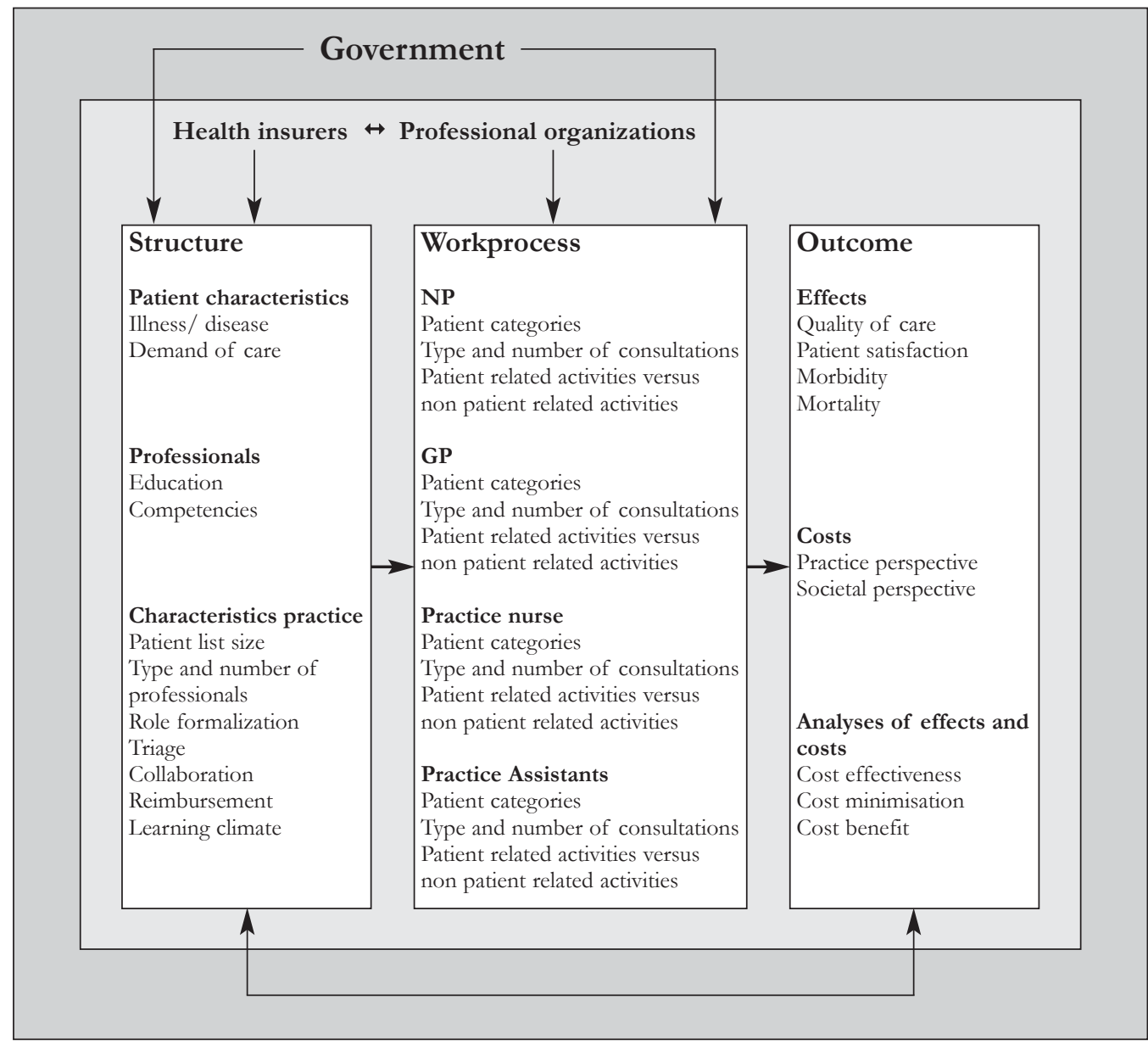

Figure 1 The validated framework adapted from Sidani and Irvine (1999) 


\section{Methodological CONSIDERATIONS}

Within this research a variety of methods has been applied, being systematic literature review, randomized controlled trial, economic evaluations, observational longitudinal design, explorative and descriptive designs. Subsequently, the strengths and weaknesses of the methods are discussed.

\section{Strengths and weaknesses of the research}

The study contributes to the national and international body of knowledge related to the implementation of the NP in the care for patients with common complaints and related to the effectiveness in terms of quality of the care and costs. The study was unique in different ways. This evaluation study can be defined as practice related research. The researchers had the opportunity to investigate the intervention during a period of four years, so insight was obtained in the context and effects of this innovation. Therefore, we were able to describe the generic development of the implementation, but also the variability between the participating general practices.

This research can also be considered as research of a complex intervention (Campbell et al., 2007). Complex interventions are "built up from a number of components, which may act both independently and interdependently (Campbell et al., 2000). Evaluating complex interventions can pose a considerable challenge and requires a substantial investment of time. The design of an intervention depends on understanding the underlying problem and the context, which processes are involved in optimizing the intervention and which outcomes are appropriate to evaluate the intervention mechanism. Defining and understanding the problem and its context, developing and understanding the intervention, and developing and optimizing the evaluation are three substantial tasks but can be conducted simultaneously. Therefore, the evaluation of complex interventions requires use of qualitative and quantitative evidence. In this study we used qualitative and quantitative methods. One of the most important advantages in using mixed methods, which can lead to theoretical and substantive insights into the multidimensional nature of health care systems (Bradley et al., 2007).

Further, we developed and optimized the framework, within boundaries of a pilot project. We had the possibility to conduct this study in all participating general practices simultaneously. We made use of large patient sample sizes and our data sets were relatively complete. As the participating general practices were variable in size, location and patient population, the study results can be considered as highly external valid.

The study has also some characteristics that limit the generalizability of the results. It was not a blinded randomised controlled trial. Blinding is a research method which is used to prevent research outcomes from being influenced by either the placebo-effect of the observer bias. The trial took place in one region 
only, the NPs formed a small group and were senior nurses, newly graduated as NPs, and the trial was conducted in general practices which joined in a project to pilot-test the NP as a new professional in primary care. Those GPs can be seen as early adopters of this innovation.

The descriptive and explorative nature of the observational longitudinal study calls for additional (observational) research, in order to validate the results of this study.

The NPs treat a specified set of common complaints, and it was not possible to select one primary outcome. We focus on a number of process and effect variables and costs, which are affected by the implementation of the NP. We were also aware of the preference for cost-effectiveness analyses and costeffectiveness planes as a valuable tool in the interpretation of both costs and effects (Drummond et al., 2003; Bosmans et al., 2007). The use of cost minimization analysis is in most cases regarded as inappropriate in studies designed to compare two interventions on their cost-effectiveness (Bosmans, 2007; Briggs and Brien, 2001). However, in comparing NP or GP care no significant differences in outcome or process measures were found. Consequently, we considered that the sum of these measures represents equivalence between the intervention group and reference group within the NPGP-practices. As a result, we did not conduct a cost-effectiveness analysis. If we would have done so, it is very unlikely this would have altered our findings on costs, given the equivalence in effectiveness.

\section{INTERPRETATION OF THE RESULTS FOR PATIENTS AND PROFESSIONALS IN GENERAL PRACTICE}

The results demonstrate that it is possible to educate and employ NPs in the care for patients with common complaints. As we found in this study, patients with common complaints highly appreciate the care in both groups. High satisfaction with nurse led care does not mean that patients inevitably prefer nurses to GPs. Patient preferences in most studies are mixed (Laurant et al., 2004). Nurses may be favored when patients see their problems as "minor" or "routine", but doctors are preferred when the problem is thought to be "serious" or "difficult". Given the assurance that nurses working in advanced roles are well qualified for that work, most patients accepted being allocated to a nurse and were subsequently satisfied with the care they received. Professionals have to prevent that the care for patients will be shred. With the introduction of the NP, a new career perspective for senior nurses is created. They provide medical activities and complementary nursing activities in the improvement of collaboration, education of health professionals, and perform activities to improve the quality of care and the practice of evidence based care.

We have also concluded that variation occurred in the way NPs explore their new roles. These variation is influenced by the individual competencies of NP 
(professional and psychological), and developed by personal interests, experiences and knowledge in their earlier jobs as a senior nurse. For example, a NP expands the set of common complaints or uptakes the care for other complaints (i.e. chronic care), or focuses more on non-patient related activities, such as the quality improvement of care or research. On the other hand, GPs working together in a general practice have also their specific vision and expectations of the NP. Patient populations and patient needs, the degree of delegating GP activities, the match between the NP and the other professionals and the availability of clear job descriptions of (other) professionals (e.g. practice nurses, specialized nurses), will also result in a variation of work characteristics of the individual NPs.

By the introduction of a new professional, the GP's role towards their patients will change (Woodroffe, 2006). It is likely that the GP treats less patients with common complaints and relatively more patients with multi morbidity, complex diagnoses or the chronically ill Some of them experience this as a challenge, while others experience this as an increasing workload. Other changes occurred in the workload of the GPs, e.g. spending more time in supervision, specializing, or innovation projects.

GPs determine to which degree activities are delegated to the NP (Sibbald, 2008). Too often GPs continue to provide the same services as nurses, leading to duplication, rather than substitution of care (Laurant, 2006). Efficiency gains are possible only if GPs discontinue the services that nurses provide and focus on the tasks only doctors can perform (Richardson, 1999). GPs' skills might usefully be targeted to health problems with a high degree of uncertainty regarding diagnosis or treatment, such as the management of people with medically unexplained symptoms or undifferentiated presentations and those with complex co-morbidities.

How the role of GPs will develop is dependent of the vision of this group of professionals. This profession is going through an evolution and a selfexamination that touches specifically upon the systemic boundaries of its identity, caused by changes in the demand of care, changes in governance systems that accompanied and many reform initiatives and the emphasis on inter-professional collaboration (Beaulieu et al., 2008).

\section{INTERPRETATION OF THE RESULTS FROM AN ORGANIZATIONAL PERSPECTIVE}

To implement the NP in an effective way, the organization of care delivered within general practice has to be changed. Triage will be implemented and new job descriptions are made. But in reality, organizations do not start from a clean slate from which ideal choices can be made. Systems only develop within the framework which they have inherited, building on what has gone before. Often, organizations are memorials to old problems, institutional residues that reflect the historical processes through which problems have been tackled. (Kernick and Scott, 2002; Pratt et al., 2000) 
Interdisciplinary practice refers to people with distinct disciplinary training working together for a common purpose, as they make different, complementary contributions to patient-focused care (Mc. Callin, 2001; Leathard, 1994). Overlap in job descriptions of different professionals -e.g. the practice assistant, the practice nurse and the NP- should be avoided. What is important is what teams do, how they do it, whether it improves patient outcomes, and whether it benefits the organization and the service funder (Singh Muncherij, 2007; Mc. Callin, 2001).

A more educated nursing sector has resulted in pressure on existing professional boundaries and access to many areas that were previously the prerogative of doctors (Kernick and Scott, 2002). Important competencies of the NP are their role in improving the collaboration, the quality of the care and their role in evidence based practice. Much nursing literature, refers to these competencies (Dunn and Nicklin, 1995; Sidani and Irvine, 1999; Bryant-Lukosius et al., 2004). The National College of General Practitioners in the Netherlands questions the introduction of the NP in general practice. Or as described in their vision (NHG, 2007): they prefer to work with three types of professionals in general practice: a practice assistant, a practice nurse, and the GP, to maintain an effective organization of care. On the other hand, this study supports the evidence that competencies of nurses in general practice can be expanded, by their involvement in the care for patients with common complaints. We agree that the number of types of professions in general practice should be limited. Based on the analysis of the demand of care, the activities and roles would be determined and the last phase to develop a team consisting of the professions needed. As there is evidence for the effective role of practice nurses and nurse specialists in the care for chronically ill (Vrijhoef, 2002; Laurant, 2006) and the NP in the care for patients with common complaints, a professional with a nursing background will have an added value.

\section{INTERPRETATION OF THE RESULTS FROM THE PERSPECTIVE OF POLICYMAKERS}

An analysis of the needs of patients or the demand of care should be leading to determine a new model of care and to describe the type of activities and roles in general practice. The project was an initiative of GPs in 2003. The NP was considered as one of the solutions for their high workload and the scarceness GPs in the future. The main goal was to increase service capacity, to meet a rising demand of care, and to improve access by the introduction of a NP. This was also one of the main concerns in Health Policy, which is reflected in the support of the project by the Government and Health insurers. This known fact can also be considered as a contradiction. We have focused in this study on the processes and effects of the implementation of a NP, but the objective analysis of the changing and increasing demand of patient care per practice, has not been conducted. 
One of the prior conditions which hampered the broad scaled implementation of the NP is the current financial structure in the Dutch health care system. Currently, skill mix in general practice is based on financial structures and not on the needs of patients. As a result of this evaluation study, this problem has been partly solved. The financial structures are adapted. GPs can employ practice nurses, nurse specialists or NPs under the same the financial conditions. Nevertheless, for GPs who have employed a practice nurse it is not possible to employ also a NP, because Health insurers do not allow that the additional reimbursement will be overdrawn.

In comparing NP care with GP care, a lowest cost difference of $€ 2.00$ per consultation was found. To illustrate the impact of such a difference on national level, we calculated a scenario wherein all consultations of common complaints would be performed by NPs instead of GPs. In this scenario a cost reduction of $€ 19$ million per year can be realized. This amount should not be considered as a pure economical saving. When involving the NP in the care for patients with common complaints, this substantial amount should be used partly for redesigning primary care. As a result, GPs could have longer consultations for an increasing number of patients with complex diagnoses or multi morbidity, more time for coordination between professionals, and more time for their supervisory role to other professionals.

The government is focused on the improvement of primary care with GPs being considered as main care providers for chronically ill, or patients with multi morbidity (Klink, 2008). Regarding the training program of GPs the question arises whether GPs are well prepared to focus on these patient populations, including patients with multi morbidity, or on changing roles as main coordinator in primary care or supervisor of other professionals. When GPs' knowledge about patients with chronic diseases or multi morbidity expand, this will reflect in their skills of diagnosing, treatment and secondary prevention.

Nationwide or internationally there is no consensus about the specific patient populations which can be treated by NPs or other nursing professionals. Consequently, there are differences in the NP or other nursing training programs nationwide. These occurrences result in confusion about the different nursing roles.

\section{RECOMMENDATIONS FOR POLICY AND PRACTICE}

Before the introduction of NPs, these patients are diagnosed and treated by GPs. NPs in training need the same knowledge of common complaints as educated by GPs in training. A generic training Program Master in Advanced Nursing Practice, combined with the differentiation "Primary Care" is one of the solutions.

To make the value of NPs in general practice transparent, it will be helpful to define NP core competencies, including patient and non-patient related activities. As there is much confusion about different nursing roles, the obscurity 
in terminology have to be removed by reducing the number of nursing titles, by describing the corresponding competencies and by determining the level of education. This is happening now by restructuring the nursing professions (CBOG, 2009). Regarding the results of this study a "nurse" with a master level of education is recommendable as one of the types of professionals working in general practice, who can treat different patient populations (with a specified set of common complaints or the treatment of chronically ill). In this way, the "nurse" is flexible and employable dependent on the patient needs in general practice.

GPs should take their role on the chronically ill, patients with multi morbidity, prevention and detecting patients' at risk (Starfield, 2008). They have to be trained in the role as supervisor and main coordinator in general practice. When this group of professionals invest in their specializations and consult each other, the body of knowledge of these patient groups will increase consequently, and may decrease the number of referrals and care provided in secondary care. The government is responsible for the prior conditions and The National College of General Practitioners would have a leading role.

An analysis of patient needs or the changing or increasing demand of care has not been conducted in this study. The development of policy of a skill mix in health care should be the result of an analysis of patients needs and describing activities and roles, that goes beyond professional boundaries. This implies also that government, Health insurers, and professional (nursing and medical) organisations are not thinking within current (organizational) structures, but have an open, creative mind for restructuring health care and health care organizations. For implementing a new professional, general practices should be guided. A model to analyze the demand of care per practice to obtain the most effective skill mix, should be developed. (Grumbach and Bodenheimer, 2002; Grumbach and Bodenheimer, 2004; Starfield, 2008). Main theme is how to develop the right doctor/nurse skill mix and the problems of obtaining correct solutions from the perspective of efficient and effective care (Kernick and Scott, 2002). 


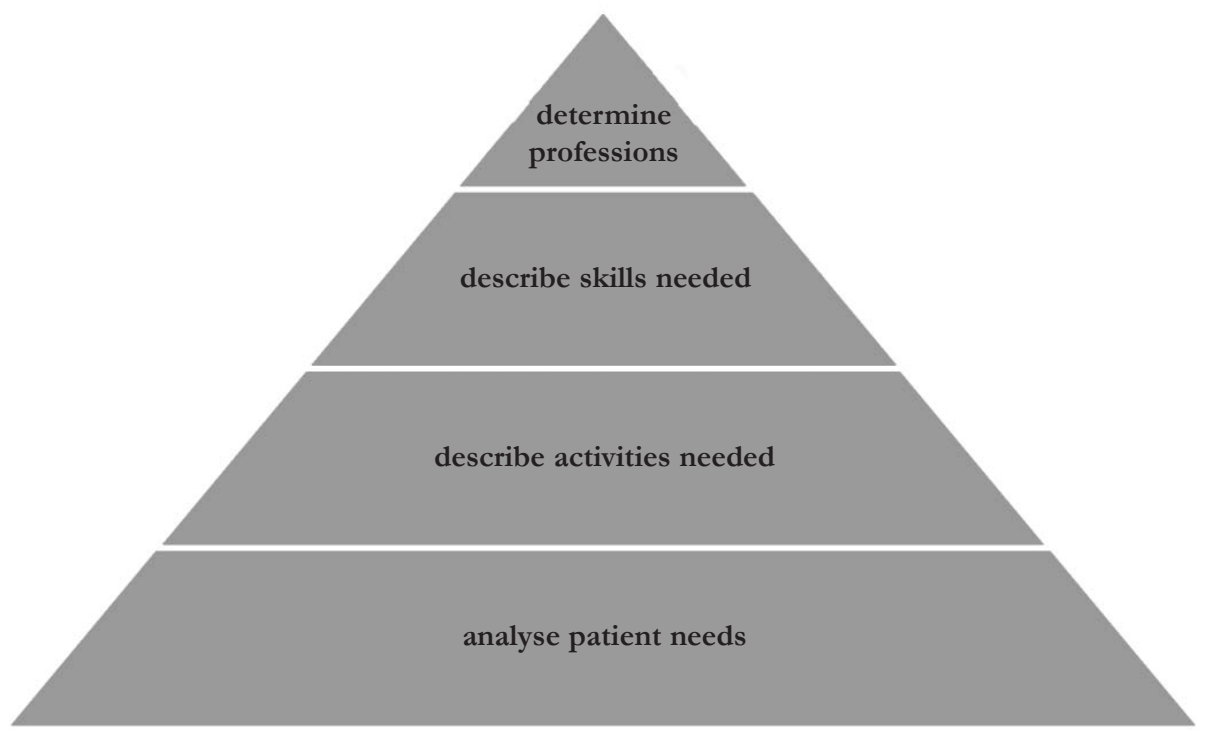

Figure 2 Model to obtain the right skill mix for an effective and efficient patient care per practice

\section{UNANSWERED QUESTIONS AND FUTURE RESEARCH}

Given the complexity of this type of research, as well as the variety of interests of the stakeholders involved, a combination of both quantitative and qualitative studies might be the best way forward. We do not know whether side effects or adverse events occur on a long term, influenced by the intercollaboration between professionals.

We have evaluated some prior conditions, processes and effects. These results can be considered as the first steps to obtain evidence about the effectiveness of the NPs in general practice. Future research is needed, including an analysis of the changing and increasing demand of care per practice, to see which conditions are needed to organize the care effectively. Insight in structure, process and outcome, and the relationships between these components is essential. We were able to create a model explaining only a marginal amount of the variance in costs, so more research is needed. Qualitative research is a source of indirect evidence on which prior belief may be based and it is especially relevant to social and managerial decisions (Lilford and Braunholtz, 2000). Qualitative research should be performed to explore factors which influence costs followed by quantitative research to retest the model. Finally, we recommend more research to cost-effectiveness of innovations in health care over a long term period i.e. beyond the time horizon of a trial and international comparisons -e.g. United Kingdom and the Netherlands-, where the role of GPs, is comparable. 


\section{REFERENCES}

1. Beaulieu MD, Rioux M, Rocher G, Samson L, Boucher L. Family practice: Professional identity in transition. A case study of family medicine in Canada. Social Science and Medicine 2008; 67: 1153-63.

2. Bradley EH, Curry LA, Devers KJ. Qualitative Data Analysis for Health Services Research: Developing taxonomy, themes and theory. Health Service Research 2007; 42 (4): 1758-72.

3. Bryant-Lukosius D, Dicenso A, Browne G, Pinelli J. Advanced practice nursing roles: development, implementation and evaluation. Journal of Advanced Nursing 2004; 48(5): 519-29.

4. Bosmans JE, de Bruijne MC, et al. Practical Guidelines for Economic Evaluations Alongside Equivalence Trials. International Society for Pharmacoeconomics and Outcomes Research 2007; 11 (2): 251-8.

5. Briggs AH, O'Brien BJ. The death of cost minimization analysis? Health Economics 2001; 10:179-84.

6. Campbell NC et al. Designing and evaluating complex interventions to improve health care. British Medical Journal 2007; 334: 455-9.

7. Campbell M, et al. Framework for design and evaluation of complex interventions to improve health. British Medical Journal 2000; 321: 694-6.

8. Dunn K, Nicklin W. The status of advanced nursing roles in Canadian teaching hospitals. Canadian Journal of Nursing Administration 1995, Jan-Feb: 111-35.

9. Drummond, MF, O'Brien, B, Stoddart, GL, Torrance GW. Methods for the economic evaluation of health care programmes, second edition. Oxford, Oxford University Press 2003.

10. Grumbach K, Bodenheimer T. Putting the house in order. A Primary Care Home for Americans: Putting the House JAMA 2002; 288(7): 889-93.

11. Grumbach K, Bodenheimer T. Can Health Care Teams Improve Primary Care Practice? JAMA 2004; 291(10): 1246-51.

12. Kernick D, Scott A. Economic approaches to doctor/nurse skill mix: problems, pitfalls, and partial solutions. British Journal of General Practice 2002; 52: 42-6.

13. Klink A. (2008). Kamerstuk "Visie op Dynamische eerstelijnszorg. (In Dutch)

14. Klink A, Bussemaker J. (2008) Kamerstuk "Programmatische aanpak voor chronische ziekten". (In Dutch)

15. Laurant M, Reeves D, et al. Substitution of doctors by nurses in primary care. The 317 Cochrane Database of Systematic Reviews Collaboration, 2004 (4).

16. Laurant M. Changes in skill mix: The impact of adding nurses to the primary care team. Dissertation. Nijmegen, 2006.

17. Leathard A. Going Interprofessional: Working Together for Health and Welfare. Routledge London, 1994.

18. Lilford RJ, Braunholtz DB. Who is afraid of Thomas Bayes? J Epidemiol Community Health 2000; 54: 731-739.

19. McCallin A. Interdisciplinary practice: a matter of teamwork. An integrated approach. Journal of Clinical Nursing 2001; 10: 419-28.

20. Pratt J, Gordon P, Plamping D. Working whole systems. Putting theory into practice in organizations. London: King's Fund, 2000.

21. Richardson G. Identifying, evaluating and implementing cost-effective skill mix. Journal of Nursing Management 1999; 7(5): 265-70. 
22. Sibbald B. Should primary care be nurse led. British Medical Journal 2008; 337: 658-9.

23. Sidani S, Irvine D. A conceptual framework for evaluating the nurse practitioner role in acute care settings. Journal of Advanced Nursing 1999; 30(1): 58-66.

24. Singh AK, Muncherij N.Team Effectiveness and its Measurement: A Framework. Global Business Review 2007; (8): 119-33.

25. Starfield B. Access, Primary Care, and the Medical Home Rights of Passage. Medical Care 2008; (46) 10: 1015-6.

26. Nederlands Huisartsen Genootschap. NHG-Standpunt Toekomstvisie Huisartsenzorg GGZ in de huisartsenzorg. Utrecht 2007. (In Dutch)

27. Vrijhoef H. Is it justifiable to treat chronic patients by nurse specialists? Dissertation. Maastricht, 2002.

28. Woodroffe E. Nurse-led general practice: the changing face of general practice? British Journal of General Practice 2006; 632-3.

29. Website: http://www.cbog.nl/page/Lopende-projecten/VBOC-VVO. Latest access: 7 th July 2009. (In Dutch) 


\section{SUMMARY}

The background and the objectives of this dissertation are in detailed described in Chapter 1.

Against the background of the need to increase service capacity, to meet a rising demand, and to improve access to primary care, the project Nurse Practitioner in General Practice (NPGP- project) was initiated in the Netherlands. This evaluation study is divided in a process evaluation and a cost-effectiveness evaluation. The aim of the process evaluation is to explore the feasibility of the implementation of the nurse practitioner (NP) in the care for patients with common complaints and the conditions needed (structure and process). The objective of the effectiveness evaluation is to investigate, the impact on quality of the care and the level of (cost-) effectiveness of care provided by the NP in general practice.

In Chapter 2 the results of a systematic review are described. Substitution of skills has been introduced to increase health service efficiency, but little evidence is available about its cost-effectiveness. This systematic review aims to identify economic evaluations of substitution between professionals, to assess the quality of the study methods applied and to value the results for decision making. Eleven studies were finally included of 7,605 studies: three cost effectiveness studies, three cost minimisation studies, and five studies related to partial economic evaluations. Small numbers of participating professionals and several limitations in the cost valuation and the measurement of costs were identified. Several potential limitations influence the validity and generalisability. Full economic evaluations per se are of limited value for making decisions about substitution of skills. The tenuous relationship between structural, process and outcome variables is not sufficiently investigated.

In Chapter 3 the concordance of the NP role with the initial concepts of the NP training program are described. Therefore an observational longitudinal design, including mixed methods, was conducted.

All NPs provide care to patients with common complaints as main focus, as well as managing quality of care projects. The NP roles are, in this way, in concordance with the NP training program. During the training program, the NPs productivity increased from 0 to 225 consultations per month. In the period after graduation, consultation rates increased further to 285 consultations per month and the number of home visits increased from 1 to 26 per month. The GP consultation rates raised from 325 to 445 per month and home visits from 15 to 33 per month. Differences between NPs are reported in the percentages of home visits, care for elderly, patient related activities versus non patient related activities. NPs contribute to the accessibility and availability of primary care as well as to the collaboration in and quality of primary care. The adopted roles are influenced by practice needs and financial incentives. 
The evaluation of process and outcomes of care as provided by NPs or GPs for patients with common complaints at first point of contact is described in Chapter 4. A randomised controlled trial was conducted. In both groups patients highly appreciated the quality of care. It is demonstrated that the items, related to communication, attitude, and provision of information (scored on a Likert-type scale 1-6), were highly appreciated by patients from both groups $(\min =5.46, \max =5.61)$. Comparable results were found in groups for the items related to the provision of information $(\min =5.13, \max =5.42)$. No significant difference in overall satisfaction was reported (scored on a Likert type scale 010): patients in the intervention group (NP led care) scored a mean of 8.19 $(\mathrm{SD}=1.18)$, patients in the reference group (GP led care) a mean of 8.20 (SD= 1.26). No significant differences were found in health status, medical consumption, and compliance of practical guidelines. Patients allocated to the NP were more invited to re-attend $(p=0.001)$, had more follow up consultations $(p=0.04)$ and their consultations took significantly more time than patients allocated to the GP $(\mathrm{p}<0.001)$. These findings support an increased involvement of specially trained NPs in the Dutch primary care and contribute to the knowledge on the effectiveness of care provision by NPs from a national and international perspective.

In Chapter $\mathbf{5}$ an estimation of the costs of consultations by GP or NP dealing with patients with common complaints is given from two perspectives: from the general practice and from the societal perspective. Within NPGP-practices a significant difference in direct costs appeared between the NP consultations and GP consultations: a mean difference in direct costs of $€ 8.21$ in favor of the NP consultations was found $(\mathrm{p}=0.001)$. Between NPGP-practices and reference practices a significant difference was found in the direct costs within health care. The mean difference in direct costs was $€ 3.45$ per consultation in favor of the NPGP-practices $(p=0.04)$. With patients in the reference groups being significantly older, a sensitivity analysis was performed by selecting the data for patients younger than 65 years of age. In so doing, it was found that within NPGP-practices the mean direct costs and productivity costs for NP consultations were $€ 161.57(\mathrm{SD}=33.98)$ and for GP consultations $€ 170.75$ $(\mathrm{SD}=46.58 ; \mathrm{p}<0.001)$. Furthermore, mean costs for consultations in NPGPpractices were $€ 165.69(\mathrm{SD}=40.37)$ and $€ 168.25$ for consultations in the external reference practices $(S D=40.48 ; \mathrm{p}=0.13)$. Cost differences are mainly caused by the difference in salary between NPs and GPs. By involving NPs, substantial economic "savings" could be used for redesigning primary care, to optimize the best skill mix, and to cover the full range of primary care activities.

Chapter 6 focuses on NPs employment from an economic perspective in relation to achieve an optimal skill mix. The results, demonstrated by means of a descriptive and explorative design on a national level, are reflected. The 
conditions under which the nurse practitioner is able to earn back his/her own cost of employment, were identified. Preferences and expectations of GPs and Health insurers about NP reimbursement were made transparent. Although GPs and Health insurers acknowledge the importance of the nurse practitioner in accommodating primary care demands, they have polarized views about reimbursement. The employment of NPs is seldom economically viable. It requires a reallocation of $(80 \%$ of $)$ the general practitioner's freed up time towards practice growth $(12 \%$; patients). This study provided insight into the complex interaction of the (cost)parameters that result in economic viability and feeds a further discussion about the content of the NP role in general practice based on optimal quality of care versus efficiency. Effective and efficient health care can only be provided if the actual care needs of a population provide the basis for deciding which mix of professionals is best equipped to deal with the changing and increasing demand of care. A macro level intervention is needed to help a broad scale introduction of the NP in general practice.

The main conclusion, as described in Chapter 7, is that care delivered by specially trained NPs for patients with common complaints is feasible and effective and costs less than usual care. With the transfer of these care activities being justified, the availability and accessibility of primary care can be safeguarded for the nearby future by the introduction of the NP in general practice in the Netherlands. However, the economic viability of the NP has proven difficult to achieve in every day health care practice.

To show the value of NPs for general practice, the NP core competencies, including patient related and non-patient related activities need to be clearly defined. This is taking place on national level by the restructuring of the nursing profession (CBOG). Based on the results of this study it is recommended to employ NPs in general practice for the treatment of people with minor complaints. GPs should take their role on the chronically ill, patients with multimorbidity, prevention and detecting patients' at risk. When these professionals invest in their scopes of practice, function as a team and consult each other, the body of knowledge for the treatment of these patients in general practice will increase consequently, and may eventually result in a decreased number of referrals to secondary care. The development of policy regarding skill mix in health care should be the result of 1 . an analysis of patients' needs; and 2 . the description of activities and roles of health workers that goes beyond professional boundaries. Further, a model to obtain the most effective skill mix per practice should be developed. Future research should also include an analysis of the changing and increasing demand of care per practice, to see which conditions are needed to organize the care effectively. 


\section{SAMENVATTING}

De achtergrond en de doelstellingen van deze dissertatie zijn beschreven in Hoofdstuk 1. In het licht van de noodzaak om de capaciteit uit te breiden in huisartsenpraktijken, om tegemoet te komen aan een stijgende zorgvraag en om de toegankelijkheid van de huisartsenzorg te verbeteren, is het project "Nurse Practitioner in de huisartsenpraktijk" (NPH-project) geïnitieerd in Nederland. Het onderzoek is verdeeld in een evaluatie van de processen en een evaluatie van de kosteneffectiviteit. De doelstelling van de procesevaluatie is het onderzoeken van de uitvoerbaarheid van de implementatie van de NP in de zorg voor patiënten met vaak voorkomende klachten. Daarnaast zijn de randvoorwaarden (structuur en proces) onderzocht. De doelstelling van de effectevaluatie is het onderzoeken van de impact op de kwaliteit van de zorg en de kosteneffectiviteit van de zorg, die verleend is door NPs in de huisartsenpraktijk.

In Hoofdstuk 2 zijn de resultaten van de systematische review beschreven. Substitutie van zorg is geïntroduceerd om de efficiëntie in gezondheidszorgsystemen te vergroten, maar er is weinig wetenschappelijk bewijsmateriaal beschikbaar over de kosteneffectiviteit. Deze systematische review heeft als doel economische evaluaties te identificeren, die gerelateerd zijn aan substitutie van zorg tussen professionals, het vaststellen van de kwaliteit van de onderzoeksmethoden en de waarden van de resultaten voor de besluitvorming. Elf studies zijn uiteindelijk geïncludeerd van de 7605 artikelen: drie kosteneffectiviteitsstudies, drie kosten-minimisatie studies and vijf studies gerelateerd aan gedeeltelijke economische evaluaties. Het kleine aantal deelnemende professionals en de verschillende beperkingen in de kostenwaardering en de meting van kosten, zijn toegelicht. Deze beperkingen beïnvloeden de validiteit en de generaliseerbaarheid van de resultaten. Volledige economische evaluaties zijn op zich zelf van een beperkte waarde voor de besluitvorming over de substitutie van zorg. De essentiële relaties tussen structuur-, proces- en effectvariabelen zijn onvoldoende onderzocht.

In Hoofdstuk 3 is onderzoek verricht naar de samenhang tussen de NP rollen en de initiële concepten van de NP opleiding. Daarvoor is een observationeel longitudinaal onderzoek, inclusief gemengde onderzoeksmethoden (kwalitatief en kwantitatief) uitgevoerd. Alle NPs hebben als belangrijkste aandachtsgebied het verlenen van zorg aan patiënten met vaak voorkomende klachten. Daarnaast verrichten zij ook activiteiten op het gebied van kwaliteitsprojecten. In deze zin sluiten de NP rollen aan op de initiële concepten van de opleiding. Tijdens de opleiding steeg de productiviteit van geen naar 225 consulten per maand. $\mathrm{Na}$ diplomering, stegen de consulten verder naar 285 consulten per maand en het aantal visites van 1 naar 26 per maand. De consulten bij huisartsen stegen van 325 naar 445 per maand en het aantal huisbezoeken van 15 naar 33 per maand. Verschillen tussen de NPs onderling zijn gevonden in de percentages van het 
aantal huisbezoeken, het aantal consulten voor ouderen, het percentage patiëntgerelateerde activiteiten versus niet-patiënt gerelateerde activiteiten. NPs dragen bij aan de beschikbaarheid en de toegankelijkheid van de huisartsenzorg, maar ook in de verbetering van de samenwerking en de kwaliteit van zorg. De aangenomen rollen en activiteiten zijn beïnvloed door de behoeften in de betreffende praktijken en financiële stimuli.

De evaluatie van processen en effecten van zorg, verleend door NPs en de huisartsen bij patiënten met vaak voorkomende klachten tijdens het eerste consult, is beschreven in Hoofdstuk 4. Een gerandomiseerd gecontroleerde trial werd uitgevoerd. In beide groepen waarderen de patiënten de kwaliteit van zorg zeer hoog. Het is aangetoond dat thema's gerelateerd aan communicatie, bejegening en voorlichting (gescoord op een 6-puntsschaal) hoog werden gescoord door patiënten in beide groepen $(\min =5,46, \max =5,61)$. Er is geen verschil in de overall tevredenheid gevonden (10-punts-schaal). De interventiegroep (patiënten toegewezen aan de NP) scoorde een gemiddelde van 8.19 ( $\mathrm{SD}=1,18)$, de referentiegroep (patiënten toegewezen aan de huisarts) scoorde gemiddeld 8.20 ( $\mathrm{SD}=1,26)$. Er zijn geen verschillen aangetoond in gezondheidsstatus, medische consumptie, en de mate waarin de zorgverleners de NHG-standaarden opvolgden. Patiënten in de interventiegroep werden vaker uitgenodigd voor een vervolgconsult $(p=0,001)$, hadden ook meer vervolgconsulten $(p=0,04)$ en de consulten duurden significant langer dan bij de patiënten toegewezen aan de huisartsen. Deze bevindingen ondersteunen een grote betrokkenheid van speciaal opgeleide NPs in de Nederlandse huisartsenzorg en deze studie draagt bij aan de kennis van de effectiviteit van zorg, verleend door NPs, vanuit een nationaal en internationaal perspectief.

In Hoofdstuk $\mathbf{5}$ is een schatting van de kosten beschreven van consulten verleend door huisartsen of door NPs bij patiënten met vaak voorkomende klachten, vanuit twee perspectieven: vanuit het perspectief van de huisartsenpraktijk en vanuit maatschappelijk perspectief. Binnen de NPHpraktijken is een significant verschil aan getoond in directe kosten tussen de NP consulten en de huisartsen consulten. Het gemiddelde verschil was $€ 8,21$ per consult ten gunste van de NP consulten $(p=0,001)$. Bij een analyse waarbij de $\mathrm{NPH}$ praktijken met externe referentiepraktijken werden vergeleken, is er ook een direct verschil aangetoond in directe kosten. Het gemiddelde verschil was $€ 3,45$ per consult ten gunste van de NPH-praktijken $(p=0,04)$. Patiënten in de referentiegroepen waren significant ouder, daarom is een sensitiviteits-analyse toegepast door patiënten te selecteren jonger dan 65 jaar. Het resultaat was, dat binnen de NPH-praktijken de gemiddelde directe kosten en productiviteitskosten voor NP consulten $€ 161,57$ (SD=33,98) waren en voor huisarts consulten $€ 170,75$ (SD=46,58; $\mathrm{p}=0,001)$. De gemiddelde kosten voor consulten in NPH-praktijken waren $€ 165,69(\mathrm{SD}=40,37)$ en $€ 168,25$ voor 
consulten in de externe referentie praktijken $(\mathrm{SD}=40,48 ; \mathrm{p}=0,13)$. Verschil in kosten worden voornamelijk veroorzaakt door het verschil in salaris tussen een huisarts en een NP. Door de NP in te zetten, zouden er substantiële economische "besparingen" gebruikt kunnen worden voor het herontwerpen van de eerstelijnszorg, voor het optimaliseren van de beste mix van competenties en voor het afdekken van het volledige scala aan eerstelijns activiteiten.

In Hoofdstuk 6 wordt de functie van de NP vanuit economisch perspectief beschreven, in relatie tot het realiseren van een optimale mix van competenties. De resultaten, aangetoond door een beschrijvend, exploratief design en uitgevoerd op landelijk niveau, worden toegelicht. De condities waaronder de NP zichzelf dient terug te verdienen, zijn gë̈dentificeerd. Voorkeuren en verwachtingen van huisartsen en zorgverzekeraars over de financiering van de NP zijn toegelicht. Alhoewel huisartsen en zorgverzekeraars beiden het belang inzien van de NP in de huisartsenvoorziening, hebben ze gepolariseerde inzichten met betrekking tot de financiering. De functie van de NP is niet kostendekkend. Het vereist een herschikking van (80\% van) de vrij gekomen tijd van huisartsen, ingezet voor praktijkgroei (12\% patiënten). De studie verschafte inzicht in de complexe dimensie van kostenparameters die resulteert in deze kostendekkendheid. Daarnaast voedt het de discussie over de inhoud van de functie van de NP in de huisartsenpraktijk, gebaseerd op een optimale kwaliteit van zorg versus efficiëntie. Een effectieve en efficiënte gezondheidszorg kan alleen worden gerealiseerd als de actuele zorgbehoefte de basis is voor de besluitvorming welke professionals ingezet dienen te worden bij een veranderende en stijgende zorgvraag. Een interventie op macroniveau is nodig om een introductie van de NP in de huisartsen op landelijk niveau te realiseren.

De belangrijkste conclusie, beschreven in Hoofdstuk 7, is dat zorg verleend door speciaal opgeleide NPs voor patiënten met vaak voorkomende klachten uitvoerbaar en effectief is en minder kost dan reguliere zorg. Het verschuiven van deze zorg, door het introduceren van de NP in de huisartsenzorg, is daar mee gerechtvaardigd en draagt bij aan de toekomstige beschikbaarheid en toegankelijkheid van de toekomstige huisartsenzorg. Ook is gevonden dat het moeilijk is om een kostendekkende inzet van de NP te realiseren.

Om de waarde van de NP in de huisartsenpraktijk inzichtelijk te maken, dienen de kerncompetenties van de NP, inclusief patiëntgerelateerde en niet patiënt gerelateerde activiteiten helder geformuleerd te zin. Dit vindt nu ook plaats door het herstructureren van de verpleegkundige professie (CBOG). Gebaseerd op de resultaten van dit onderzoek is het aan te bevelen een NP in te zetten op de zorg voor patiënten met vaak voorkomende klachten. Huisartsen zouden een grote(re) rol moeten nemen in de zorg voor chronisch zieken, patiënten met multi-morbiditeit, preventie en het screenen van de zogenaamde risicogroepen. Indien huisartsen investeren in deze scoop op praktijkvoering, het functioneren 
als een team en elkaar onderling consulteren, zal de hoeveelheid kennis over deze patiëntengroepen zich consequent uitbreiden, wat mogelijk resulteert in een afname van verwijzingen naar de tweedelijnszorg. De beleidsontwikkeling over het realiseren van een optimale mix van competenties in de gezondheidszorg zou moeten resulteren in 1 . een analyse van de zorgvraag en 2 . de beschrijving van activiteiten en rollen van professionals, waarbij de grenzen van professies uitgebreid kunnen worden. Verder zou er een model ontwikkeld dienen te worden, om de meeste effectieve mix van skills per praktijk vast te stellen. Verder onderzoek is nodig, inclusief een analyse van de veranderende en toenemende zorgvraag per praktijk, om te beoordelen welke condities nodig zijn om de zorgverlening effectief te organiseren. 


\section{DANKWOORD}

Het was een voorrecht om een dergelijk onderzoek te mogen uitvoeren. Dank aan alle leden van de stuurgroep NPH en de financiers die het project mogelijk maakten: het Ministerie van VWS, de zorgverzekeraars Univé-VGZ-IZA-Trias, CZ, Ros Robuust en de Provincie Noord-Brabant. Ook een woord van een dank aan alle sponsoren van dit proefschrift.

Bijna vijf jaar mocht ik in de keuken van de praktijken kijken, van patiënten, dokterassistenten, huisartsen en NPs. Elke praktijk kende zijn eigen feiten, verhalen en ervaringen. Het was boeiend om deze verhalen te mogen beschrijven in de vorm van onderzoek. Een woord van dank aan alle patiënten en medewerkers in de praktijken die deelnamen aan het onderzoek, in het bijzonder aan alle NPs en alle huisartsopleiders; de transparantie en bereidheid om deel te nemen aan dit voor jullie zo intensieve onderzoek. NPs, ik heb veel bewondering voor hoe jullie het pionieren vorm hebben gegeven, het volgen van een intensieve opleiding en de tact en het geduld om steeds maar weer uit te leggen wat je functie inhoudt. Wat dat betreft zijn jullie allen prachtmeiden. Huisartsenopleiders, dank ook voor alle openheid en uitleg tijdens de vele bijeenkomsten en interviews. Dankzij jullie heb ik inzicht mogen krijgen in de huisartsenzorg, wat voor mij een nieuw gebied was.

Dit onderzoek is een coproductie en was nooit op deze wijze afgerond, als deze personen er niet bij betrokken waren geweest. Allereerst wil ik mijn dank uitspeken aan Cor Spreeuwenberg en Job Metsemakers. Cor, ik heb je consciëntieuze inzet en betrokkenheid zeer gewaardeerd, maar ik heb je ook leren kennen als een visionair. Ook na je "pensionering" ging je voor dit onderzoek met bevlogenheid verder. Beste Job, hartelijk dank voor jouw effort en steun. Je zorgvuldigheid, de beelden over innovaties in de huisartsenzorg, en het feit dat je nog steeds als huisarts werkzaam bent, hebben voor mij een absolute meerwaarde gehad. Van ICPC-codes en substitutiepercentages, daarvan zal ik blijven dromen.

Ik had de eer kennis te mogen maken met Bert Vrijhoef als co-promotor en dagelijks begeleider. Bert, het is dat je niet nog een keer kunt promoveren op het begeleiden van promovendi, anders was jij de eerste die dat zou verdienen. Ik heb vooral steun ervaren aan de rust die je uitstraalt, je gevatte opmerkingen, relativeringsvermogen en de vele tips hoe je als promovendus het beste ten strijde kan trekken, oftewel strategisch kunt zijn. Je aanstelling als Bijzonder Hoogleraar Chronische Zorg is de verdiende kroon op je werk. Hopelijk dat we ook in de toekomst gezamenlijk onderzoeksprojecten kunnen oppakken.

Ook een woord van dank aan mijn "economisch ingestelde collegaatjes", Lotte Steuten en Arla Romeijn. Dank dames voor jullie expertise in dit onderzoek. Lotte, dank voor je advies tijdens de analyses en het schrijven van de artikelen. Als je nog eens zin hebt in een partijtje bootstrappen, ik houd me aanbevolen. 


\section{$136 \mid$ Dankwoord}

En onthoud goed: zelfgemaakte peperkoek en andere mutsige zaken daar is niets mis mee, het maakt het leven alleen maar mooier en lekkerder.

Arla, dank voor je waardevolle bijdrage in het financiële hoofdstuk van het onderzoek. Ik heb ontzettend veel gehad aan het telefonisch en digitaal sparren met jou.

Een van de belangrijkste personen die dit complexe project tot een goed einde heeft gebracht, was Emmy Derckx. Emmy, we hebben vaak gesproken over onze onderzoeksgroep, waarbij wetenschap en praktijk mooi in elkaar vloeiden. Vooral onze gesprekken over hoe de gezondheidszorg er werkelijk uit zou moeten zien werden discussies die moeilijk te stoppen waren. Maar wat hebben we ook een lol gehad. De geur van 4711 zal nooit meer hetzelfde zijn. Laat staan onze voorbereiding: wat wordt het vandaag: B of B (Barbies of Bitches)? Dank voor je inspiratie, je humor, en feedback.

Een bijzonder woord van dank voor mensen die hun inhoudelijke bijdrage leverden: Wim van Geldrop, Marianne Meulepas, Thea Toemen, Yvonne van Leeuwen, Marja Legius; en de huisartsen die een rol speelden in de klankbordgroep: Peter Meulesteen, Joost Lombarts, Ullrich Schultz. Marianne, dank voor jouw expertise, opdat zo'n immense data-extractie, met de ondersteuning van je medewerkers van Meetpunt Kwaliteit en in samenwerking met Pharmo, gerealiseerd kon worden.

Dank aan de RVE Transmurale Zorg van MUMC+ in Maastricht, met name Hans Fiolet en alle collega-onderzoekers, in het bijzonder Mariëlle Kroese, Yvonne van Eyk, Pytha Albers en Inge Duimel. En dan de onderzoeksassistenten Joyce Janssen en Wendy Engering. Joyce, vanaf het begin ben jij mijn grote steun geweest, met name bij de zaken die maar enigszins naar ICT roken. Hoe groter en complexer het databestand, hoe blijer jij werd. Mede dankzij jou ben ik door de bomen het bos blijven zien. Wendy, jij was het organisatietalent in de voorbereiding en uitvoering van het RCT. Bedankt, meiden!

Alle medewerkers van Stichting $\mathrm{KOH}$ en van Meetpunt Kwaliteit. Dank voor alle ondersteuning. Het was een gezellige werkplek daar in het Eindhovense. Dide en Carin, bedankt voor de secretariële ondersteuning. Diane, dank dat je mijn kamergenootje was en dat ik bij je terecht kon voor statistische aangelegenheden. En dan de 30 werkstudenten die een rol speelden in de dataextractie, data-invoer en in de uitvoering van het RCT in de huisartsenpraktijken. Heel veel dank!

Terug naar het Eindhovense; mijn collegae van de Dienst Onderwijs en Onderzoek van het Catharina-ziekenhuis. Een bijzonder woord van dank voor Lieve van Coppenolle en Jeanne Visser. Lieve, dank dat jij mij afgelopen jaren de ruimte hebt gegeven om dit onderzoek uit te voeren. Jeanne, vanaf het eerste uur betrokken bij de hersenspinsels om een promotietraject te beginnen en af te maken. Je bent een bijzondere vrouw. Wellicht een idee om een reflectiecentrum 
op te richten, zo na je pensionering? Want daar ben je een kei in.

Lieve pa en ma, Eric en Anton, schoonzusjes, schoonfamilie en vrienden. Jullie wil ik bedanken voor de steun en het vertrouwen, ook al waren mijn verhalen niet altijd even herkenbaar voor jullie. Pa, het onvoorwaardelijke geloof en de vele kaarsjes die zijn aangestoken, daar ben ik je zeer erkentelijk voor. Lieve mams, jouw zorgzaamheid en hartelijkheid, er is geen fijnere plek om even bij te tanken. Dankjewel.

Daan en Inez, lieve kindjes. Hoe klein jullie beide ook zijn, jullie lijken wel twee accuutjes, die door een klein moment, een stralende glimlach, of vrolijk gekwetter, zorgen voor bergen energie. En relativeringsvermogen. Want zoals Daan zegt: "Computerwerken is toch niet zo moeilijk, mama?" Tot slot Serge. Jouw liefde, enthousiasme en rotsvast vertrouwen hebben mede geleid tot dit resultaat. Ik ben trots en gelukkig dat we dit samen hebben gepresteerd, dit is onze beker. Ik hou ontzettend veel van je. Dank voor alles. 


\section{Curriculum Vitae}

Angelique Dierick was born on January 9, 1973 in Koewacht. After finishing secondary school (VWO) in 1991 at the Jansenius Lyceum in Hulst, she started the vocational study Nursing at the Academy in Eindhoven. She graduated cum laude in 1995. After her graduation she was employed as a nurse in the psychiatric hospital Jan Wier in Tilburg during the next four years. In the same period she followed the part-time study Health Care Sciences at Maastricht University. She chose for the specialization Nursing Science. In 1999 she received her master's degree in Health Care Sciences after finishing her thesis about the abuse of cannabis by psychiatric patients.

Immediately after, she started working as a teacher in the Catharina-Hospital in Eindhoven at the department of Gynaecology and Geriatrics. In 2000 she was employed by the department of Education, as an advisor in Education, later as a staff member. Since 2004 she is also a member of the management team of the department Education and Research in the Catharina-Hospital. In the period 2000-2008 she guided several innovation projects in nursing. In 2003 she got acquainted with the project: the introduction of the Nurse practitioner. She did some research and contributed to policy reports to introduce the nurse practitioner in the Catharina-Hospital. She was also a teacher at the training program Master in Advanced Nursing Practice at Fontys in Eindhoven.

Starting from 2004, she was appointed as a researcher for the project "Nurse Practitioner in General Practice". Her PhD-research resulted in this dissertation. Since December 2008 she is employed as Manager of the SkillsLab in the Catharina-Hospital and concerned with the organization of nursing and medical training programs and research regarding the development and validation of education tools. Finally, in 2009 she collaborated with colleagues in the research project "Internet Raadplegen Donorregister" at the Maastricht University in Maastricht. 


\section{LIST OF PUBLICATIONS}

Dierick-van Daele ATM, Derckx EWCC, Spreeuwenberg C, Metsemakers JFM, Vrijhoef HJM. (2005) Nurse practitioner in de huisartsenpraktijk. NederlandsVlaams wetenschappelijk tijdschrift voor verpleegkundigen 2005; 20 (4): 311-12. (In Dutch)

Dierick A, Derckx E. Wie is die "nieuwe" professional in de eerste en tweede lijn? HaCaSpect. 2007; 5 (14): 7-10. (In Dutch)

Dierick-van Daele ATM, Derckx EWCC, Spreeuwenberg C, Metsemakers JFM, Vrijhoef HJM. (2007) Tussentijdse bevindingen pilot "NP in de huisartsenpraktijk". Eerstelijns nurse practitioners lijken zorg te verbeteren. Nederlands Tïdschrift voor Nurse Practitioners 2007; 2 (2): 9-12. (In Dutch)

Dierick-van Daele ATM, Spreeuwenberg C, Derckx EWCC, Metsemakers JFM, Vrijhoef HJM. Critical appraisal of the literature on economic evaluations of substitution of skills between professionals: a systematic literature review. Journal of Evaluation in Clinical Practice 2008; 14: 481-92.

Dierick-van Daele ATM, Metsemakers JFM, Derckx EWCC, Spreeuwenberg C, Vrijhoef HJM. Nurse practitioner in de huisartsenpraktijk, het onderzoeksrapport. Maastricht UMC+, Maastricht 2008. (In Dutch)

Dierick-van Daele ATM, Metsemakers JFM, Derckx EWCC, Spreeuwenberg C, Vrijhoef HJM. Nurse practitioners substituting for general practitioners in the care for patients with common complaints; a randomised controlled trial. Journal of Advanced Nursing 2009; 65(2): 391-401.

Derckx E, Dierick A, Vrijhoef B. De 'nurse' de maat genomen. TVZ 2009; 119(3): 23-7. (In Dutch)

Dierick-van Daele ATM, Steuten LMG, Metsemakers JFM, Derckx EWCC, Spreeuwenberg C, Vrijhoef HJM. (2009). Economic evaluation of substituting nurse practitioners for general practitioners. British Journal of General Practice 2010; (60) 570: 28-35.

Dierick-van Daele ATM, Metsemakers JFM, Toemen T, Van Leeuwen Y, Legius M, Derckx EWCC, Spreeuwenberg C, Vrijhoef HJM. (2009). The value of the nurse practitioner. Submitted.

Dierick-van Daele ATM, Metsemakers JFM, Steuten LMG, Romeijn, A, Derckx EWCC, Spreeuwenberg C, Vrijhoef HJM (2009). The optimal skill mix hampered by financial structures. Submitted. 


\section{List of publications}

\section{Presentations related to this PhD-Research}

NHG-Wetenschapsdag, Utrecht 2009.

ICN-Congress, Durban 2009.

Nordic Congress for General Practice, Copenhagen 2009.

Hogeschool Leiden, Master in Advanced Nursing Practice 2009.

NP-Tweedaagse, Eede 2009.

Slotconferentie Project "Nurse practitioner in de huisartsenpraktijk", de eindresultaten, Eindhoven 2008.

Regiobijeenkomst NP, Eindhoven 2007.

KNMG-congres, Utrecht 2007.

Invitational Conference Project "Nurse practitioner in de huisartsenpraktijk", de tussentijdse bevindingen, Eindhoven 2006.

KNMG-congres, Nieuwegein 2005. (poster)

Nederlands-Vlaams Wetenschappelijk Congres, Leuven 2005. (poster)

\section{AWARD}

March 2009: Crebolder Award for societal impact of Research, CAPHRI (Care and Public Health Research Institute), Maastricht UMC+, Maastricht. 

